TESE DE DOUTORADO EM ENGENHARIA DE SISTEMAS ELETRÔNICOS E AUTOMAÇÃO

\title{
DEVELOPMENT AND FUNCTIONAL ASSESSMENT OF NATURAL LATEX MEMBRANES: A NEW PROPOSAL FOR THE TREATMENT OF AMBLYOPIA
}

JAQUELINE ALVES RIBEIRO

Brasília, junho de 2016

\section{UNIVERSIDADE DE BRASÍLIA}


UNIVERSIDADE DE BRASÍLIA

FACULDADE DE TECNOLOGIA

DEPARTAMENTO DE ENGENHARIA ELÉTRICA

\section{DEVELOPMENT AND FUNCTIONAL ASSESSMENT OF NATURAL LATEX MEMBRANES: A NEW PROPOSAL FOR THE TREATMENT OF AMBLYOPIA}

\section{JAQUELINE ALVES RIBEIRO}

ORIENTADORA: Prof ${ }^{a}$. Dra ${ }^{a}$. SUÉLIA DE SIQUEIRA RODRIGUES FLEURY ROSA

TESE DE DOUTORADO EM ENGENHARIA DE SISTEMAS ELETRÔNICOS E AUTOMAÇÃO

PUBLICAÇÃO: 108/2016 TD.PPGEA BRASÍLIA/DF: JUNHO - 2016 


\section{UNIVERSIDADE DE BRASÍLIA \\ FACULDADE DE TECNOLOGIA \\ DEPARTAMENTO DE ENGENHARIA ELÉTRICA}

\section{DEVELOPMENT AND FUNCTIONAL ASSESSMENT OF NATURAL LATEX MEMBRANES: A NEW PROPOSAL FOR THE TREATMENT OF AMBLYOPIA}

\section{JAQUELINE ALVES RIBEIRO}

TESE DE DOUTORADO SUBMETIDA AO DEPARTAMENTO DE ENGENHARIA ELÉTRICA DA FACULDADE DE TECNOLOGIA DA UNIVERSIDADE DE BRASÍLIA, COMO PARTE DOS REQUISITOS NECESSÁRIOS PARA A OBTENÇÃO DO GRAU DE DOUTOR.

APROVADA POR:

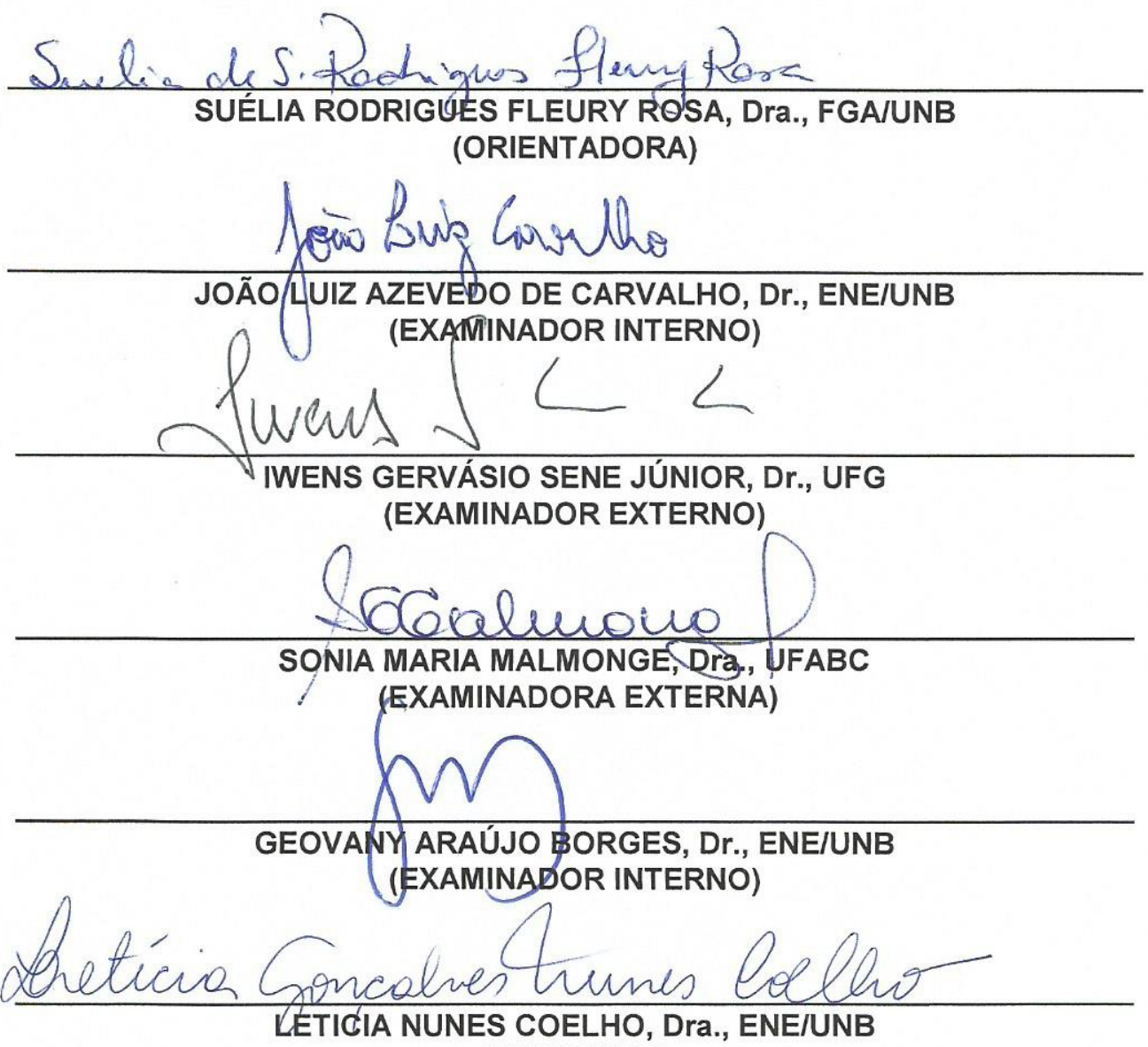

(SUPLENTE) 


\section{FICHA CATALOGRÁFICA}

Ribeiro, Jaqueline Alves

RR484d Development and functional assessment of natural latex membranes: a new proposal for the treatment of amblyopia / Jaqueline Alves Ribeiro; orientador Suélia de Siqueira Rodrigues Fleury Rosa. -Brasilia, 2016.

$122 \mathrm{p}$.

Tese (Doutorado - Doutorado em Engenharia de Sistemas Eletrônicos e de Automação (Tese)) -Universidade de Brasilia, 2016.

1. Amblyopia. 2. Biomaterial. 3. Latex. 4. Membranes. 5. Occluder. I. Fleury Rosa, Suélia de Siqueira Rodrigues, orient. II. Título.

\section{REFERÊNCIA BIBLIOGRÁFICA}

Ribeiro, J.A. (2016). Development and functional assessment of natural latex membranes: a new proposal for the treatment of amblyopia. Tese de Doutorado em Engenharia de Sistemas Eletrônicos e Automação, Publicação PPGEA.TD 108/2016, Departamento de Engenharia Elétrica, Universidade de Brasília, Brasília, DF, 122p.

\section{CESSÃO DE DIREITOS}

AUTOR: Jaqueline Alves Ribeiro.

TÍTULO: Development and functional assessment of natural latex membranes: a new proposal for the treatment of amblyopia.

GRAU: Doutor

ANO: 2016

É concedida à Universidade de Brasília permissão para reproduzir cópias desta tese de doutorado e para emprestar ou vender tais cópias somente para propósitos acadêmicos e científicos. $\mathrm{O}$ autor reserva outros direitos de publicação e nenhuma parte dessa tese de doutorado pode ser reproduzida sem autorização por escrito do autor.

Jaqueline Alves Ribeiro

Rua 12 n.297 Centro

76.300-000 Ceres - GO - Brasil. 
"Each dream you leave behind is a part of your future that will no longer exist."

Steve Jobs iii 
Dedico esse trabalho à memoria do grande homem da minha vida, meu pai. Antônio José Ribeiro Amor incondicional!!!! 


\section{AGRADECIMENTOS}

A Deus, por me dar força interior, coragem para concluir este trabalho e perseverança para nunca desistir.

Aos meus pais, Antônio (in memoriam) e Luzia, que sempre apoiaram meus estudos, em especial a papai que sofreu comigo a finalização deste trabalho.

À minha irmã, Andrea, por me apoiar e me ajudar nos momentos que mais necessito.

Aos meus sobrinhos Gabriel Victor e Pedro Arthur com as brincadeiras, risadas e momentos de distração; ao meu cunhado Alessandro, pelo apoio prestado, às vindas em Brasília na reta final e a toda minha família, tios, tias, primos e primas, que sempre torceram pelo meu sucesso.

À professora e orientadora Dra. Suélia de Siqueira Rodrigues Fleury Rosa pela oportunidade da realização deste trabalho e confiança depositada em mim.

A Dra. Fátima Mrué pelos conhecimentos transmitidos e pela colaboração no desenvolvimento deste trabalho.

A Professora Dra. Lourdes Mattos Brasil, pelo apoio prestado e orientação no início da pesquisa.

Ao Professor Dr. Iwens G. Sene Júnior por participar do meu exame geral de qualificação com significativas discussões e sugestões de aprimoramento para este trabalho.

Aos professores Dra. Cicília Maia, Dra. Letícia Coelho e Dr. José Felício, pelos conselhos e disposição em avaliar meu trabalho.

Aos coordenadores da Pós-graduação com os quais tive contato durante minha caminhada pelo apoio, acreditando em minha capacidade para concluir esta jornada; à secretária Adriana pela atenção e assistência prestadas e a todos os funcionários da Faculdade de Engenharia Elétrica da Universidade de Brasília que contribuíram de alguma maneira para a conclusão deste trabalho.

A todos os professores do programa da Pós-Graduação em Engenharia de Sistemas Eletrônicos e Automação e aos professores da Faculdade do Gama - FGA pelos conhecimentos, pois sem alguns deles nada disso teria sido possível.

Ao Programa de Pós-Graduação em Engenharia de Sistemas Eletrônicos e Automação PGEA e a Decanato de Pesquisa e Pós-Graduação - DPP/UnB que colaboraram financeiramente para a participação em congressos. 
A todos os professores que compõem a banca, pelas discussões realizadas para a finalização deste trabalho, e também a disponibilidade em participar da defesa.

Ao IF Goiano, em especial ao IF Goiano - Campus Ceres pelo apoio e esforços cedidos para minha capacitação profissional.

A todos os professores e colaboradores UERN Campus Mossoró que proporcionou a realização técnica e grande conhecimento científico na área.

Ao Laboratório BioEngLab ${ }^{\circledR}$ onde aprendi a técnica de biomaterial Látex e foi implementada para o desenvolvimento das membranas.

Ao Laboratório de Química Instrumental do IF Goiano - Campus Ceres e ao professor Deomar Costa pelo auxílio nas análises de caracterização.

Ao Laboratório de Física Geral do IF Goiano - Campus Ceres e ao professor Mairon Marques pelo auxílio nas medições de espessura das amostras.

A Ótica Cristal e seu proprietário Leandro Luiz Fleury Rosa pela parceria da patente, serviços prestados e ensaios optométricos.

Aos colegas do programa de pós-graduação da FT, da FGA e do BioEngLab ${ }^{\circledR}$ que tive oportunidade de conhecer e compartilhar conhecimentos, em especial aos que participaram comigo, Diogo Motoca, Danilo Oliveira, Marlete Maria da Silva, Alexandre Seiji Ribas. O apoio de todos, não só profissionalmente como também no âmbito da amizade, somou de forma significativa para a conclusão deste trabalho.

Aos colegas de trabalho da família IF Goiano pelo apoio que contribuíram de forma indireta para a realização deste trabalho.

A todos os meus amigos, por direta ou indiretamente por me auxiliarem na imensa e inacabável tarefa de autoconhecimento.

Um trabalho como este encerra uma longa jornada e inaugura uma nova caminhada. A todos que contribuíram para que este caminho pudesse ser trilhado, expresso os meus mais sinceros agradecimentos. 


\section{RESUMO}

\section{Desenvolvimento e avaliação funcional de membranas de látex natural: uma nova proposta para o tratamento da ambliopia}

O crescente desenvolvimento tecnológico e os avanços no campo da medicina permitiram uma significativa melhoria na qualidade de vida da população. Como por exemplo, desenvolvimento de biomateriais, que são empregados para substituir total ou parcialmente tecidos orgânicos perdidos ou danificados, ou mesmo serem utilizados em contato direto e contínuo com o corpo para realização de tratamento não farmacológico. A disfunção oftálmica ambliopia, também conhecido popularmente como olho preguiçoso, consiste na baixa de visão em um olho por não ter se desenvolvido adequadamente na infância. $O$ objetivo desse trabalho foi a obtenção e caracterização de membranas de borracha natural a fim de avaliar sua viabilidade de aplicação como uma membrana oclusora com propriedade de alterar a passagem de luz e estimular o olho amblíope. Trata-se de uma nova proposta para tratamento de pacientes amblíopes utilizando membranas de látex. As membranas de látex foram confeccionadas pelas técnicas de deposição e a técnica criada denominada de Van Gogh sendo caracterizadas através de métodos físicos e químicos, a fim de analisar as propriedades do látex in natura e das membranas de borracha natural, tratadas termicamente a 40 e $70{ }^{\circ} \mathrm{C}$. Os métodos utilizados para a caracterização das amostras foram: microscopia eletrônica de varredura (MEV), medidas de fluorescência, difração de raios $\mathrm{X}(\mathrm{XRD})$, análises termogravimétricas (TG), calorimetria exploratória diferencial (DSC), análise de absorção em soro fisiológico, espectroscopia por FT-IR modo ATR, análise de componentes principais e análise de passagem de luz. Na caracterização das membranas foram analisadas as propriedades dos polímeros com o intuito de se obter dados sobre a viabilidade do uso de uma membrana de látex LENCOC $^{\circledR}$ no tratamento de ambliopia com segurança e conforto para o usuário. Foi possível verificar a passagem de luz das membranas de Van Gogh M1 e M2 com a oclusão parcial e total, respectivamente. Conclui-se que, os ensaios utilizados na caracterização da membrana de látex LENCOC $^{\circledR}$ mostraram-se satisfatórios e promissores para sua utilização no tratamento da ambliopia.

Palavras-chaves: Membranas, Ambliopia, Látex, biomaterial, oclusor. 


\section{ABSTRACT \\ Development and functional assessment of natural latex membranes: a new proposal for the treatment of amblyopia}

The growing technological development and the advancements in the field of medicine caused significant improvement in the quality of life of the population. One example is the development of biomaterials, which are used to completely or partially replace parts of lost or damaged organic tissues and are also used in direct and continuous contact with the body in non-pharmacological treatments. Amblyopia, an ophthalmic disorder commonly known as lazy eye, result in decreased vision in one eye that does not develop properly during childhood. The objective of this study was to obtain and characterize natural rubber membranes in order to evaluate the feasibility of its application as an occluder membrane with the capacity of changing the course of light and stimulating the amblyopic eye. This is a new proposal for treating amblyopic patients using latex membranes. The latex membranes were produced with the deposition technique and a new technique called Van Gogh. They were characterized using physical and chemical methods in order to analyze the properties of latex in natura and of the natural rubber membranes, thermally treated at $40{ }^{\circ} \mathrm{C}$ and $70{ }^{\circ} \mathrm{C}$. The methods used to characterize the samples were: scanning electron microscopy (SEM), Fluorescence measurements, X-ray diffraction (XRD), thermogravimetric analyses (TG), differential scanning calorimetry (DSC), saline absorption analysis, FT-IR spectroscopy ATR mode, principal component analysis (PCA) and light crossing analysis. When characterizing the membranes, we analyzed the properties of the polymers with the goal of obtaining data on the feasibility of using a LENCOC $^{\circledR}$ latex membrane in the treatment of amblyopia with safety and comfort for the patient. The light crossing analysis of the M1 and M2 Van Gogh membranes presented partial and total occlusion, respectively. We concluded that the tests used for characterizing the LENCOC $^{\circledR}$ latex membrane were satisfactory and promising regarding its use for the treatment of amblyopia.

Keywords: Membranes, Amblyopia, Latex, Biomaterial, Occluder. 


\section{SUMMARY}

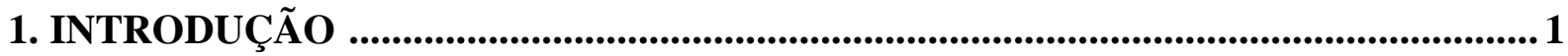

1.1 - JUSTIFICATIVA _................................................................................................................. 4

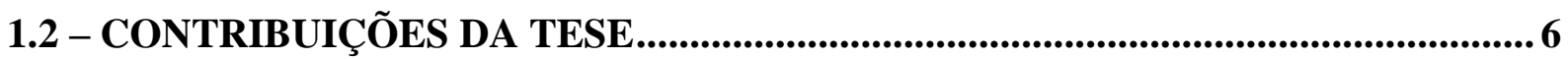

1.3 - OBJETIVOS............................................................................................................................ 6

1.4 - AMBLIOPIA ……........................................................................................................... 7

1.5 - MATERIAIS E MÉTODOS ….........................................................................11

1.5.1 - Preparação do Látex.................................................................................................. 11

1.5.2 - Preparação do molde ...................................................................................................... 13

1.5.3 - Preparação do protótipo ............................................................................................... 13

1.5.4 - Caracterização do produto ......................................................................................... 15

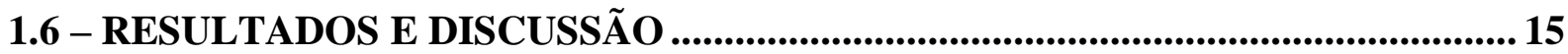

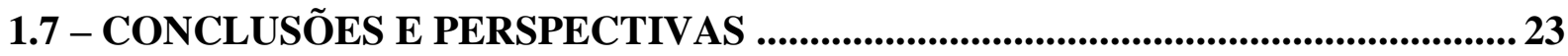

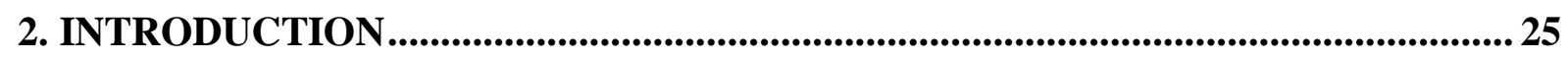

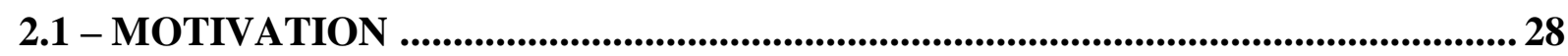

2.2 - CONTRIBUTIONS OF THE THESIS............................................................................ 30

2.3 - OBJETIVES ............................................................................................................................... 30

2.4 - DOCUMENT STRUCTURE _.................................................................................. 31

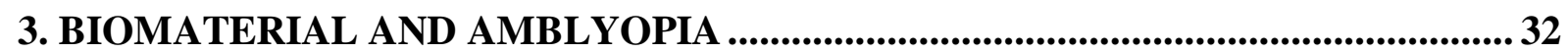

3.1 - ANATOMY AND PHYSIOLOGY OF THE HUMAN EYE........................................ 32

3.2 - AMBLYOPIA .......................................................................................................................34

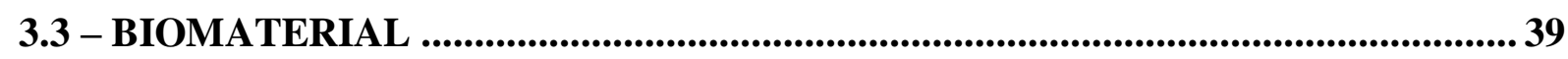




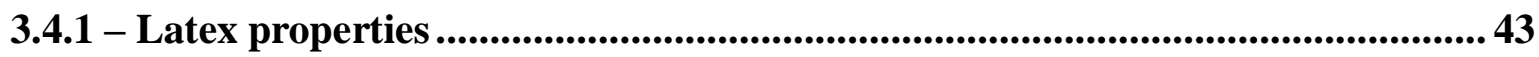

3.4 .2 - Clone

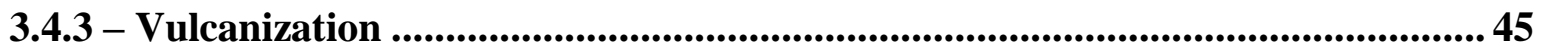

3.4.4 - Applicability of latex in medicine ............................................................................ 46

3.4.5 - Allergy and toxicity ....................................................................................... 49

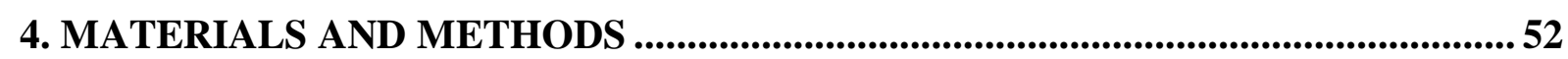

4.1 - EXPERIMENTAL DESIGN OF THE LATEX MEMBRANE .........................5 52

4.2 - MANUFACTURING PROCESS .......................................................................5 54

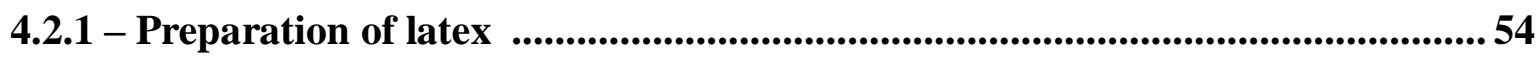

4.2.2 - Preparation of the mold ................................................................................. 55

4.2.3 - Preparation of the prototype ................................................................56

4.3 - CHARACTERIZATION OF THE PRODUCT ....................................................59

4.3.1 - Scanning Electron Microscopy (SEM) .................................................59

4.3.2 - Fluorescence measurements ............................................................................. 60

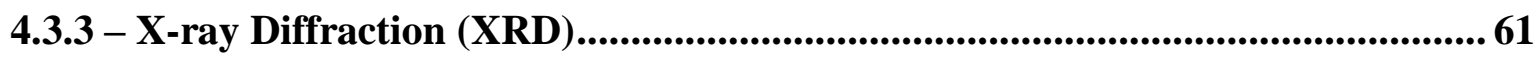

4.3.4 - Thermogravimetry (TG) / Differential Scanning Calorimetry (DSC) .............. 61

4.3.5 - Saline absorption measurements ...................................................................6 62

4.3.6 - Infrared spectroscopy (FT-IR) ATR mode ................................................... 63

4.3.7 - Principal component analyses of the latex membrane (PCA) ....................... 63

4.3.8 - Light crossing analysis ................................................................................................ 64

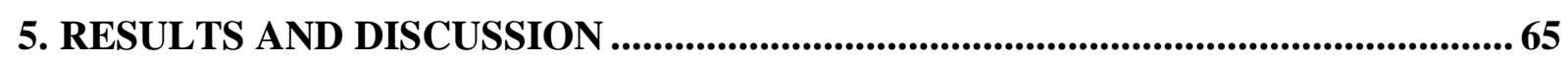

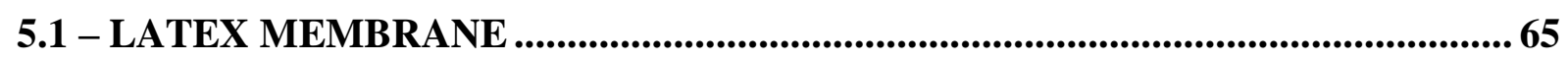


5.3 - CHARACTERISATION OF THE LATEX MEMBRANE.................................. 68

5.3.1 - Scanning Electron Microscopy (SEM) ................................................................... 68

5.3.2 - Fluorescence measurements ............................................................................... 70

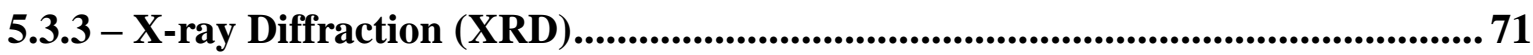

5.3.4 - Thermogravimetric (TG) and differential scanning calorimetry (DSC) ......... 73

5.3.5 - Saline absorption measurements ........................................................................ 77

5.3.6 - Infrared spectroscopy (FT-IR) ATR mode ......................................................... 80

5.3.7 - Principal component analyses of the latex membrane (PCA) ......................... 84

5.3.8 - Light crossing analysis ...................................................................................... 86

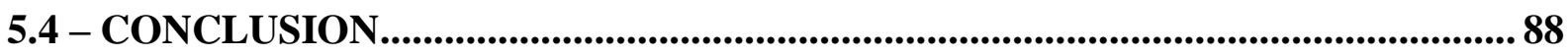

6. CONCLUSIONS AND PERSPECTIVES ........................................................93

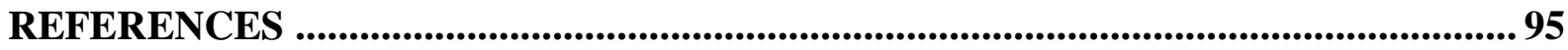

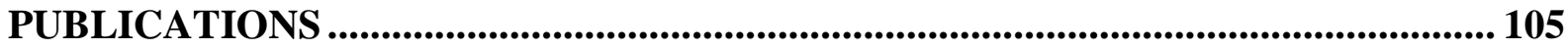




\section{LIST OF TABLES}

Tabela 1.1 - Resumo das caracterizações das membranas ............................................. 22

Table 3.1 - Treatment of amblyopia, pros and cons.................................................. 38

Table 3.2 - Classification of biomaterials.................................................................... 41

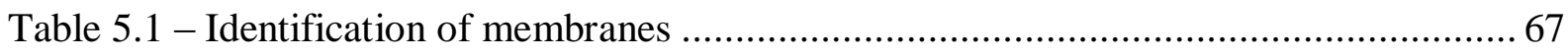

Table 5.2 - Chemical composition of the M1, M2, M3, and M4 membranes (\%) ................ 70

Table 5.3 - Thermogravimetric data obtained from the treated membranes. ...................... 74

Table 5.4 - Time of absorption of the latex membranes............................................... 79

Table 5.5 - Attributions of the ranges spectra of the infrared region in the ATR method ...... 83

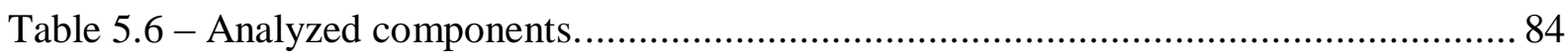

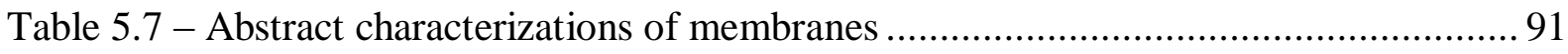




\section{LIST OF FIGURES}

Figura 1.1 - Membranas confeccionadas utilizando a técnica de Van Gogh e deposição, em

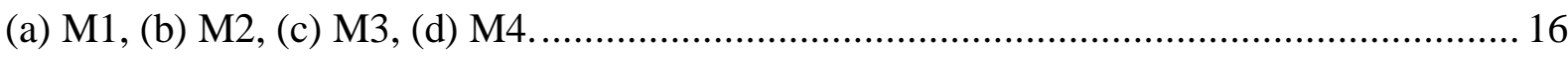

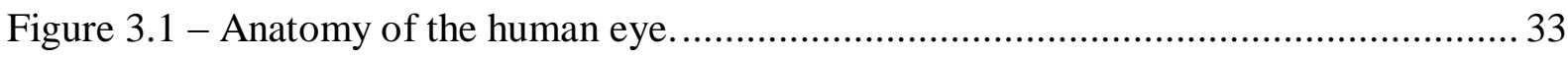

Figure 4.1 - Flowchart with steps to be performed. .................................................. 53

Figure 4.2 - Flowchart of membrane confection with the Van Gogh technique.................... 57

Figure 4.3 - Flowchart of membrane confection with the deposition technique. ...................58

Figure 5.1 - Membranes prepared using the Van Gogh and deposition techniques, in (a) Van Gogh (three baths), (b) Van Gogh (four baths), (c) deposition $\left(40{ }^{\circ} \mathrm{C}\right)$, (d) deposition $\left(70{ }^{\circ} \mathrm{C}\right)$.

Figure 5.2 - Micrograph of the Van Gogh membrane M1 (a) and M2 (b), membranes produced with the deposition technique M3 (c) and M4 (d).

Figure 5.3 - X-ray diffractograms of latex membranes Van Gogh membrane M1 and M2 and membranes produced with the deposition technique M3 and M4.

Figure 5.4 - TG curves for natural rubber latex (NRL) and membranes M1, M2, M3 and M4.

Figure 5.5 - DTG curves for natural rubber latex (NRL) and membranes M1, M2, M3, and M4.

Figure 5.6 - DSC curves for natural rubber latex (NRL) and membranes M1, M2, M3 and M4.

Figure 5.7 - Normalization of the mass of the membranes and a non-linear function, in Van Gogh membrane M1 (a) and M2 (b), membranes produced with the deposition technique M3 (c) and M4 (d).....

Figure 5.8 - Spectra of the infrared region in the ATR method of the Van Gogh membrane M1 (a) and M2 (b), membranes produced with the deposition technique M3 (c) and M4 (d) in the region of 4000 a $500 \mathrm{~cm}^{-1}$. 
Figure 5.9 - Spectra of the infrared region in the ATR method of the M1, M2, M3 and M4 latex membranes, in the region of 4000 a $500 \mathrm{~cm}^{-1}$.

Figure 5.10 - On the biplot, $\mathrm{PC}^{\mathrm{a}}$ with vectors coming from the origin shows the relation of the variables $(\bullet) . \mathrm{PC}^{\mathrm{b}}$ shows the relations of the samples $(\bullet)$.

Figure 5.11 - Measuring the membranes with the focimeter, M1 (a), M2 (b), M3 (c) e M4 (d). In the images, the angle of the focimeter display and the dark environment of the optometry clinic. 


\section{LIST OF SYMBOLS}

AT - Assistive Technology

ATR - Attenuated Total Reflection

BioEngLab $^{\circledR}$ - Engineering and Biomaterial Laboratory

CCL - Cosmetic Contact Lens

CL - Contact Lens

Co - Cobalt

$\mathrm{Cu}$ - Copper

DSC - Differential Scanning Calorimetry

DTG - Derived Thermogravimetry

EDX - Energy Dispersive X-Ray

$\mathrm{Fe}-$ Iron

Gd- Gadolinium

IBGE - Brazilian Institute of Geography and Statistics

ISO - International Organization for Standardization

I\&D - Investigation and Development

$\mathrm{K}-$ Potassium

LATEQ - Chemical Technology Laboratory

LED - Light Emitting Diode

Mn - Manganese

$\mathrm{Ni}$ - Nickel

NRL - Natural Rubber Latex

$\mathrm{P}$ - Phosphorus

PCA - Principal Component Analysis 
$\mathrm{Rb}-$ Rubidium

R\&D - Research and Development

S - Sulfur

SEM - Scanning Electron Microscope

TAC - Technical Assistance Committee

TG - Thermogravimetry

VA - Visual Acuity

Zn - Zinc

XRD - X-ray diffraction

WHO - World Health Organization 


\section{1 - INTRODUÇÃO}

O setor de Tecnologia Assistiva (TA), dentre outras questões, tem como finalidade proporcionar e aumentar habilidades funcionais de pessoas acometidas por doenças; desde injúrias leves até graves deficiências, almejando uma melhor qualidade de vida e autonomia ao paciente. Como área de conhecimento no Brasil, a nominada TA, surgiu em 16 de novembro de 2006, através da portaria número 142, estabelecida pelo Decreto $\mathrm{n}^{\mathrm{o}}$ 5.296/2004 no âmbito da Secretaria Especial dos Direitos Humanos da Presidência da República. O Comitê de Ajudas Técnicas (CAT) foi regulamentado na perspectiva de aperfeiçoar, bem como dar transparência e legitimidade ao desenvolvimento da TA no Brasil (Brasil, 2009).

Devido à institucionalização da área representada pela TA mostrar-se tão recente, é natural que haja uma desassociada produção acadêmico-científica especializada, tanto nos aspectos de Investigação e Desenvolvimento (I\&D) quanto em Pesquisa e Desenvolvimento $(\mathrm{P} \& \mathrm{D})$, devido à pulverizada produção nos canais científicos. Esse fato acarreta duas consequências importantes: i) baixa produção conceitual e tecnológica; ii) índices inferiores de políticas públicas que ofertem a TA em Saúde (Souza et al, 2014, Brasil, 2009).

Um dos grandes desafios das ciências exatas e das engenharias atualmente é traduzir em termos e relações matemáticas o funcionamento de fenômenos e sistemas que compõem o universo. Para desenvolver e usar esse conhecimento é necessário interpretar como um dos fatores do sistema que se relaciona para adequar e melhorar os processos que se interagem (Rosa et al., 2015).

Entre esses fenômenos encontra-se a ambliopia, que consiste em uma patologia do olho desenvolvida na infância, a qual dispõe de poucos recursos de tratamento. Essa doença tem como consequência a diminuição da acuidade visual, produzida por um desenvolvimento anormal visual em idades precoces da vida. A prevalência da ambliopia em crianças é estimada entre 1 a $4 \%$, sendo a causa mais comum de redução da acuidade visual na infância (Almeida, 2005; Ribeiro et al., 2013). Essa patologia é o defeito visual mais comum em crianças, no entanto, seu diagnóstico e tratamento precoce trazem 
resultados satisfatórios (Salata et al., 2001, Almeida, 2005).

O crescente desenvolvimento tecnológico e os avanços no campo da medicina permitiram uma significativa melhoria na qualidade de vida da população. Dentre estes avanços, pode-se destacar o desenvolvimento de biomateriais, que são empregados para substituir total ou parcialmente partes de tecidos orgânicos perdidos ou danificados, ou mesmo serem utilizados em contato direto e contínuo com o corpo para realização de tratamento não farmacológico. O bom desempenho de um biomaterial usado como dispositivos médicos, além da biocompatibilidade, está relacionado à capacidade e à facilidade do material em ser moldado em formatos complicados. Geralmente, os requisitos de um biomaterial podem ser agrupados em quatro grandes categorias: biocompatibilidade, capacidade de ser esterilizado, funcionalidade e reprodutibilidade (Silva et al., 2012).

A membrana de látex natural da seringueira (Hevea Brasiliensis) pode ser considerada uma órtese (do grego orthós), classificada pela TA, um dispositivo aplicado a qualquer parte do corpo, isoladamente ou abrangendo mais de uma articulação, tendo como função estabilizar ou imobilizar, prevenir ou corrigir deformidades, proteger contra lesões e auxiliar na cura ou maximizar a função (Thomazini et al., 2004, Macdonald, 1990). Neste caso específico, a membrana de látex será colocada no olho bom por algumas horas ou dias de acordo com o tratamento adequado preconizado pelo médico oftalmologista, ocasionando a aceleração da visão do olho preguiçoso, diagnosticado com ambliopia.

Quimicamente, a constituição heterogênea do látex configura uma densidade elevada e a presença de impurezas que devem ser tratadas e alteradas. Neste estudo, foram realizadas as técnicas que permitem a degradação de polímeros, regenerando, se possível, os monômeros para uma introdução de hidróxido e formaldeído - deixando o látex apenas como uma película de borracha que permita a nesse primeiro momento um objeto translúcidos, com passagem luz, porém com trajetórias irregulares (impede a visualização completa do objeto), com refração difusa e com mínima absorção para não gerar calor, (Ribeiro et al., 2014, Ribeiro et al., 2015).

As maneiras utilizadas na construção de dispositivos derivados de látex vêm sendo empregadas desde 1994 - descrita e proposto por (Mrué, 1996; Mrué et al., 2004), 
citado em (Ribeiro et al., 2014), que desenvolveram uma metodologia de produção validada até o presente momento para inúmeros artefatos, a serem utilizados como indutores de neovascularização e reparação tecidual.

Deve-se ressaltar que o látex já foi utilizado na confecção de próteses esofágicas, biomembranas e módulo controlador de fluxo esofagiano (Rodrigues, 2009). O látex é um excelente indutor em situações em que são necessários reparos, como em perdas ósseas, pele e vasos sanguíneos (Bolognesi et al., 2015). Também foi observado que membrana de borracha natural favorece a cicatrização conjuntival e a angiogênese quando submetida a testes "in vivo" utilizando a conjuntiva ocular em coelhos (Pinho et al., 2004).

Os biomateriais podem facilitar a confecção de membranas como oclusores, uma vez que são definidos como substâncias ativas capazes de interação com os tecidos circundantes, sem causar uma resposta imune (Drewnowska et al., 2013).

A adoção de uma nova técnica e de um novo material na medicina exige uma série de estudos criteriosos para confirmar sua eficácia e, sobretudo, a segurança de sua aplicação. Para tanto, muitos passos devem ser seguidos e este estudo será a primeira parte desse trajeto em busca de um tratamento inovador para ambliopia. Primeiramente, iniciouse com a escolha do material, baseado-se em a partir de pesquisas anteriores que usavam o látex para fins medicinais, por ser considerado um material simples e de fácil manuseio (Pinho et al., 2004, Ribeiro et al., 2014, Ribeiro, Rodrigues, 2014).

As membranas foram confeccionadas e patenteadas com registro BR 102012007483-4 em abril de 2012 com o título "Lente de contato oclusora derivada de látex" e já publicada na Revista de Propriedade Industrial (RPI) (Brasil, 2015). Posteriormente foi registrada a marca LENCOC $^{\circledR}$ com número de registro 906573572 e publicada na Revista de Propriedade Industrial (RPI), para fins de futura comercialização (Brasil, 2016).

Este estudo apresenta uma abordagem simples de oclusão do olho baseada em membrana oftálmica a partir de um biomaterial oclusor derivado do látex da borracha natural. As membranas de borracha natural foram desenvolvidas a partir de duas diferentes técnicas, a técnica de Van Gogh e a técnica por deposição. As diferentes membranas desenvolvidas foram caracterizadas através de métodos físicos e químicos, a fim de 
analisar as propriedades do látex in natura e das membranas tratadas termicamente a 40 e $70{ }^{\circ} \mathrm{C}$. Os métodos utilizados para a caracterização dos materiais obtidos foram microscopia eletrônica de varredura (MEV), medidas de fluorescência de raios X, difração de raios $\mathrm{X}(\mathrm{DRX})$, termogravimetria (TG), calorimetria exploratória diferencial (DSC), análise de absorção em soro fisiológico, espectroscopia por FT-IR modo ATR e a análise de componentes principais (PCA) e análise de passagem de luz. A partir das análises de suas propriedades físicas e químicas avaliou a aplicabilidade das membranas de látex da borracha natural como oclusores oftálmicos biocompatíveis.

\section{1 - JUSTIFICATIVA}

Por cerca de 250 anos, a oclusão tem sido a modalidade terapêutica mais importante para o tratamento de ambliopia para que haja estímulo do olho afetado; porém sua eficácia permanece incerta, com relatos de sucesso variando de 30 a 92\% (Salata et al, 2001). Esse tipo de tratamento traz bons resultados, na dependência do paciente realizá-lo adequadamente, devendo ser mantido por período variável, conforme a idade da criança sendo, em média, de três anos, ou mantido até a idade de 10 ou 11 anos, com oclusão de pelo menos uma hora por dia (Fielder et al., 1995, Arakaki et al, 2004).

Quando existe alteração anatômica, observa-se que a oclusão total do olho diretor também pode ter sucesso, principalmente em casos de opacidade moderada de meios. Em outros casos, como lesão macular ou anomalia de nervo óptico, o prognóstico é pior. Há indícios de que existe melhora da acuidade visual e função binocular nos pacientes submetidos a tratamento oclusivo, sendo que o índice de sucesso varia com a idade do início da terapia, desde que o paciente tenha boa adesão e que seja monitorizado por um longo período (Arakaki et al, 2004).

Estudos demonstram que a adesão ao tratamento por terapia oclusiva depende da idade do paciente no início do tratamento, da acuidade visual inicial com correção, do nível socioeconômico do paciente e do envolvimento dos pais. A não adesão, contudo, fica em 
$50 \%$, cujos principais fatores estão a terapia prolongada e a não aceitação da criança (Arakaki et al, 2004, Salata et al, 2001, Fielder et al., 1995).

A utilização de técnicas de oclusão parcial é de particular interesse no contexto da binocularidade no tratamento de ambliopia. Isso ocorre porque essas técnicas podem permitir a combinação binocular enquanto ainda penalizar a visão do olho de fixação. Esses métodos de oclusão parcial podem proporcionar uma abordagem simples e com tempo de uso inferior a seis horas ( $\mathrm{Li}$ et al, 2012). Isso já está sendo discutido no Brasil, entre a comunidade oftalmológica, apesar dos estudos relacionados (Vasconcelos \& Costa, 2013).

Apesar destes dados, a terapia oclusiva ainda continua sendo a melhor forma de tratamento. A busca por novos métodos para a ambliopia é plenamente justificada, sendo necessária uma nova abordagem de tratamento uma vez que até o momento ainda não existem relatos de um tratamento eficaz. Esta tese de doutorado aponta a necessidade de se criar uma nova abordagem na tentativa de solucionar o problema da oclusão com o tampão e corrigir o olho preguiçoso.

Muitas pesquisas que utilizaram o biomaterial látex (Hevea Brasilienses) como implante, em diferentes tecidos têm demonstrado resultados satisfatórios, o que motiva a realização de novos trabalhos nesta área, em diferentes espécies (Mrué et al, 2004, Pinho et al, 2004). Foi comprovado que a biomembrana apresenta importantes propriedades biológicas, tais como: atividade neoangiogênica, promoção de adesão celular e formação de matriz extracelular. Em estudos experimentais, essa biomembrana favoreceu o reparo de defeitos parciais de esôfago de cães (Mrué, 2000), o processo de reparo da conjuntiva ocular de coelhos (Pinho et al, 2004) e de uma palmilha cicatrizante com sistema indutor de neoformação tecidual para pé diabético (Reis, 2013). Portanto, esse material demonstrou ser biocompatível em todos os experimentos já realizados, sem nenhum tipo de reação alérgica, ser de baixo custo e de fácil manuseio.

Este trabalho desenvolveu e viabilizou um novo método e uma metodologia de confecção de uma membrana de látex $\operatorname{LENCOC}^{\circledR}$. 


\section{2 - CONTRIBUIÇÃO DA TESE}

Este trabalho, traz na sua composição, a possibilidade de utilização do látex como um novo método de membrana oclusora para o tratamento de doenças oculares, especificamente para a ambliopia.

O conceito de oclusores está defasado, não havendo mudanças nos materiais há mais de uma década. A falta de produtos com novas tecnologias faz com que não haja incentivo por parte dos profissionais que cuidam desta doença. Assim, a membrana de látex poderá promover um impacto no mercado. Concomitantemente, mudarão os conceitos dos profissionais de saúde que cuidam do tratamento da ambliopia, pois uma nova dinâmica no tratamento gerará um maior índice de acerto nos tratamentos, deixando os pacientes e os profissionais mais satisfeitos.

Ressalta-se que o teste in vivo não foi possível para este estudo devido à inovação desta pesquisa. O presente estudo aborda o tema da membrana de látex, em uma perspectiva diferente, utilizando experimentos in vitro para explicar alguns dos resultados in vivo e ampliar a base de evidência para as principais conclusões. Com isso, utilizaram-se técnicas in vitro para provar a oclusão da membrana.

Os resultados deste trabalho inferem que em um futuro próximo, a um novo método de tratamento de ambliopia, de baixo custo, um produto nacional, descartável. Posteriormente poderá ser utilizado em animais e, se com êxito, em humanos.

\section{3 - OBJETIVOS}

Este trabalho tem como objetivo a obtenção e caracterização de membranas de látex a fim de avaliar sua viabilidade de aplicação como uma membrana oclusora com propriedade de alterar a passagem de luz e estimular o olho, no tratamento da ambliopia. Destacam-se:

i. Confeccionar a membrana a partir do látex natural da seringueira (Hevea 


\section{Brasiliensis);}

ii. Desenvolver e avaliar um protocolo de confecção da membrana de Van Gogh e de deposição;

iii. Avaliar a eficiência do método desenvolvido, através da caracterização das membranas com as seguintes técnicas:
a. Microscopia eletrônica de varredura (MEV),
b. Medidas de fluorescência de raios X,
c. Difração de raios X (DRX),
d. Termogravimetria (TG), calorimetria exploratória diferencial (DSC),
e. Análise de absorção de água,
f. Espectroscopia por FT-IR modo ATR,
g. Análise de componentes principais (PCA).
h. Avaliar as propriedades oclusivas com a análise de passagem de luz.

\section{4 - AMBLIOPIA}

A palavra "ambliopia" tem origem grega e é formada pela união de duas palavras: amblio, que significa fraco, vago, e ops, que significa ver, visão; portanto, sua definição é “visão vaga ou fraca". É conhecido popularmente como "olho preguiçoso" (Rhein, 2013).

Segundo a OMS, no Brasil, existem mais de 6,5 milhões de pessoas com deficiência visual, sendo 582 mil cegas e seis milhões com baixa visão, segundo dados do Censo 2010, do Instituto Brasileiro de Geografia e Estatística (IBGE). Atualmente, cerca de $40 \%$ das causas de cegueira infantil é evitável ou tratável (Brasil, 2014).

A etiologia da ambliopia é a falha na consolidação da acuidade visual (AV) unilateral ou bilateral decorrente da falta de estímulos ou presença de estímulos inadequados durante o período crítico do desenvolvimento da visão, também denominado olho preguiçoso. A causa da ambliopia pode ser devida a qualquer condição que impeça o 
uso normal dos olhos ou o desenvolvimento ocular. Na literatura constam três principais causas: i) estrabismo (olho desviado) - a imagem do olho desviado é suprimida, para evitar a visão dupla, e a criança utiliza apenas o melhor olho; ii) erro de refração (anisometropia) - quando um olho tem mais miopia, hipermetropia ou astigmatismo que o outro, o olho com visão borrada (fora de foco) é suprimido e pode tornar-se amblíope e iii) opacidade nos meios transparentes do olho (privação da luz) - qualquer fator que impeça uma adequada focalização da imagem pode levar ao desenvolvimento de ambliopia. É o defeito visual mais comum em crianças, seu diagnóstico e tratamento precoce trazem resultados satisfatórios (Salata et al., 2001 e Almeida, 2005).

Caso o olho seja privado desse estímulo durante o seu desenvolvimento, a visão estaciona ou regride, podendo apresentar graus extremos de baixa AV - ambliopia. As causas da privação desse estímulo deve-se a erros refrativos não corrigidos, como a miopia; hipermetropia; astigmatismo; assim como a anisometropia ou problemas binoculares (Zanoni et al., 2010).

O desenvolvimento do sistema visual começa desde o nascimento e aumenta rapidamente até aos 3-4 anos, aumentando em seguida de forma mais lenta até 8-9 anos. Até esta idade fala-se de período crítico, espaço de tempo pós-natal durante o qual o cortéx visual é suficientemente variável para adaptar-se a determinadas influências podendo tanto adquirir mecanismos viciosos de processamento da informação visual como permitir a sua correção. Existem alguns fatores que influenciam durante o desenvolvimento da visão. Dentre eles: prematuridade, baixo peso ao nascer, problemas na gravidez ou parto, antecedentes familiares (estrabismo, erros de refração), atraso de desenvolvimento, fatores ambientais (tabagismo, etilismo materno) e síndromes malformativos e/ou genéticos (Rhein, 2013).

Para verificar se uma pessoa apresenta ambliopia, ela deverá passar pelo teste de AV; desta forma, seu déficit visual será avaliado. A detecção precoce de fatores de risco, diagnóstico, profilaxia e tratamento é necessário para reduzir a incidência da ambliopia (Brandner et al., 2012). O tratamento pode durar até os 9 anos de idade. Após essa idade, a ambliopia tende a não voltar mais. Se o olho amblíope não for tratado, a dificuldade visual poderá ser irreversível (Procianoy et al., 2004). 
O sistema visual é como uma luz que entra no olho através dos impulsos elétricos atravessa a retina, passa pelas vias e é interpretado pelo cérebro. $\mathrm{O}$ mecanismo da ambliopia consiste que cada um dos dois olhos envia uma imagem para o cérebro, o qual precisa juntá-las formando uma só imagem. Quando os dois olhos enviam uma imagem igual para o mesmo objeto obtém-se facilmente a fusão das imagens. Porém, quando cada olho está fixando num ponto, o cérebro recebe duas imagens muito diferentes entre si e não consegue juntá-las (Rhein, 2013).

Segundo Salata et al. (2001), cerca de $75 \%$ dos casos de ambliopia são decorrentes da presença de estrabismo, $4 \%$ devido a anisometropia e $21 \%$ por privação de luz. Em $8 \%$ dos casos, observa-se associação de fatores.

A forma tradicional de tratamento para ambliopia encontrada na literatura é a oclusão do olho de melhor visão, utilizada há cerca de 250 anos, tendo a finalidade de estimular o olho com baixa visão, sendo o tampão único recurso eficaz para tratamento. Entretanto, para que esse tipo de tratamento traga bons resultados, é necessário que o paciente o realize adequadamente, mantendo-o por período variável, conforme a idade da criança e a intensidade da doença (Fielder et al., 1995, Arakaki et al, 2004).

O tratamento da ambliopia, que são considerados relevantes na Oftalmologia Pediátrica, são levadas com o uso de correcção óptica seguido pela oclusão do olho com melhor acuidade visual. Isto é feito para permitir o desenvolvimento do olho mais fraco. $\mathrm{O}$ tratamento infantil consiste da oclusão, é feita por um tampão adesivo, que é colocado no olho bom e às vezes não é bem aceita pela criança, pois a fita colocada nos olhos incomoda. Os oclusores convencionais, fixados com esparadrapo diretamente sobre a órbita ocular da criança, geram prejuízos estéticos e também possibilita que a criança frequentemente os retire, trazendo transtornos consideráveis ao tratamento (Rhein, 2013). Algumas desvantagens caracterizam este método: i) o desconforto; ii) a remoção por questões sociais; iii ) necessidade de oclusão para um período de pelo menos 6 horas. (Li et al., 2012). Tal tendência também vem sendo observada no Brasil, entre a comunidade oftalmológica, apesar de poucas evidências clínicas nacionais (Vasconcelos \& Costa, 2013). 
A correção óptica na infância é feita preferencialmente com óculos, pois estes não requerem cuidados especiais, são cômodos para os familiares e geralmente bem aceitos pelas crianças. Entretanto, existem condições onde só as lentes de contato (LC) conseguem melhorar a AV e/ou possibilitar a visão binocular. As principais indicações para uso de LC em crianças são: afacia, anisometropia, astigmatismo irregular (decorrente, frequentemente, de traumas corneanos), alta miopia, alta hipermetropia, ceratocone, aniridia, albinismo, alguns casos de ambliopia e nistagmo (Moreira et al, 2004, Salame et al, 2008).

Em caso do uso de óculos para a ambliopia, há ainda o inconveniente da adequação dos óculos, uma vez que o apoio nasal é prejudicado pelo oclusor convencional, tornando o ato de usar óculos ainda mais incômodos. Uma desvantagem é que, ao ocluirmos o olho bom, sua visão ficará dificultada por um período de tempo, impedindo do usuário de ter um bom acompanhamento na escola, fazendo com que retire o tampão para poder enxergar melhor (Rhein, 2013).

Já o tratamento com LC só é indicada em crianças, na qual o objetivo principal da adaptação de LC é permitir um desenvolvimento normal da AV, prevenindo ou minimizando a ambliopia. A indicação mais frequente é para corrigir erros refrativos, como: afacia, anisometropia, alta miopia, alta hipermetropia, astigmatismo irregular. No caso da ambliopia pode-se utilizar a LC Cosmética (LCC), que consiste numa LCC com pupila preta que pode ser usada também para mascarar um defeito desfigurante em olho sem visão ou como forma de oclusão no tratamento. Para adaptar uma LCC oclusora, devese primeiro determinar a adaptação ideal com uma LC transparente e usar os mesmos parâmetros para adaptar a LC opaca. As desvantagens do uso da LC para ambliopia são: perda frequentemente, custo elevado, dificuldade em adaptação, estético e ter acompanhamento dos pais para manusear a LC e fazer a manutenção adequada. (Salame et al, 2008, Coral-Ghanem \& Kara-José, 1998).

Contudo, não adianta tratar apenas a causa da ambliopia. Deve-se também forçar o cérebro a usar o olho fraco para estimulá-lo. Isso só é possível ao ocluir o olho preferido na maior parte do dia, por semana ou até meses. Algumas vezes é necessário ocluir ambos os olhos alternadamente (Rhein, 2013). 
Quanto ao sucesso no tratamento da ambliopia, isso varia conforme a gravidade do problema e da idade do paciente, tendo resultados insatisfatórios se for feito após a idade escolar. O tratamento pode durar até os 9 anos de idade. Após essa idade, a ambliopia tende a não voltar mais. Se o olho amblíope não for tratado, a dificuldade visual poderá ser irreversível (Almeida, 2005).

O tratamento da ambliopia promove uma melhor qualidade de vida para o paciente amblíope, influenciando o bem estar físico do indivíduo. Ainda se observa também, outras formas de tratamentos paliativos, como o uso de colírios, óculos, lentes corretivas, com informações inexploradas e contraditórias (Rhein, 2013).

\section{5 - MATERIAIS E MÉTODOS}

Neste estudo, desenvolveu-se um modelo experimental, denominado membrana de látex utilizando como matéria prima látex natural. Com base em técnicas já existentes e modelos diversos de objetos utilizados na área médica, propôs-se um modelo físico e material inédito para a aplicação proposta, que tem por objetivo permitir a oclusão parcial e estímulos do olho bom para tratamento da patologia. Trata-se de uma nova proposta para tratamento de pacientes amblíopes utilizando membranas de látex.

O processo de confecção da membrana de látex foi realizado em três etapas principais: preparo da matéria prima, confecção do molde e confecção do protótipo.

$\mathrm{Na}$ confecção do produto realizou-se na confecção de membranas de látex pelas técnicas de Van Gogh e deposição, na temperatura de $40{ }^{\circ} \mathrm{C}$ e $70{ }^{\circ} \mathrm{C}$.

\subsection{1 - Preparação do Látex}

Através de um modelo experimental da membrana de látex utilizando como matéria prima o látex natural extraído da seringueira Hevea brasiliensis, este foi adquirido no mercado nacional. Foram comprados alguns litros de fornecedores distintos da região 
Sudeste, com base em algumas características-padrão que eram necessárias tais como quantidade de baixa de enxofre e alta viscosidade. Uma concentração elevada de enxofre conferia ao látex, após vulcanização, característica colante e baixa viscosidade, tornando o processo de confecção com tempo de fabricação elevado.

Um fator importante em qualquer aplicação do biomaterial látex é a uniformidade das suas propriedades, pois esta é uma característica essencial a reprodutibilidade e confiabilidade dos produtos finais fabricados. Para obter esta característica, a fonte de látex deve ser a mesma, ou seja, o látex deve ser proveniente de árvores de um mesmo clone, adquirido no mercado nacional confirmando a utilização do mesmo lote e de origem comercial de indústrias idôneas como o caso da "DU LATEX". O látex comprado já vem com o processo de tratamento previsto de centrifugação, com as suspensões de enxofre e resina, com objetivo de conferir ao composto final a elasticidade e a resistência necessárias para diminuir a quantidade de proteínas nele presente naturalmente, muitas delas responsáveis por reações alérgicas. A partir deste processo de preparo, o látex configura-se como um composto que em contato com a pele vulcaniza-se, tornando-se colante. Para sua remoção, contudo, utiliza-se apenas água pura.

A partir do látex natural, preparou-se um composto final por meio de adição de substâncias químicas seguindo o protocolo realizado em (Mrué, 1996), com o objetivo de conferir ao protótipo características indispensáveis para a membrana: elasticidade, suavidade, resistência, impermeabilidade e hipoalergenicidade. Após o preparo do composto para utilização na confecção da membrana devem seguir as etapas de filtragem e diluição em água bidestilada.

Para esta diluição foi considerado 50\% de látex e 50\% de água destilada. Todo o procedimento deve, referencialmente, ser realizado em temperatura baixa (inferior a 25 ${ }^{\circ} \mathrm{C}$ ), para impedir uma pré-vulcanização do líquido, devido ao calor.

No manuseio do látex, foram utilizados bastões de vidro e um fuê para mexer, recipiente de vidro para armazenar, papel filme para proteger do contato com o ar, papel alumínio para proteger da luz e flanela de algodão para limpar. Para homogeneização e armazenamento foram utilizados bastão e recipiente de vidro, com vedação com papel filme para proteção do contato com o ar. O látex é um composto que, ao contato com a 
pele (devido ao calor do corpo $\approx 36{ }^{\circ} \mathrm{C}$ ), vulcaniza-se, tornando-se colante. Para sua remoção, utiliza-se apenas água pura.

Várias concentrações de látex foram testadas durante a produção dos protótipos até se deparar com um percentual que atendesse as características pré-estabelecidas de maciez, flexibilidade, transparência e resistência da mistura.

O uso de uma máscara é importante para que a inspiração de amônia seja pequena, para não acarretar alergias, irritações e dores de cabeça, as quais foram observadas durante o desenvolvimento do trabalho.

\subsection{2 - Preparação do molde}

O primeiro passo foi conhecer o globo ocular e suas particularidades. Para isso utilizou-se um modelo humano simplificado.

Durante o processo de desenvolvimento primeiramente foi confeccionado o molde, constituído de material plástico e revestido com uma camada em acrílico de $3 \mathrm{~cm}$ de largura, $3 \mathrm{~cm}$ de comprimento e 1,5 cm de diâmetro. O molde é desenhado com base na anatomia e nas características do olho, tomando como modelo o formato esférico da bola de gude para fins do protótipo baseado em seu tamanho, forma e proporção. A confecção da membrana é totalmente individualizada, sua forma e proporções seguem fielmente as características dos olhos do paciente, proporcionando maior conforto.

A membrana foi confeccionada a partir dos moldes previamente lavados com água e sabão, secados com ar quente e esterilizados por meio de estufa a $70{ }^{\circ} \mathrm{C}$ por dez minutos.

\subsection{3 - Preparação do protótipo}

A confecção do protótipo inicia-se pela preparação do ambiente, da matéria-prima 
e dos moldes, e segue uma série de etapas, a saber: aplicação da técnica no molde com o látex na forma líquida; secagem dos moldes em estufa; remoção do látex solidificado dos moldes e inspeção final.

Na técnica de Van Gogh as membranas eram preparadas a partir de pinceladas grossas utilizando uma haste flexível com pontas recobertas por algodão a $1 \mathrm{~cm}$ de distância do molde com movimentos de vai e vem até cobrir completamente o molde. Esse procedimento era repetido por três ou quatro vezes consecutivas, seguido de secagem em estufa a uma temperatura de $40{ }^{\circ} \mathrm{C}$, com intervalos de tempo de $2 \mathrm{~h}$, a fim de se obter membranas com espessura de até $0,2 \mathrm{~mm}$. Após este período de secagem, as membranas de Van Gogh permaneceram em repouso por $24 \mathrm{~h}$ a temperatura ambiente para finalizar o processo de vulcanização. Esse procedimento de obtenção de membranas foi denominado Van Gogh, em homenagem ao pintor impressionista Van Gogh que utilizava um método peculiar de batidas com pincéis em suas obras e foi baseada na técnica de imersão (Mrué, 1996), que consiste na introdução dos moldes no interior do composto final de látex, em posição perpendicular ao plano, de forma gradual e uniforme, seguido de aquecimento em estufa com controle de temperatura.

A obtenção das membranas pela técnica de deposição na placa de Petri foi realizada conforme descrito na literatura (Herculano, 2009, Mrué, 2000, Pinho et al., 2004). A transparência da membrana é favorecida no processo pela temperatura ambiente. O procedimento de vulcanização pode deixar a membrana com o aspecto mais amarelo, contudo, para a preparação destas membranas, sempre foram utilizados em média, de três a quatro dias para sua total secagem e polimerização, pois a estrutura e o formato da membrana devem ser uniformemente preservados, exigindo um processo de confecção mais minucioso. As membranas obtidas por deposição foram fabricadas depositando $5 \mathrm{ml}$ em placas de Petri de vidro com diâmetro de $8 \mathrm{~cm}$ e $0,3 \mathrm{~mm}$ de espessura.

As membranas de látex obtidas por ambas as técnicas foram desenvolvidas baseando-se no histórico de evolução com vários protocolos diferentes até se obter um modelo que respeitasse as características principais: oclusão da luz (parcial ou total), espessura e aplicabilidade. 


\subsection{4 - Caracterização do produto}

As membranas confeccionadas foram caracterizadas através dos métodos utilizados para investigar as características do látex in natura, e das membranas de borracha natural, tratadas termicamente a 40 e $70{ }^{\circ} \mathrm{C}$. Os métodos utilizados foram microscopia eletrônica de varredura (MEV), medidas de fluorescência de raios $\mathrm{X}$, difração de raios $\mathrm{X}$ (DRX), termogravimetria (TG), calorimetria exploratória diferencial (DSC), análise de absorção em soro fisiológico e espectroscopia por FT-IR modo ATR, análise de componentes principais (PCA) e análise de passagem de luz.

\section{6 - RESULTADOS E DISCUSSÃO}

O crescente interesse da análise do uso do biomaterial como ferramenta no tratamento de patologias na medicina é muito usado atualmente. Neste estudo, especificamente a engenharia biomédica auxiliou na caracterização do desempenho de uma membrana oclusora para o tratamento da ambliopia. Como biomaterial, foi utilizado o látex natural da seringueira Hevea Brasiliensis, um produto acessível no mercado e de fácil manuseio.

As membranas foram confeccionadas, baseando-se no histórico de evolução com vários protocolos diferentes até se obter um modelo que respeitasse as características principais: oclusão total ou parcial da luz, espessura mínima e aplicabilidade.

No ensaio técnico foi utilizado o látex natural como biomaterial por suas propriedades qualitativas como: impermeabilidade, elasticidade, suavidade, flexibilidade, resistência já testados em animais e humanos pela sua biocompatibilidade e angiogênese.

Para sua confecção, usou-se a técnica inovadora denominada Van Gogh, testadas diversas vezes para não ficar homogêneo para obtenção de um espalhamento difuso. Para chegar ao produto final várias técnicas de vulcanização foram testadas de forma a obter uma membrana transparente, de baixa espessura com $2 \mathrm{~mm}$, com pouca rugosidade e mínima absorção de água. Esse processo permitiu atingir a oclusão mais biologicamente 
compatível com o olho. Estes resultados foram significativos, pois as características da membrana de látex permitem interação com o olho sem alterar suas propriedades.

As membranas de látex serão, daqui por diante, identificadas como membranas de Van Gogh obtidas a partir de três banhos (M1) e quatro banhos (M2), ambas vulcanizadas a $40{ }^{\circ} \mathrm{C}$, e membranas obtidas pela técnica de deposição, vulcanizadas a $40{ }^{\circ} \mathrm{C}(\mathrm{M} 3)$ e 70 ${ }^{\circ} \mathrm{C}(\mathrm{M} 4)$.

Na Figura 1.1, pode-se observar as membranas desenvolvidas com seu aspecto morfológico utilizando a técnica de Van Gogh e deposição.
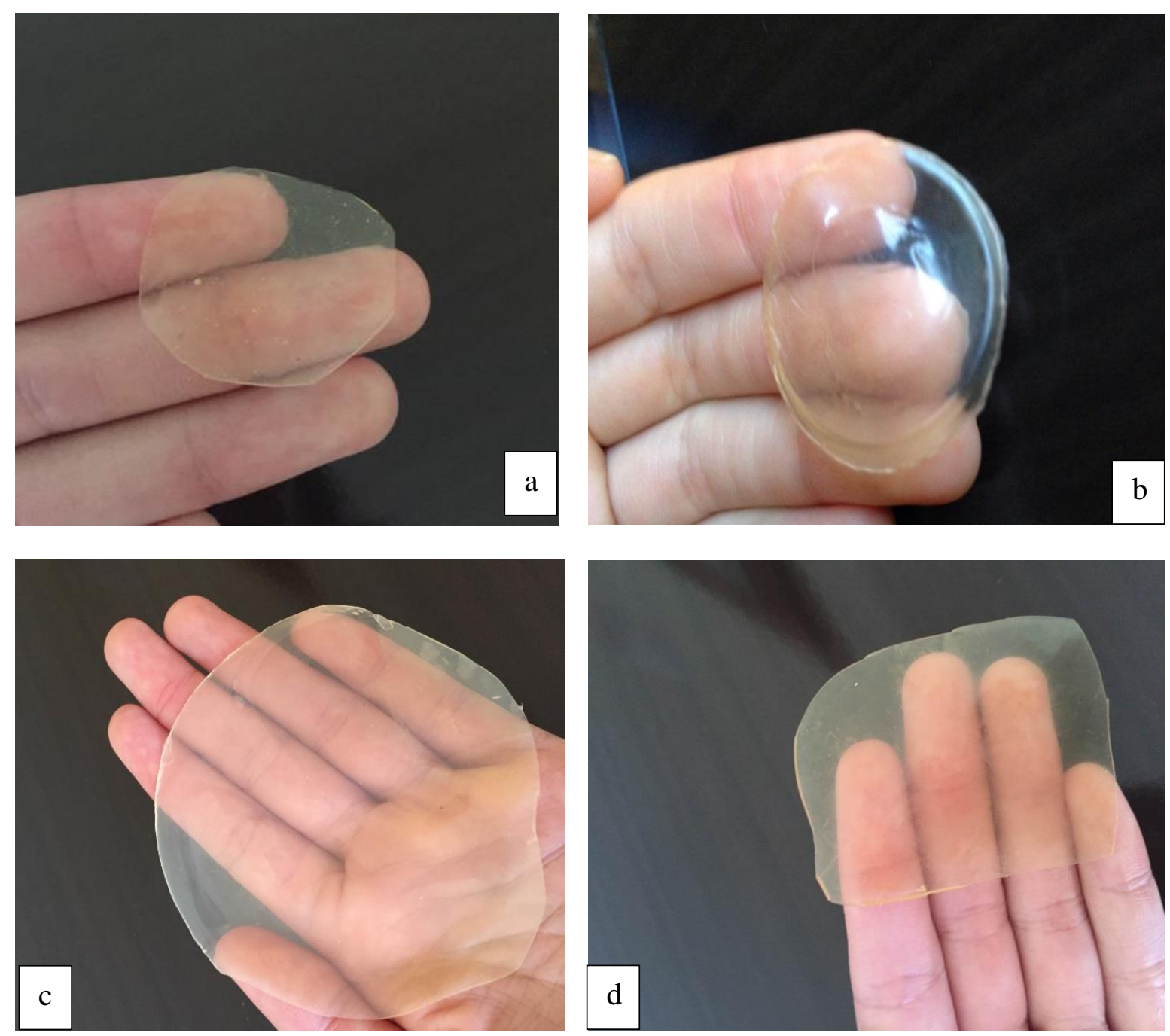

Figura 1.1 - Membranas confeccionadas utilizando a técnica de Van Gogh e deposição, em (a) M1, (b) M2, (c) M3, (d) M4. 
A membrana de látex de Van Gogh (M1 e M2) apresentaram irregularidades na superfície, menor espessura e transparente, que são características para se obter a oclusão parcial da luz. Na comparação da M1 e M2, a M1 apresentou menor espessura, na qual a M1 mostrou-se mais fina, pois teve três camadas de látex durante a confecção e M2 quatro camadas de látex. A membrana de látex por deposição (M3 e M4) não apresentaram irregularidade na superfície. Como foram vulcanizadas em temperaturas diferentes, apresentaram coloração diferente e possuem espessura maior que a M1 e M2.

As técnicas de caracterização mostraram a aplicabilidade e viabilidade da técnica de Van Gogh para confecção de membranas para o tratamento de ambliopia.

A técnica de microscopia eletrônica de varredura (MEV) é geralmente utilizado para o estudo de estruturas superficiais ou subsuperficiais das membranas e amostras com dimensões relativamente grandes, possui alta profundidade de foco, podendo obter diferentes relevos da superfície da amostra simultaneamente em foco e a rugosidade das membranas preparadas pela técnica de Van Gogh. A membrana M1 obtida a partir de 3 banhos apresentou rugosidade e porosidade por toda a área da micrografia apresentada, na qual podemos observar que os poros penetram por toda a membrana permitindo uma absorção de água. A membrana M2 observa-se que os 4 banhos utilizados durante o desenvolvimento da membrana M2 tornou-a mais densa, evidenciada pela presença de partículas de borracha. A M3 tratada termicamente a $40{ }^{\circ} \mathrm{C} \mathrm{M} 3$ apresenta a presença de partículas de borracha de forma mais organizada e densa. Na M4 tratada termicamente a 70 ${ }^{\circ} \mathrm{C}$ houve uma sintetização dos poros, deixando-se eles maiores. A técnica de Van Gogh apresentou com a rugosidade a oclusão da luz, a vantagem em relação a técnica de deposição.

A técnica de fluorescência de raios-X (EDX) foi realizada com o objetivo de se identificar os elementos químicos presentes nas membranas após todo o processo de desenvolvimento vulcanizado a 40 e $70{ }^{\circ} \mathrm{C}$. Os dados obtidos por EDX referentes a composição elementar das membranas observou-se quantidades elevadas de enxofre (S) e potássio $(\mathrm{K})$ em todas as membranas, e quantidades relativamente baixas de fósforo $(\mathrm{P})$, zinco ( $\mathrm{Zn})$, em comparação aos demais elementos detectados. Os resultados demonstram que as membranas obtidas pela técnica de Van Gogh M1 e M2 possuem quantidades 
ligeiramente maiores de enxofre quando comparadas as membranas obtidas pela técnica de deposição. A M4 apresentou uma menor quantidade de enxofre pois sofreu uma vulcanização a $70{ }^{\circ} \mathrm{C}$ e um aumento de potássio em relação as outras membranas. Este processo aconteceu porque a técnica de Van Gogh utiliza-se menor quantidade do composto. Na M1 com sua espessura menor (3 banhos) que a M2 (4 banhos) no processo de vulcanização a $40^{\circ} \mathrm{C}$, ou seja, com uma camada fina ele se vulcaniza rapidamente.

A técnica de difração de raios-X (DRX) das membranas mostra-se predominantemente amorfo, que consiste em uma banda de reflexão em $2 \theta=19^{\circ}$, o que está de acordo com dados já reportados na literatura (Agostini, 2009, Barros et al, 2016 e Aielo et al., 2014). Embora as membranas apresentem caráter amorfo, podemos observar notável diferença entre os difratogramas das membranas de acordo com a técnica de preparação. As membranas M3 e M4 apresentaram um perfil de difração de raios-X com certa cristalinidade, quando comparadas às membranas M1 e M2, embora aquelas tenham sido preparadas pela técnica de deposição em diferentes temperaturas de vulcanização. Ao compararmos ambas as técnicas, podemos evidenciar que o tempo envolvido na preparação das membranas resultou em um maior grau de reticulação química entre os segmentos de isopreno e, consequentemente, em maior cristalinidade evidenciada para as membranas de látex obtidas pela técnica de deposição.

A técnica de Termogravimetria (TG) e Calorimetria Exploratória Diferencial (DSC) é uma técnica dinâmica na qual a perda de massa de uma amostra é medida continuamente, enquanto a temperatura é aumentada a uma taxa constante para avaliar o comportamento do látex após o preparo das membranas. Para todas as amostras analisadas, não observamos significante degradação antes de $320{ }^{\circ} \mathrm{C}$. Podemos notar, para todas as membranas, que a temperatura máxima de degradação do polímero foi de aproximadamente $375-377^{\circ} \mathrm{C}$, o que aparentemente revela que a técnica de preparação das membranas não alterou significativamente o comportamento térmico das membranas. Em DSC, o comportamento térmico das membranas de látex é semelhante ao comportamento do látex natural, observados processos exotérmicos ocorridos. A técnica de Van Gogh não apresentou diferenças durante seu preparo em relação a técnica de deposição. 
A técnica de absorção em soro fisiológico foi realizada com o objetivo de avaliar o ganho de massa das membranas diante sua exposição ao soro físiológico com o intuito de avaliar qual membrana absorve água em menor quantidade. Para a execução da técnica adotou-se os seguintes tempos de imersão: 15, 30, 60, 105, 165, 255 e 375 minutos, sendo que no término de cada tempo. Nesta análise observou-se que a M3 absorveu água em maior quantidade em um intervalo de tempo maior e consequentemente ganhou maior massa, enquanto M2 e M4 teve um ganho de massa menor e em menos tempo, absorvendo pouca água. Dentre as técnicas, a técnica de Van Gogh a M2 de 4 banhos foi observado uma menor absorção de água e na técnica de deposição foi observado menor absorção na M4. A técnica de Van Gogh teve baixa absorção de água, a diferença entre M1 e M2 com absorção de 5.4 e 4.4 respectivamente. Esta diferença de apenas $1 \%$ pode não interferir na oclusão total e parcial uma vez que, em contato com olho deve absorver o mínimo possível para ser confortável e flexível no olho do paciente e as lentes de contato do mercado são confeccionadas com $80 \%$ de água.

A técnica de espectroscopia de infravermelho (FT- IR) com reflexão total atenuada (ATR) permite a obtenção de espectros qualitativos de sólidos, como no caso na borracha natural na região de 4000 a $500 \mathrm{~cm}^{-1}$. Os principais grupos químicos presentes na borracha natural vulcanizada são característicos do poli-isopreno. As membranas M1, M2, M3 e M4 mostraram três regiões de pico na banda de absorção de cis-1,4-poliisopreno em comum. A primeira 3000 a $2860 \mathrm{~cm}^{-1}$ e 1520 a $1400 \mathrm{~cm}^{-1}$ e a terceira em $860 \mathrm{~cm}^{-1}$. A borracha natural possui em 3400 ligações de O-H, em 3000 ligações de C-H, em 1715 ligações de $(\mathrm{C}=\mathrm{O})$ e em 873 ligações de $\mathrm{C}=\mathrm{H}$ (Aielo, 2014). Estas correlações FT-IR das membranas são similares a literatura que compara a borracha natural (Aielo, 2014, Agostini, 2009, Salmazo, 2011). As diferenças ocorridas da membrana possivelmente referem-se ao preparo do látex diluído e o modo de preparação das membranas.

A análise de componentes principais (PCA) é uma técnica da estatística multivariada que consiste em transformar um conjunto de variáveis originais em outro conjunto de variáveis de mesma dimensão para verificar o comportamento das membranas a partir dos dados quantitativos da caracterização. Os minerais K e P estão correlacionados a M4 e o Zn, Massa absorvida, Tempo estão correlacionados com a M3. O S está 
correlacionado com a M1. Essa correlação evidencia os dados obtidos anteriormente, pois a M3 possui maior quantidade de $\mathrm{Zn}$ e absorveu maior quantidade de água em maior tempo; a M4 apresentou maior quantidade de K e P devido sua maior temperatura durante seu preparo e a M1 com maior quantidade de enxofre. A M2 não apresentou nenhuma correlação com essas variáveis. De fato, a M2 nos resultados já apresentados, mostrou menor absorção de água em menor tempo e os minerais dentro das quantidades esperadas.

A técnica de análise de passagem de luz realizou-se com o intuito de avaliar a passagem de luz nas membranas, e verificar o comportamento da luz da superfície diante das rugosidades da técnica Van Gogh. A membrana M1 observa-se que o feixe localiza o centro óptico, indicando uma pequena passagem de luz, mas devido a superfície irregular das pinceladas o aparelho apresentou um erro de medição. Consequentemente, a técnica de Van Gogh com suas pinceladas, gerou uma rugosidade e obteve uma passagem de luz difusa. Na membrana M2 todas as membranas não foram observadas a passagem de luz, o lesômetro não localizou o centro óptico ocasionando um erro de medição. A membrana M2 tem a superfície mais irregular devido a diferença de confecção em relação a M1, pois o número de pinceladas foi maior. Esses dados comprovam a opacidade da membrana e que é característica na oclusão. Nas membranas M3 e M4 a técnica de deposição não tendo irregularidades na superfície. O lesômetro realizou a leitura através do centro óptico, medindo valores, não acusando erro, na qual permite a passagem total de luz.

Portanto, a técnica de Van Gogh com a confecção das membranas de látex podem ser consideradas viáveis para o tratamento da ambliopia. A passagem de luz foi considerada difusa devido a sua rugosidade e a sua opacidade o que poderá proporcionar a oclusão parcial ou total da luz no olho do paciente amblíope. A M1 mostrou-se uma passagem de luz difusa podendo estimular o olho além da oclusão e a M2 apresentou uma opacidade com oclusão total da luz que pode interferir de maneira benéfica ao tratamento quando comparada ao tampão.

Para uma melhor análise, os resultados são mostrados na Tabela 1.1, a qual apresenta os valores obtidos da caracterização das membranas M1, M2, M3 e M4. 
A técnica Van Gogh mostrou através da caracterização da membrana de látex como oclusora com propriedades mecânicas e térmicas para o desempenho do material com a caracterização do biomaterial na refração de luz sem eliminá-la por completo e manter as características do olho em movimento. É uma vantagem em relação ao tratamento tradicional com o uso do tampão uma vez há uma perda do seu movimento.

Para confecção da membrana oclusora, julgou-se necessário a avaliação do tamanho, forma, distribuição, uma vez que uma mudança abrupta no olho a propriedade se distancia da oclusão e gera desconforto.

Em contato direto com o olho essa membrana de látex com oclusão total poderá substituir o tampão com sua mesma função com a vantagem de dificuldade de sua fácil retirada pelo paciente, proporcionando uma resposta ao tratamento mais rápido, devido ao seu uso por maior período de tempo. E também evitar, por exemplo, o bullying na escola o que evitaria distúrbios psicológicos no futuro. Contudo, poderá proporcionar uma melhor qualidade de vida ao paciente. 
Tabela 1.1 - Resumo das caracterizações das membranas

\begin{tabular}{|c|c|c|c|c|}
\hline $\begin{array}{l}\text { Técnicas } \\
\text { /Amostras }\end{array}$ & M1 & M2 & M3 & M4 \\
\hline MEV & $\begin{array}{c}\text { Rugosa e } \\
\text { porosa }\end{array}$ & $\begin{array}{c}\text { Rugosa e } \\
\text { porosa }\end{array}$ & $\begin{array}{c}\text { Distribuição } \\
\text { organizada e } \\
\text { porosa }\end{array}$ & $\begin{array}{l}\text { Distribuição } \\
\text { organizada e } \\
\text { grandes poros }\end{array}$ \\
\hline EDX & Enxofre (S) & Enxofre (S) & Zinco $(\mathrm{Zi})$ & Potássio (K) \\
\hline DRX & $\begin{array}{c}\text { baixa } \\
\text { cristalinidade }\end{array}$ & $\begin{array}{c}\text { baixa } \\
\text { cristalinidade }\end{array}$ & $\begin{array}{c}\text { alta } \\
\text { cristalinidade }\end{array}$ & $\begin{array}{c}\text { alta } \\
\text { cristalinidade }\end{array}$ \\
\hline TG/DSC & $\begin{array}{l}\text { mesmo } \\
\text { comportamento } \\
\text { térmico }\end{array}$ & $\begin{array}{c}\text { mesmo } \\
\text { comportamento } \\
\text { térmico }\end{array}$ & $\begin{array}{c}\text { mesmo } \\
\text { comportamento } \\
\text { térmico }\end{array}$ & $\begin{array}{c}\text { mesmo } \\
\text { comportamento } \\
\text { térmico }\end{array}$ \\
\hline $\begin{array}{c}\text { Absorção em } \\
\text { soro } \\
\text { fisiológico }\end{array}$ & baixa absorção & baixa absorção & alta absorção & baixa absorção \\
\hline FT-IR ATR & $\mathrm{v}_{\mathrm{s}}(=\mathrm{C}=\mathrm{H})$ & $\mathrm{v}_{\mathrm{s}}(=\mathrm{C}=\mathrm{H})$ & $\mathrm{v}_{\mathrm{s}}(=\mathrm{C}=\mathrm{H})$ & $\mathrm{v}_{\mathrm{s}}(=\mathrm{C}=\mathrm{H})$ \\
\hline PCA & correlacionado & correlacionado & correlacionado & correlacionado \\
\hline $\begin{array}{c}\text { Análise da } \\
\text { passagem de } \\
\text { luz }\end{array}$ & $\begin{array}{c}\text { passagem de } \\
\text { luz difusa }\end{array}$ & $\begin{array}{l}\text { não apresenta } \\
\text { passagem de } \\
\text { luz }\end{array}$ & $\begin{array}{c}\text { apresenta } \\
\text { passagem de } \\
\text { luz }\end{array}$ & $\begin{array}{c}\text { apresenta } \\
\text { passagem de } \\
\text { luz }\end{array}$ \\
\hline
\end{tabular}

Por ser uma técnica nova, a técnica de Van Gogh, é passível que ocorra erros, porém, todos interferentes possíveis foram minimizados. A técnica de Van Gogh mostrouse eficaz na oclusão total e parcial da luz, pois a técnica de pinceladas apresenta-se como uma rugosidade que interferem na passagem de luz. 


\section{7 - CONCLUSÕES E PERSPECTIVAS}

Este estudo da engenharia óptica pode evidenciar o potencial uso e grandes vantagens da membrana de látex $\operatorname{LENCOC}^{\circledR}$ no tratamento de ambliopia com segurança e conforto para o usuário.

As TA traz aos pacientes novas ferramentas proporcionando novas habilidades ao tratamento das patologias consequentemente melhora na qualidade de vida do paciente. A LENCOC $^{\circledR}$ pode ser considerada uma órtese, através da TA, por ser um dispositivo aplicado no olho humano tendo como função de inibir a passagem de luz e estimular o olho no tratamento de doenças oculares.

No presente estudo elaborou-se um sistema complexo para se chegar ao produto final confeccionado uma membrana de látex oclusora no tratamento da ambliopia. Várias técnicas foram usadas no sentido de reforçar sua aplicabilidade e viabilidade, assim como a eliminação de interferentes. Através dos ensaios realizados pode-se concluir que:

i. O látex natural da seringueira pode ser usado como biomaterial, devido suas propriedades estruturais para desenvolver uma membrana oclusora visando o tratamento da ambliopia;

ii. Um protocolo foi estabelecido após vários ensaios para a realização e consolidação da técnica de Van Gogh. As propriedades examinadas foram obviamente satisfatórias quando se refere à visibilidade, flexibilidade e espessura. A cor clara da membrana deve-se à diminuição da temperatura durante sua confecção. Os resultados apresentam fortes indícios de que as membranas confeccionadas pela técnica de Van Gogh apresentam-se como uma membrana de passagem de luz difusa promovendo uma oclusão parcial, que mantem o olho com movimentos e estímulos;

iii. Durante o processo de caracterização, foram definidos quatro tipos distintos de amostras de membrana de acordo com diferentes temperaturas e técnica de Van Gogh e deposição. Todas foram testadas em diferentes equipamentos para análise física e química do biomaterial. A membrana M1 apresentou uma passagem de luz 
difusa, ocasionando uma oclusão parcial, preservando os movimentos oculares e estímulos do olho, e a membrana M2 uma opacidade, sem a passagem de luz e tem espessura pequena, transparente e pouca absorção de água, que poderá ser usada no tratamento de ambliopia, substituindo o tampão, com melhor conforto e um tratamento com menor duração.

Este trabalho apresentou através da caracterização a utilização da membrana de látex LENCOC $^{\circledR}$ para o tratamento da ambliopia. A técnica usada Van Gogh apenas com a comprovação de testes de caracterização demostraram que as características físicas e químicas da membrana de látex apresentam resultados compatíveis com o olho aplicado como um oclusor, reforçando sua característica de biomaterial. O método de confecção é reprodutível e a membrana de látex é muito estável.

A membrana de látex poderá oferecer uma adesão ao tratamento da ambliopia mais eficaz, tendo em vista uma melhor aceitação da criança e consequentemente a diminuição do tempo de tratamento. Além de uma menor possibilidade de rejeição, já que se trata de um biomaterial. Ela poderá ser usada por um período de tempo pelo paciente, em caso de crianças principalmente, sua retirada seria mais difícil e evitaria situações constrangedoras e mais eficiente, já que além de seu uso mais prolongado permitiria estimulação do olho através da oclusão parcial. 


\section{2 - INTRODUCTION}

The Assistive Technology (AT) sector has, among other things, the goal of providing and increasing functional abilities for people affected by diseases, from minor injuries to severe deficiencies, aiming to provide better quality of life and autonomy for the patient. As an area of knowledge in Brazil, AT started on November 16, 2006, through Ordinance No. 142, established by Decree No. 5296/2004 from the Secretariat for Human Rights of the Presidency of the Republic. The Technical Assistance Committee (TAC) was regulated with the intention of improving, adding transparency and giving legitimacy to the development of AT in Brazil (Brazil, 2009).

Due to the recent institutionalization of the area of AT, it is natural for specialized academic/scientific production to be detached, both in the aspects of Investigation and Development (I\&D) and of Research and Development (R\&D), because of the atomized production in scientific channels. This fact causes two important consequences: i) low theoretical and technological production; ii) low indices of public policies that offer AT in healthcare (Souza et al., 2014, Brazil, 2009).

One of the biggest current challenges engineering and the exact sciences are facing is to translate into mathematical terms and relations how phenomena and systems that compose the universe function. In order to develop and use this knowledge, it is necessary to interpret it as one of the factors of the system that relates to others to adapt and improve the processes that interact among themselves (Rosa et al., 2015).

One of these phenomena is amblyopia, which is an eye disease that develops during childhood and has few options for treatment. It causes a reduction in visual acuity because of an abnormal visual development in early years of life. The prevalence of amblyopia in children is estimated to be between $1 \%$ and $4 \%$. It is the most common cause of reduced visual acuity in childhood (Almeida, 2005, Ribeiro et al., 2013). This disease is the most common visual defect in children; however, its early diagnosis and early treatment have satisfactory results (Salata et al., 2001, Almeida, 2005).

The growing technological development and advancements in the field of medicine brought significant improvement to the quality of life of the population. One 
example is the development of biomaterials, which are used to completely or partially replace parts of lost or damaged organic tissues and are also used in direct and continuous contact with the body in non-pharmacological treatments. A good performance of biomaterials used as medical device depends on biocompatibility, as well as on the capacity and ease of molding said material into complicated shapes. Usually, the requirements of a biomaterial can be grouped into four major categories: biocompatibility, capacity of being sterilized, functionality, and reproducibility (Silva et al., 2012).

The natural latex membrane of rubber trees (Hevea brasiliensis) can be considered to be an orthesis (from the Greek, orthós), classified by AT as a device applied to any part of the body, isolated or covering more than one joint, with the function of stabilizing or immobilizing, preventing or correcting deformities, protecting against injury and facilitating the cure or maximizing the function (Thomazini et al., 2004, Macdonald, 1990). In this specific case, the latex membrane will be placed on the good eye for a few hours or days, according with the appropriate treatment recommended by the ophthalmologist, to accelerate the vision of the lazy eye diagnosed with amblyopia.

Chemically, the heterogeneous constitution of latex has high density and presence of impurities which must be treated and changed. In this study, the techniques that were used enable the degradation of polymers, regenerating, if possible, the monomers, so hydroxide and formaldehyde can be introduced - rendering the latex as simply a rubber film, an object, in this first moment - translucent, with entrance of light, but with irregular trajectories (preventing a complete view of the object), with diffuse refraction and minimal absorption so as not to generate heat (Ribeiro et al., 2014, Ribeiro et al., 2015).

The methods used for the construction of latex-derived devices have been employed since 1994 - described and proposed by (Mrué, 1996, Mrué et al., 2004). They were cited in Ribeiro et al. (2014), who developed a methodology of production that has been validated for many artifacts until the present moment, used as inductors of neovascularization and tissue repair.

It should be emphasized that latex has already been used in the confection of esophageal prostheses, biomembranes and esophageal flow controller modules (Rodrigues, 2009). Latex is an excellent inducer for situations in which repairs are necessary, such as 
when there is loss of bone, skin and blood vessels (Bolognesi et al., 2015). It has also been observed that natural rubber membranes help conjunctival scarring and angiogenesis when used on in vivo tests using the ocular conjunctiva in rabbits (Pinho et al., 2004).

Biomaterials may facilitate the confection of membranes to be used as occluders, since they are defined as active substances capable of interacting with the surrounding tissues without causing an immune response (Drewnowska et al., 2013).

Adopting new techniques and materials in medicine requires a series of rigorous studies to confirm their effectiveness and, above all, their safety of application. To this end, many steps must be followed. This study will be the first part of this path to an innovative treatment for amblyopia. We started with the choice of material, based on previous studies that used latex for medicinal purposes because it is considered to be simple and easy to handle (Pinho et al., 2004, Ribeiro et al., 2014, Ribeiro \& Rodrigues, 2014).

The membranes were then produced and patented under registry BR 102012007483-4 on April 2012 with the name "Latex-derived occluder contact lens" ("Lente de contato oclusora derivada de látex"), already published in the Industrial Property Journal (Revista de Propriedade Industrial (RPI)) (Brazil, 2015). Afterwards, the LENCOC $^{\circledR}$ brand was registered under the number 906573572 and published in the Industrial Property Journal (Revista de Propriedade Industrial (RPI)) for future commercialization (Brazil, 2016).

This study presents a simple approach to eye occlusion based on the ophthalmic membrane from an occlusive biomaterial derived from natural rubber latex, disposable method and a domestic product. The natural rubber membranes were developed with two different techniques, the Van Gogh technique and the deposition technique. The different membranes developed were characterized using physical and chemical methods in order to analyze the properties of latex in natura and of the membranes thermally treated at $40{ }^{\circ} \mathrm{C}$ and $70{ }^{\circ} \mathrm{C}$.

The objective of the occlusive partial membrane is to allow the incident beam to undergo a response with diffuse rays and stimuli of movements for there to be physical and chemical interaction of the membrane with the eye for a treatment that seeks a dynamic response to correct eye pathologies, specifically lazy eye. 
The methods used to characterize the materials were: scanning electron microscopy (SEM), fluorescence measurements, X-ray diffraction (XRD), thermogravimetry (TG), differential scanning calorimetry (DSC), saline absorption analysis, Infrared spectroscopy (FT-IR) attenuated total reflection (ATR) mode, principal component analyses (PCA) and light crossing analysis. From the analyses of their physical and chemical properties, we intend to evaluate the applicability of the natural rubber latex membranes as biocompatible ophthalmic occluders.

The primary focus of this study was to characterize the latex membranes for use as an occluder for the treatment of amblyopia with membranes disposable and made by a national product.

\section{1 - MOTIVATION}

For about 250 years, occlusion has been the most important therapeutic the treatment of amblyopia with stimuli of the affected eye, but its effectiveness remains uncertain, with success reports ranging from 30 to $92 \%$ (Salata et al., 2001). This type of treatment has good results, depending on the patient carrying it out properly. The length of the treatment varies, depending on the age of the child; on average, it lasts three years, or up to the age of 10 or 11 years old, with occlusion for at least one hour per day (Fielder et al., 1995, Arakaki et al., 2004).

When there is anatomical change, we observe that the total occlusion of the dominant eye can also be successful, mainly in cases of moderate opacity. In other cases, such as macular lesions or malfunction of the optic nerve, the prognosis is worse. There is evidence that there is an improvement of visual acuity and binocular function in patients who underwent occlusive treatment. The success rate varies with the age of the patient at the start of therapy, if there is good adherence by the patient and if the treatment is followed up for a long period (Arakaki et al., 2004).

Studies demonstrate that adherence to treatment with occlusion therapy depends on the age of the patient at the beginning of the treatment, the initial visual acuity with correction, the socioeconomic status of the patient and the involvement of the parents. 
Non-adherence, however, reaches $50 \%$, and the long duration of the treatment and nonacceptance by the child are the main contributing factors (Arakaki et al., 2004, Salata et al., 2001, Fielder et al., 1995).

The use of partial occlusion techniques is of particular interest in the context of binocularity in the treatment of amblyopia. This occurs because these techniques may allow binocular combination while still exercising the vision of the fixing eye. These partial occlusion methods can be a simple approach, with time of use of less than six hours (Li et al., 2012). This is already being discussed in Brazil among the ophthalmological community, despite related studies (Vasconcelos \& Costa, 2013).

Despite these data, occlusive therapy is still the best form of treatment. The search for new methods for the treatment of amblyopia is fully justified. It is necessary to find a new treatment approach because there are no reports of effective treatments to date. This doctoral thesis emerged from a need of creating a new approach to try to solve the problem of occluding the eye with an eyepatch and correcting the lazy eye.

Many studies that used latex biomaterial (Hevea Brasiliensis) as an implant in different tissues have had satisfactory results, which motivates further work in this area, in different species (Mrué et al., 2004, Pinho et al., 2004). It has been proven that biomembranes present important biological properties, such as: neoangiogenesis, promotion of cell adhesion and formation of extracellular matrix. In experimental studies, this latex biomembrane favored the repair of partial defects of dog esophagus (Mrué, 2000), the repair process of the ocular conjunctiva of rabbits (Pinho et al., 2004) and of a healing insole with a system that induced tissue neoformation for diabetic feet (Reis, 2013). Therefore, this material demonstrated to be biocompatible in all experiments carried out to date, without any type of allergic reaction, with low cost and easy handling.

Based on the above, this study had the objective of developed and viable a new method and a methodology for producing a $\mathrm{LENCOC}^{\circledR}$ latex membrane. 


\section{2 - CONTRIBUTIONS OF THE THESIS}

This study shows the possibility of using latex as a new occlusive membrane method for the treatment of eye conditions, specifically amblyopia.

The concept of occluders is outdated, without any changes in the materials in the last decade. The lack of products with new technologies leads to a lack of incentive for the professionals who work with this disease. Thus, the latex membrane may cause an impact in the market. Concomitantly, the ideas of the health professionals who treat amblyopia will change, because a new dynamic in the treatment will make treatments more accurate, leaving patients and professionals more satisfied.

It is important to emphasize that in vivo tests were not possible in this study due to its innovative nature. This study deals with the theme of latex membranes under a different perspective, using in vitro experiments to explain some of the in vivo results and broaden the basis of evidence for the main conclusions. Thus, in vitro techniques were used to prove the occlusion of the membrane.

The results of this study suggest that it may lead, in a near future, to a method low cost, a domestic product for the treatment of amblyopia. It may be used later in animals and, if successfully in humans.

\section{3 - OBJETIVES}

The objective of this study is to obtain and characterize latex membranes in order to evaluate the feasibility of their application as occlusive membranes with the property of changing the course of light and stimulating the eye in the treatment of amblyopia. The following objectives stand out:

i. Preparing the membrane from the natural latex of rubber trees (Hevea brasiliensis); 
ii. Developing and evaluating a protocol for producing the Van Gogh membrane and the deposition membrane;

iii. Evaluating the efficiency of the method developed here, through characterization of the membranes with the following techniques:
a. Scanning electron microscopy (SEM);
b. Fluorescence measurements;
c. X-ray diffractometry (XRD);
d. Thermal analysis;
e. Saline absorption measurements;
f. Infrared spectroscopy (FT-IR) attenuated total reflection (ATR) mode
g. Checking the principal component analysis (PCA).
h. To assess the occlusive properties with the light crossing analysis.

\section{4 - DOCUMENT STRUCTURE}

- Chapter 3 brings a bibliographic review on amblyopia, latex and important parameters.

- Chapter 4 brings the materials and methods and details the latex membrane development process.

- Chapter 5 brings the results and discussions with the production of the techniques and the characterization of latex membranes.

- Chapter 6 closes the work, concluding that the results are promising for the confection of a latex membrane for the treatment of amblyopia. 


\section{3 - BIOMATERIAL AND AMBLYOPIA}

Vision plays a fundamental role in the development of children during the first years of life, as it encourages communication and the execution of actions. The best time to treat ocular alterations is during childhood, since untreated problems in this stage may have irreparable consequences. The visual system evolves from birth until 12 years of age, a period during which the eye grows and develops because of visual stimuli (light and forms), which are essential (Zanoni et al., 2010).

Below, we will present information to facilitate the understanding of this work, related to concepts of anatomy and physiology of the human eye, to the disease and to methods of treatment of amblyopia. We will also present information on latex biomaterial and its uses, advantages and applications in the medical sector.

\section{1 - ANATOMY AND PHYSIOLOGY OF THE HUMAN EYE}

Vision is responsible for approximately $75 \%$ of human perception. Summing up extremely briefly, the act of seeing is the result of three distinct actions: optical operations, chemical operations and nervous operations (Guyton \& Hall, 2011). In fact, approximately $85 \%$ of learning happens through vision. The World Health Organization (WHO) estimates that 7.5 million school-age children have some type of visual impairment. However, only $25 \%$ of them present symptoms; thus, the other $75 \%$ require specific tests to identify the problem (Zanoni et al., 2010).

The eye is the most external organ of the human vision. Its function is to act as a light sensor and convert it into electrochemical signals, sent via the optical nerve to the visual cortex in the brain, for information processing. Light enters the cornea, crosses a cavity filled with a colorless liquid called aqueous humor, passes through an opening in the iris, called pupil, and is focused by the crystalline to reach a surface formed by more than 100 million photoreceptors, called retina (Palmer, 1999). The human eye is a complex optical system, formed by various transparent media, as well as a physiological system 
with several components.

The eye is composed of three layers: outer, middle and inner (Figure 3.1). The outer layer acts as a protective layer of the eye, constituted by the cornea, the transparent part of the eye that works as a lens, and sclera, popularly called the white of the eye. The middle layer comprises the iris, the choroid and the ciliary body. This layer is also called vascular tunic. The retina lies in the inner layer, the nervous layer. In the retina, more than one hundred million photosensitive cells transform the light in electrochemical impulses, which are sent to the brain by the optic nerve. In the brain, more precisely in the visual cortex, the processing of the images received by the left and right eye occurs, completing our visual sense (Guyton \& Hall, 2011).

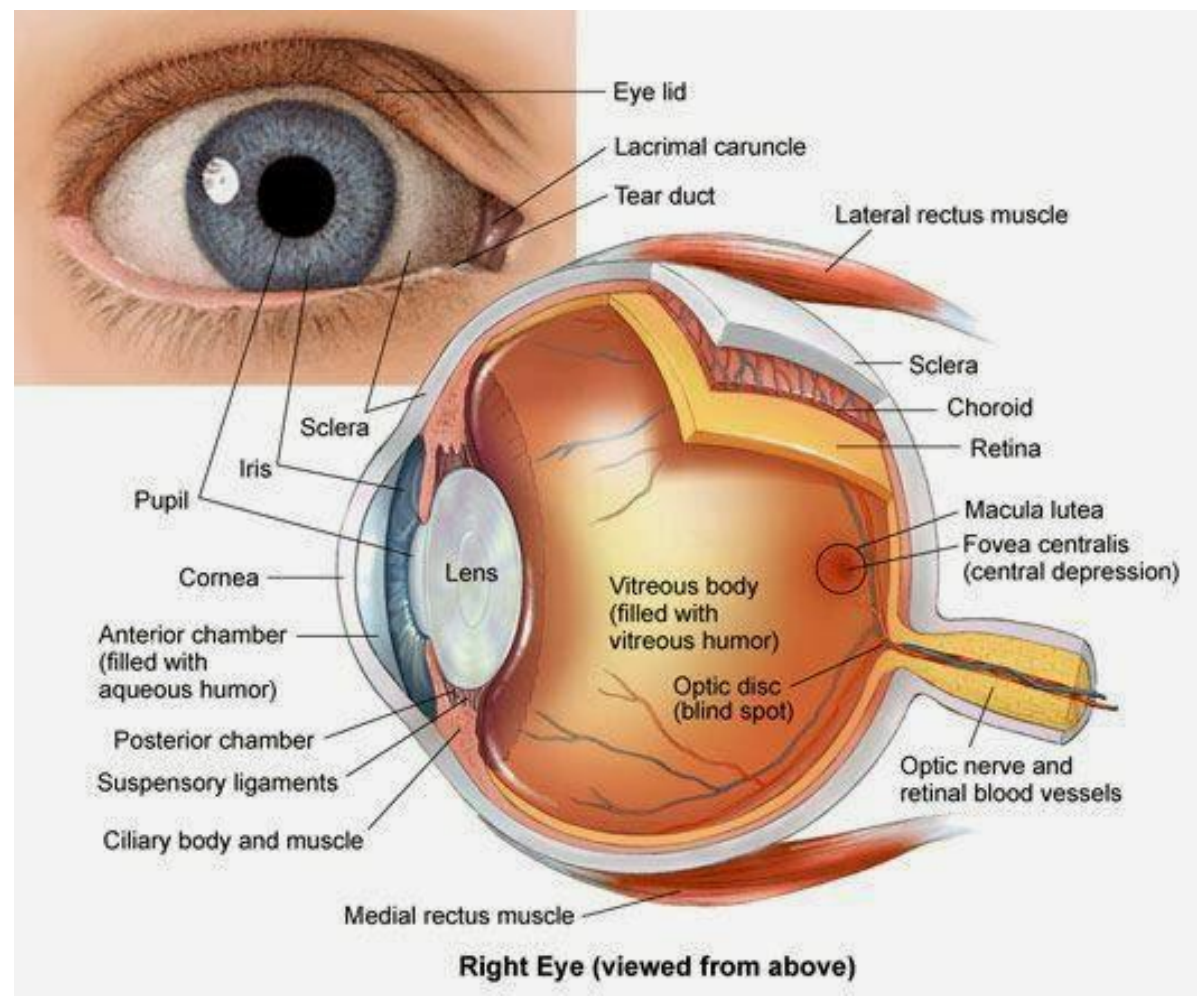

Figure 3.1 - Anatomy of the human eye (Adapted from Grant, 2015).

The ocular globe in a normal eye is almost spherical, with a radius around $1.2 \mathrm{~cm}$. The cornea, whose refraction index is around 1.38, has a curvature radius of approximately 
$0.80 \mathrm{~cm}$ in its anterior portion and of approximately $0.65 \mathrm{~cm}$ in the posterior portion. Its thickness is approximately $0.06 \mathrm{~cm}$ in the central part (the pole, on the main axis), and it is a little thicker on the sides. The internal lens, also called crystalline, has curvature radii that may vary, allowing it to focus on close or distant images. The thickness of the lens is approximately $0.4 \mathrm{~cm}$. The distance between the anterior surface of the lens and the cornea is approximately $0.35 \mathrm{~cm}$. The refraction index of the lens is not uniform, changing from the center to the edge. The geometrical dimensions vary from person to person. For example, myopic eyes are longer, and hypermetropic eyes are shorter along the direction of the main axis. There are also variations of the distance between the lens and the cornea; the rays of the cornea may also vary from person to person (Helene \& Helene, 2011).

\section{2 - AMBLYOPIA}

The word "amblyopia" has a Greek origin and is formed by the union of two words: amblys, which means dulled, blunt, and ops, which means eye; therefore, its definition is "dulled or blunt vision". It is popularly known as "lazy eye" (Rhein, 2013).

According to the $\mathrm{WHO}$, in Brazil, there are more than 6.5 million people with visual disabilities, 582 thousand blind and six million with low vision, according to data from the 2010 Census by the Brazilian Institute of Geography and Statistics (IBGE). Currently, about $40 \%$ of the causes of infant blindness are avoidable or treatable (Brazil, 2014).

The etiology of amblyopia is the failure to consolidate unilateral or bilateral visual acuity (VA) resulting from lack of stimuli or presence of inappropriate stimuli during the critical period for the development of vision - this is also called lazy eye. Amblyopia may be caused by any condition that prevents the normal use of the eyes or normal ocular development. The literature names three main causes: i) strabismus (diverted eye) - the image of the diverted eye is deleted to avoid double vision, and the child uses only the more accurate eye; ii) error of refraction (anisometropia) - when an eye has more myopia, hypermetropia or astigmatism than the other one, the image produced by the eye with 
blurred vision (out of focus) is deleted and can become amblyopic; and iii) opacity in the transparent media of the eye (deprivation of light) - any factor that prevents a proper focus of the image can lead to the development of amblyopia. It is the most common visual defect in children. Its diagnosis and early treatment have satisfactory results (Salata et al., 2001, Almeida, 2005).

If the eye is deprived of this stimulus during its development, the vision stops evolving or declines, and may present extreme degrees of low VA - amblyopia. The causes for the deprivation of this stimulus can be uncorrected refractive errors, such as myopia; hypermetropia; astigmatism; as well as anisometropia or binocular problems (Zanoni et al., 2010).

The development of the visual system starts from birth and quickly increases until the age of 3-4, increasing then more slowly up to 8-9 years of age. Up to this age, we talk about a critical period, which is a post-birth length of time during which the visual cortex is sufficiently variable to adapt to certain influences and may both acquire vicious mechanisms of visual information processing and enable their correction. There are some factors that influence the development of vision, including: prematurity, low birthweight, problems in pregnancy or childbirth, family history (strabismus, refractive errors), delayed development, environmental factors (smoking, maternal alcoholism), malformation syndromes and/or genetic syndromes (Rhein, 2013).

To find out if a person presents amblyopia, the person should undergo the VA test; this way, their visual deficit will be assessed. Early detection of risk factors, diagnostic, prophylaxis, and treatment are necessary to reduce the incidence of amblyopia (Brandner et al., 2012). Treatment may last until 9 years of age. After this age, amblyopia tends not to return anymore. If the amblyopic eye is not treated, visual difficulty may be irreversible (Procianoy et al., 2004).

The light enters the eye and through the electrical impulses crosses the retina, passes through the conduits and is interpreted by the brain. The mechanism of amblyopia consists in each eye sending an image to the brain, which needs to combine them, forming a single image. When the two eyes send the same image for the same object, the fusion of 
the images is easily obtained. However, when each eye focuses on a different point, the brain receives two very different images and is not able to combine them (Rhein, 2013).

According to Salata et al. (2001), about $75 \%$ of the cases of amblyopia are due to the presence of strabismus, $4 \%$ due to anisometropia and $21 \%$ due to deprivation of light. In $8 \%$ of cases, an association of factors was observed.

The traditional form of treatment for amblyopia found in the literature is the occlusion of the better eye. It has been used for over 250 years and has the goal of stimulating the eye with low vision; the eyepatch is the only effective resource for its treatment. However, for this type of treatment to have good results, the patient must carry it out properly, maintaining it for a variable period, depending on the age of the child and the intensity of the disease (Fielder et al., 1995, Arakaki et al., 2004).

The treatment for amblyopia, which are considered relevant in Pediatric Ophthalmology, are carried out with the use of optical correction followed by occlusion of the eye with better visual acuity. This is done to allow the development of the weaker eye. Currently, for infant treatment, occlusion is carried out with an adhesive eye pad placed on the healthy eye. Some failure factors characterize this method: i) discomfort; ii) removal of the eye patch for social situations; iii) necessity of occlusion for a period of at least 6 hours (Li et al., 2012). This trend has also been observed in Brazil among the ophthalmological community (Vasconcelos \& Costa, 2013).

Optical correction in childhood is carried out preferably with eyeglasses, because they do not require special care, are comfortable for the family and are usually wellaccepted by children. However, there are conditions where only contact lenses (CL) can improve VA and/or enable binocular vision. Contact lenses are indicated for children for treating: anisometropia, irregular astigmatism (frequently due to corneal trauma), high myopia, high hypermetropia, keratoconus, and some cases of amblyopia (Moreira et al., 2004, Salame et al., 2008). When glasses are used for treating amblyopia, there is also the inconvenience of adapting to the glasses, because the nasal bridge is obstructed by the conventional occluder, making the act of wearing glasses even more cumbersome. Another disadvantage is that, when the good eye is occluded, vision will be hampered by a period 
of time, thus preventing the user from having a good performance in school, causing the user to remove the eyepatch to see better (Rhein, 2013).

On the other hand, the treatment with CL is only recommended in children when the main goal of the CL is to allow a normal development of the VA, preventing or minimizing amblyopia. It is usually recommended to correct refractive errors, such as: anisometropia, high myopia, high hypermetropia, irregular astigmatism. In the case of amblyopia, the cosmetic contact lens (CCL) may be used. It consists of a contact lens with a black pupil that may also be used to mask a disfiguring defect in a blind eye, or as a form of occlusion during treatment. To adapt an occluder CCL, the ideal adaptation must first be determined with a transparent CL and the same parameters must be used to adapt the opaque CL. The disadvantages of the use of CL for amblyopia are: frequent loss, elevated cost, difficult adaptation, aesthetics and need for parental supervision to handle the CL and perform proper maintenance (Salame et al., 2008, Coral-Ghanem \& Kara-José, 1998).

However, it is not enough to treat only the cause of amblyopia. The brain must also be forced to use the weak eye so as to stimulate it. This is only possible by occluding the preferred eye during most of the day, for weeks or even months. It is sometimes necessary to occlude both eyes alternately (Rhein, 2013).

The success of the treatment of amblyopia varies according to the severity of the problem and the age of the patient, with unsatisfactory results if performed after school age. Treatment may last until 9 years of age. After this age, amblyopia tends not to return anymore. If the amblyopic eye is not treated, visual difficulty may be irreversible (Almeida, 2005).

The treatment of amblyopia promotes a better quality of life for the amblyopic patient, having an influence on the physical well-being of the individual. Other forms of palliative treatments can also be noticed, such as the use of eyedrops, eyeglasses, and corrective lenses, with unexplored and contradictory information (Rhein, 2013).

Table 3.1 shows the pros and cons of each treatment in relation to the types of amblyopia. 
Table 3.1 - Treatment of amblyopia, pros and cons

\begin{tabular}{|l|l|l|l|}
\hline Amblyopia- types & Treatment & Pros & Cons \\
\hline Strabismic & $\begin{array}{l}\text { Occlusive therapy } \\
\text { - occlusive } \\
\text { eyepatch } \\
\text { Optical correction } \\
\text { (glasses or contact } \\
\text { lens) }\end{array}$ & $\begin{array}{l}\text { variable } \\
\text { depending on the age } \\
\text { of the child and the } \\
\text { disease. }\end{array}$ & $\begin{array}{l}\text { Difficulty of use, } \\
\text { removing it } \\
\text { prematurely, school } \\
\text { bullying. }\end{array}$ \\
\hline Anisometropy & $\begin{array}{l}\text { Refractive surgery } \\
\text { (intraocular lens } \\
\text { implant); optical } \\
\text { correction }\end{array}$ & Faster treatment & There are no conclusive \\
studies on surgery.
\end{tabular}

Source: Adapted from Rhein (2013).

In all situations that cause amblyopia, treatment is based on the selective stimulation of the affected eye. To this end, the better eye is occluded for a certain period, depending on the level of amblyopia and the age when the therapy starts. As a basic rule, occlusion is made during a period matched with the age, i.e., occlusion of the normal eye for two weeks for two-year-old children, occlusion of five weeks for five-year-old children, and so on. In order to monitor the evolution and reinforce the adhesion to the treatment, literature suggests weekly reassessments in the first month, biweekly reassessments in the second month, and monthly reassessments from the third month. At this point, it is believed to be possible to obtain significant improvement of visual acuity, 
and the occlusion time of the healthy eye may be reduced to one or two hours every day until both eyes are equal (Rhein, 2013).

Even though the eyepatch has been a form of treatment of amblyopia for decades, with the advance of biotechnology new tools can be developed, such as, for example, an occlusive membrane made from biomaterial. This would allow for a more effective treatment, with more comfort and acceptance by the patient.

\section{3 - BIOMATERIAL}

In the literature, a biomaterial is defined as any substance that is not a drug, of synthetic or natural origin, which can be used by any period of time, acting in the replacement of any tissue, organ or function of the body, or even used in direct contact, in order to maintain and/or change the quality of life of the patient in a safe, responsible, economical and physiologically acceptable way (Willians,1987, Recum \& Jacobi, 1998, Orefice et al., 2005, Park \& Lakes, 2007).

For more than one century, researchers have made efforts to find materials with adequate characteristics for the restoration and replacement of bone tissues in the human body, or even for direct use. Initially, they searched for these compounds by using materials of biological origin, as in the case of grafts and transplants, which are classified as autogenous (the donor is the receiver), allogeneic (the donor and the recipient are from the same species) and xenogeneic (the donor is from a different species). Due to the disadvantages of these materials and to the great scientific and technological development, many studies have been conducted with the objective of developing materials of synthetic origin with adequate characteristics that allow for the decrease and in some cases elimination of the use of materials of biological origin (Guastaldi, 2004).

Biomaterials may be classified according to their biological response and according to their chemical composition (Paula, 2010). Taking into account the biological response caused by biomaterials in the host tissue, we can classify them into four categories: 
1) Bioinert - does not cause foreign body reaction in the organism and is in direct contact with the receptor tissue. Examples: titanium, zirconia and alumina.

2) Biotolerated - moderately accepted by the receptor tissue and usually surrounded by fibrous tissue. Examples: stainless steel, Cr-Co alloys and polymethylmetacrylate (PMMA).

3) Bioactive - directly connected to living tissues due to ions, such as $\mathrm{Ca}^{+2}$ and/or $\mathrm{PO}_{4}{ }^{-2}$, present in bone substitutes, which favor a chemical link with the bone tissue. Examples: hydroxyapatite (HAp) and bioglass.

4) Resorbable - slowly degradable and gradually replaced by the tissues. Examples: tricalcium phosphate (TCP) and bioglass.

With regards to the chemical composition, they can be classified as either synthetic or biological (natural); biological biomaterials are further subclassified as soft or hard; and synthetic biomaterials, as polymeric, metallic, ceramic and composites, as can be seen on Table 3.2 (Teoh, 2004).

These materials, used as biomaterials, must meet certain essential requirements, such as: biocompatibility, biofunctionality, bioadhesion, and mechanical properties similar to those of the bone, such as: elasticity module, resistance to traction and fatigue, processability, resistance to corrosion. Also, the prices should be consistent with the Brazilian reality (Rodrigues, 2009).

Among these characteristics, biocompatibility is the most important one. This is because biofunctionality of the material can only manifest itself when there is biocompatibility. When a foreign material enters into contact with the biological fluids, protection responses are triggered and manifest as inflammatory or immunological processes, with the objective of eliminating the foreign body. Therefore, a good performance of a biomaterial is linked to a balance between biocompatibility and biofunctionality (Reis, 2013). 
Table 3.2 - Classification of biomaterials

\begin{tabular}{|c|c|}
\hline Biological materials & Biomedical synthetic materials \\
\hline $\begin{array}{l}\text { 1) Soft tissue: } \\
\text { Skin, tendons, } \\
\text { pericardium, cornea. }\end{array}$ & $\begin{array}{l}\text { 1) Polymeric: } \\
\text { High-density polyethylene (UHMWPE), polymethylmetacrylate } \\
\text { (PMMA), PEEK, polyurethane (PU), silicone, } \\
\text { polytetrafluoroethylene (PTFE). }\end{array}$ \\
\hline \multirow[t]{3}{*}{ Bone, dentin, cuticle. } & $\begin{array}{l}\text { 2) Metallic: } \\
\text { Stainless steel, cobalt alloy (Cr-Co-Mo), titanium alloy (Ti-Al- } \\
\text { V), gold, platinum. }\end{array}$ \\
\hline & $\begin{array}{l}\text { 3) Ceramic: } \\
\text { Alumina, zirconium, carbon, hydroxyapatite } \\
[\mathrm{Ca} 10(\mathrm{PO} 4) 6(\mathrm{OH}) 2] \text {, tricalcium phosphate }[\mathrm{Ca} 3(\mathrm{PO} 4) 2)] \text {, } \\
\text { bioglass or phosphate glass }[\mathrm{Na} 2 \mathrm{O}(\mathrm{CaO})(\mathrm{P} 2 \mathrm{O} 3)(\mathrm{SiO} 2)] \text {, } \\
\text { calcium aluminate }[\mathrm{Ca}(\mathrm{A} 2 \mathrm{O} 4)] \text {. }\end{array}$ \\
\hline & $\begin{array}{l}\text { 4) Composite: } \\
\text { Carbon fibers (CF/PEEK, CF/UHMWPE, CF/PMMA), } \\
\text { zirconium/silica/BIS-GMA. }\end{array}$ \\
\hline
\end{tabular}

The International Organization for Standardization (ISO), for about ten years, collected studies that have resulted in a document known as ISO 10993 - Biological evaluation of medical devices, a set of standards for assessment of devices and materials for medical use, some of which are used in this project. There is a great diversity of biomaterials, which are differentiated according to aspects such as the form of application of the product, the form of contact and time of permanence in the body, and the material used for its manufacture, which, in turn, determine the complexity of developing a new product (Orefice et al., 2005). 


\section{4 - LATEX}

Natural latex was found by researchers to be a natural healing agent from the rubber tree (Hevea brasiliensis); since then, studies have been developed to prove the characteristics that induce neovascularization and tissue repair (Mrué, 1996).

In 1839, Charles Goodyear discovered the vulcanization process in his lab, when he accidentally dropped a mixture of natural rubber and sulfur in an oven and heated it. Due to this fact, Goodyear showed that the mixture of rubber and sulfur formed a new material with better properties than raw rubber, including the valuable properties of resistance and elasticity (Paula, 2010).

The vulcanization process consists in the heating of rubber with sulfur. This is converted into a viscous tangle of long-chain molecules in a three-dimensional elastic network, chemically bonding these molecules at various points along the chain. A system of vulcanization contains vulcanizing agents (sulfur, metal oxides, difunctional compounds and peroxides) and, if necessary, accelerators, activators, retardants etc., used to produce the desired vulcanization characteristics and the intended vulcanized properties. Such properties of vulcanized rubber latex have allowed this material to be employed in several areas with different purposes, such as in the medical context (Souza et al., 2014).

As is the case with many great discoveries, the first known study that used latex for medicinal purposes happened by chance, when a researcher at the University of Ribeirão Preto (USP - Ribeirão Preto), while trying to reproduce a model of an already known esophageal prosthesis, replaced a certain constituent by natural latex. To the surprise of the team, the results were favorable and encouraged other studies, which continue up to the present. This study, conducted by Mrué (1996), proposed the replacement of a segment of 4 to $6 \mathrm{~cm}$ of the cervical esophagus in dogs by a prosthesis based on natural latex, with different permanence times. 


\subsection{1 - Latex properties}

In Brazil, latex has already been the focus of large production in 1940s and 1950s. Rubber is nowadays part of the Brazilian import quota. However, the State of Tocantins, with the incentive of the state government, has been implementing the production of rubber trees, known as heveiculture, and placing the producers from that state in the local agenda of latex production for the internal market in Brazil. In addition to being a significant source of income for small producers, rubber plantations are a form of production that does not harm the environment and that improves the microclimate in the region where it grows (ITeB, 2015).

The Hevea brasiliensis species is the main source of extraction of the latex produced in the world. It is a tree native to the Amazon rainforest in Brazil; however, in 1876, the English took its seeds to Asia. Currently, the biggest producers of natural rubber are Thailand, Indonesia and Malaysia, which together produce approximately $70 \%$ of the world total. The rubber tree is a source of natural rubber - latex -, which is the raw material used in the sectors associated with transportation, medicine, industry, war, etc. Latex is a white secretion (also called "milky coagulated sap") produced by the trunk of the rubber tree (Hevea brasiliensis) when it suffers an incision in the bark, called “bleeding” (Alves, 2004, IteB, 2015).

The latex of natural origin, extracted from the Hevea brasiliensis rubber tree, is a wound healing agent, a natural defense of the plant, which has properties for inducing neovascularization and tissue regeneration, formation of the extracellular matrix, and also has the advantage of having low cost, without risk of pathogen transmission and having a great clinical and social applicability (Reis, 2013). Latex is a polyphase and polydisperse colloidal system that contains molecules of poly $(\mathrm{cis})$ isoprene in suspension. Latex is stable due to the presence of proteins that are insoluble in water and lipids that act as natural surfactants. In the composition of natural latex, there are particles of rubber hydrocarbon, and non-starchy, suspended in a phase of aqueous serum, whose average composition is 36 $\%$ hydrocarbons, $1.4 \%$ protein, $1.6 \%$ carbohydrates, $1 \%$ neutral lipids, $0.6 \%$ glycolipids plus phospholipids, $0.5 \%$ inorganic components, $58.5 \%$ water and $0.4 \%$ other substances 
(Rodrigues, 2009).

The physiological functions in the plant, such as the transport and reserve of nutritious materials; protection to the plant, participating in the process of wound healing and control of insect attacks; composing a reserve of water to be used in periods of drought; and providing the tissues with a continuous supply of substances derived from cyclopentose, due to the cyclical metabolism of phosphate-pentose, are essential to the development of the tree (Cavalcante, 2013).

Natural latex is a raw material of high quality and durability. It has biocompatible physical and chemical characteristics, antigenicity, hypoallergenicity, impermeability, elasticity, smoothness, flexibility, resistance and low cost, and is used for the production of membranes (Ribeiro et al., 2015). These characteristics are in accordance with the most upto-date scientific studies and provide more comfort for patients and a reduction in the risk of developing allergies (Pinho et al., 2004, Mrué et al. 2004, Pinho, 2011).

Essentially, the natural function of latex is to help the tree heal injured tissues. Immediately after bleeding, latex flows quickly, decreasing at a uniform and decelerating speed until it finally stops flowing. The impairment of flow is due to the obstruction of the latex vessels caused by the clot formed in the opening of the cuts (Alves, 2004).

After the latex is extracted from the tree by puncture, a preservative is added, usually ammonia (to avoid spontaneous coagulation) and the resulting mixture is centrifuged, thus producing a concentrated product, with $60 \%$ solids and $40 \%$ water. The latex concentrate is then treated by a process called vulcanization, in which the rubber molecules form cross links in the presence of accelerators containing sulfur and due to heating. This makes the product thermally stable, gives it a good physical resistance and makes it at the same time soft, flexible and elastic. Chemical compounds, accelerators, antioxidants, extensors and other ingredients are added to latex to obtain the final product, which contains $2 \%$ to $3 \%$ of leftover proteins from natural latex (Paula, 2010).

Therefore, its main characteristics are elasticity and flexibility, resistance to abrasion (wear), impermeability, hypoallergenicity, easy adhesion to tissues and steel and resistance to chemical products (Rodrigues, 2009). 


\subsection{2 - Clone}

A clone is a plant obtained by vegetative propagation from a mother plant. Thus, all the trees from a field cloned from the same mother plant have the same genetic composition, which gives the desired uniformity to the group.

The important factor in any application that uses natural raw material is the uniformity of its properties, because it is an essential characteristic for obtaining the reproducibility of results and products (Rodrigues, 2009). To obtain this characteristic, the latex source must be the same, i.e., the latex should be derived from trees of the same clone. All clone trees of the same matrix, under the same environmental conditions, have low variability in relation to different characteristics, such as strength, bark thickness, production, property of latex, annual leaf senescence, nutrition and tolerance to pests and diseases (ITeB, 2015, Marques et al., 2007).

Latex is considered to be an Eco-product, since it is produced without harming the environment and the health of living beings, from the use of renewable natural raw materials that have the smallest possible impact on the environment during its manufacturing process and post-use (Ribeiro et al., 2014).

\subsection{3 - Vulcanization}

Vulcanization is a thermo-chemical process applied to elastomeric polymers, also called rubber. Due to vulcanization, rubbers acquire the physical properties that make them suitable to several applications. This process consists on adding sulfur and heat. Consequently, rubber acquires mechanical resistance through the increase of its elasticity module, its hardness, and its resistance to strain and abrasion (Pinheiro, 2001).

Latex is a rubber dispersion in an aqueous serum; it thus contains other mineral and organic substances. It has a variable viscosity (depending on the rubber content), so that its density varies between 0.94 and 0.97 . Considering this, the main rubber production 
processes are coagulation and dehydration. In the latter, a mold is immersed in a concentrated latex compound, and slowly removed with circular movements in order to redistribute the excess emulsion. Afterwards, the device undergoes the drying process and the vulcanization process, when, considering the temperature-time binomial, the rubber in the mold hardens. In this step, the artifact is removed from the mold (Peres et al., 2006).

The vulcanization systems - used in latexes for them to have a technological application - are dispersions whose efficiency depends not only on its components, but, mainly, on the size of the particle and the solubility of the components in the latex composite. These systems typically consist of three components: sulfur, accelerator, and zinc oxide (Trombetta et al., 2007, Juve, 1998, Rodrigues, 2009).

Considering the sulfur and accelerator contents, vulcanization systems can be classified as: a) efficient (EV): sulfur content between 0.3 and $1.0 \mathrm{phr}$ (parts per dry weight) and accelerator between 2.0 and $6.0 \mathrm{phr}$; b) semi-efficient (Semi-EV): sulfur content between 1.0 and $2.5 \mathrm{phr}$ and accelerator between 1.0 and $2.5 \mathrm{phr}$; c) conventional: sulfur content between 2.0 and $3.5 \mathrm{phr}$ and accelerator between 0.5 and $1.0 \mathrm{phr}$ (Trombetta et al., 2007).

An important aspect of latex that must be considered is directly related to the fact that it has functions that meet a wide range of services, i.e. latex must present resistance to oils, resistance to aging, permanent deformation when compressed, elasticity, plasticity, resistance to wear, electrical insulation and impermeability for liquids and gases (Rodrigues, 2009, Ribeiro et al., 2015, Cólon et al., 2015).

\subsection{4 - Applicability of latex in medicine}

Latex, plus other substances, was initially used as material for inducing healing in injured esophageal walls. It consisted in the development of a biosynthetic esophageal prosthesis model and its use was successful in the reconstruction of the esophagus of dogs. The results revealed that the biomembrane made of natural latex or polylysine has biochemical characteristics that make it capable of interfering in the process of tissue 
repair by favoring the prompt and regular formation of a new tissue, in addition to being easy to handle, without the need of complex techniques for its manufacture and use (Mrué, 1996, Mrué, 2000).

From these data, other studies with the use of latex have been performed, such as for myringoplasty ${ }^{1}$ in humans (Oliveira et al., 2003) and the implementation of latex biomembranes for the treatment of ischemic ulcers in the leg, so that they act as an inducer agent for healing tissue (Frade et al., 2004).

Rabelo et al. (2005) employed this membrane in recurring umbilical hernioplasties ${ }^{2}$ and found that it was effective in twelve dairy cattle. In orthopaedic studies with the objective of achieving more effective bone regeneration, latex was efficient in repairing fractures in a rabbit tibia, demonstrating a great potential for this type of application. In cattle, it became evident that the composite formed by latex, polyamide and polylysine at $0.1 \%$ ensures a good level of security for use in hernioplastias and may be of aid in surgical corrections of a permanent nature.

Balabanian et al. (2006) investigated the biocompatibility of a biopolymer based on plant latex extracted from the Hevea brasiliensis rubber tree implanted in the alveolar bone cavity after dental extraction in rats. The results showed that the material tested is biologically compatible and progressively integrated to the alveolar bone, simultaneously speeding up bone formation and playing an important role in the healing process.

A new microperforated vascular prosthesis model was developed using fabric coated with a compound derived from natural latex of rubber trees. As control, they used an expanded polytetrafluoroethylene prosthesis in the contralateral pelvic limb in the same animal (Brandão et al., 2007). The study was performed by applying both prostheses to fifteen dogs. The microperforated tissue and latex prosthesis showed structural qualities (adaptability, elasticity, impermeability and possibility of suture) that are satisfactory as a vascular substitute. It stimulated endothelial growth ${ }^{3}$, beyond contact regions with the artery in anastomoses ${ }^{4}$ and was biocompatible with the dog's arterial system, presenting

\footnotetext{
Surgery to control the infection in the middle ear and to repair the eardrum.

Reappearance of a disease after a long cure period.

Regarding the layer that coats the blood vessels and lymphatic vessels internally.

Communication surgically created between two blood vessels.
} 
adequate tissue integration.

Other important contributions regarding the application of latex have been presented by the scientific community. Among them, Carvalho et al. (2008) evaluated the use of the natural latex mold in the postoperative period of the surgical confection of a neovagina ${ }^{5}$ with the objective of inducing healing and maintaining the functional cavity in nine patients with the Mayer-Rokitansky-Küster-Hauser syndrome (MRKH). The results confirmed the properties of refitting and tissue regeneration of natural latex derived from Hevea brasiliensis and acceleration of the healing process without rejection.

An important contribution regarding the application of latex in medicine was presented by Rodrigues (2009), who developed a device to aid in the treatment of obesity, based on the control of the flow of substances in the esophagus. In the proposed method, a device placed in the esophagus decreased its radius, reducing, as a consequence, the speed and the flow with which the food can be consumed. The basis of the method is a latex module with an approximately cylindrical format, which is placed in the esophagus. The results demonstrate that control of the ingestion of food occurred, which promoted weight loss. This method is a new possibility for the treatment of obesity in human and nonhuman animals. The animal tests were performed in dogs.

Herculano et al. (2010) developed a latex membrane of topical use for controlled release of a drug. In other areas of medicine, latex has been studied and used successfully in the process of ulcer healing, in burned surfaces of the body and in conjunctive reconstruction (Oliveira et al., 2003, Pinho et al., 2004). The latex biomembrane was studied as a possibility for ocular conjuctive repair in rabbits and humans. The results showed that the natural latex biomembrane also seems to favor conjunctival scarring and neoangiogenesis (Pinho et al, 2004, Pinho, 2011).

Fujimoto et al. (2007) evaluated the use of latex biomembrane (Biocure ${ }^{\circledR}$ Pele Nova $^{\circledR}$ ) in a post-orbitary exenteration wound by basal cell carcinoma in a 72 -year-old male patient from the state of Bahia, Brazil, with a lesion in the left eye that for two years had presented pruritus, bleeding, lacrimation, and pain.

\footnotetext{
5 It is the result of a surgical technique that consists in building a vagina in patients with vaginal agenesis or in transexuals.
} 
The behavior of a shred of latex biomembrane was evaluated in diaphragmatic lesions experimentally induced in rabbits. After fifteen days, there was tissue neoformation, and thirty days after surgery, there was adherence of the liver and the lung to the area of the implant. Clinical-surgical observations supplemented by the analysis of histological changes allowed the conclusion that it is indicated to employ latex membranes in repairing diaphragmatic lesions, due to ease of being obtained, low cost, easy applicability, resistance and satisfactory response in relation to healing time (Friolani, 2008).

Similar results were found in Andrade et al., 2008, where there was tissue neoformation in mice, induced by latex biomembrane. In this case, the biomembrane actively stimulated the phases of healing. Another application was a system that induces tissue neoformation for diabetic feet, with a Light Emitting Diode (LED) circuit and use of natural latex. This system is composed of a healing insole and an electronic tissue regeneration circuit (Reis, 2013).

Nunes et al. (2016) were to develop and test a system for inducing the regeneration of diabetic foot ulcers based on a natural latex insole and a device using light emitting diodes (LEDs) with test in humans, all selected patients had type 2 diabetes, and some had more than one ulcer.

In 2003, Pele Nova Biotecnologia S/A was created for producing and commercializing the first product with latex biomembrane, with patented technology in more than 60 countries. In 2004, the BIOCURE ${ }^{\circledR}$ product was launched, i.e. the first practical application of the latex biomembrane. It is available to health professionals under the registration number 80177640001 , and it is commercialized by the Brazilian National Agency for Sanitary Surveillance. It was originally intended for the treatment of chronic ulcers of the lower limbs (Pinho, 2011, Anvisa, 2015).

\subsection{5 - Allergy and toxicity}

In accordance with the ISO 10993 standard, the in vitro cytotoxicity test is the 
first test to evaluate the biocompatibility of any material for use in biomedical devices, and the study of the product biocompatibility may continue only after its non-toxicity is proven, performing necessary tests on laboratory animals (Rogero et al., 2003).

The centrifuged latex loses a large quantity of proteins, including those that cause allergic reactions and those that promote the proliferation of new vessels; therefore, it requires greater care in preparation, in addition to being more expensive than noncentrifuged latex (Paula, 2010).

Zimmermann (2007) conducted a study on biocompatibility and resistance of seven latex membranes in twelve rabbits of the New Zealand breed. Six types of latex membranes were implanted; they were prepared in the Chemical Technology Laboratory of the University of Brasília (LATEQ-UnB). The implants were removed after fifteen days and underwent histological examinations. According to the results, they concluded that the membranes offer adequate resistance for use in the repair of the muscle sheath in rabbits; however, immunologic reactions contraindicate its use in that species.

According to Paulo et al., (2005), there are probably differences between species, receiving tissues and manufacturing of latex membrane, which indicates the necessity of continuing research in this field. The performed a biocompatibility test with latex membrane in rats for a period of 21 days and confirmed the absence of rejection (Mente et al., 2001). In the study carried out by Oliveira et al., (2003), the natural latex membrane with $0.1 \%$ polylysine made from rubber trees (Hevea brasiliensis) showed an excellent interaction with the tissues of the human tympanic membrane, excellent biocompatibility, no toxicity and absence of allergic manifestations.

The natural latex membrane has been used successfully in the reconstruction of the esophagus (Mrué, 1996), of the abdominal wall (Mrué, 2000) and of the pericardium in dogs (Sader et al., 2000). This biocompatibility and favoring of tissue repair was observed in dogs, cattle, rats and humans (Zimmerman et al., 2007).

As described by Frade et al. (2004) and Oliveira et al. (2003), latex applied to humans has satisfactory results. The properties of latex were also studied (Pinho, 2011, Fujimoto et al. 2007), in which the regeneration of the ocular conjunctiva in humans was boosted in the group that used the latex membrane. In a study for choosing the material to 
be used in the production of the ocular membrane, latex was chosen because it has particular features that can be used in several different areas of medicine, and it is cheap and easy to handle. Its characteristics and contributions based on literature justify its use in this study. 


\section{4 - MATERIALS AND METHODS}

\section{1 - EXPERIMENTAL DESIGN OF THE LATEX MEMBRANE}

This is a new proposal for treating amblyopic patients using latex membranes. In this study, we developed an experimental model, called latex membrane, using natural latex as raw material. Based on already existing techniques and various models of objects used in the medical area, we proposed an unprecedented physical and material model for this use, which has the goal of enabling total and partial occlusion and still allow stimuli for the good eye in the treatment of this pathology.

In the development of the latex membrane, the support of the Engineering and Biomaterial Laboratory - BioEngLab ${ }^{\circledR}$ was essential. This laboratory is linked to the UnB Gama College, under the guidance of its coordinator and founder, Prof. Dr. Suélia Siqueira Rodrigues Fleury Rosa. In that lab, the proponent of this work has learned to deal with the techniques for the use of latex. The proponent also had the support of Leandro Luiz Fleury Rosa, owner of Ótica Cristal, and of the Electrical Engineering Department of the University of Brasília (ENE-UnB), where her doctorate studies took place. Most of the membrane development work was performed at the Engineering and Biomaterial Laboratory - BioEngLab ${ }^{\circledR}$ and the characterization was carried out in partnership with: Magnetic and Optical Analysis Laboratory (LAMOp), Catalysis, Environment and Materials Laboratory at the University of the State of Rio Grande do Norte, Vibrational and Molecular Spectroscopy Laboratory of the Federal University of Ceará - Pici Campus, and Instrumental Chemistry Laboratory and General Physics Laboratory of the Federal Institute of Goiano - Ceres Campus.

The production of the latex membrane was carried out in three main steps: preparation of raw material, confection of mold and production of the prototype.

The confection of the product was carried out with the preparation of latex membranes using the Van Gogh and deposition techniques at a temperature of $40{ }^{\circ} \mathrm{C}$ and $70{ }^{\circ} \mathrm{C}$. 
This methodology is illustrated in the flowchart in Figure 4.1, with all the stages of development of the latex membrane.

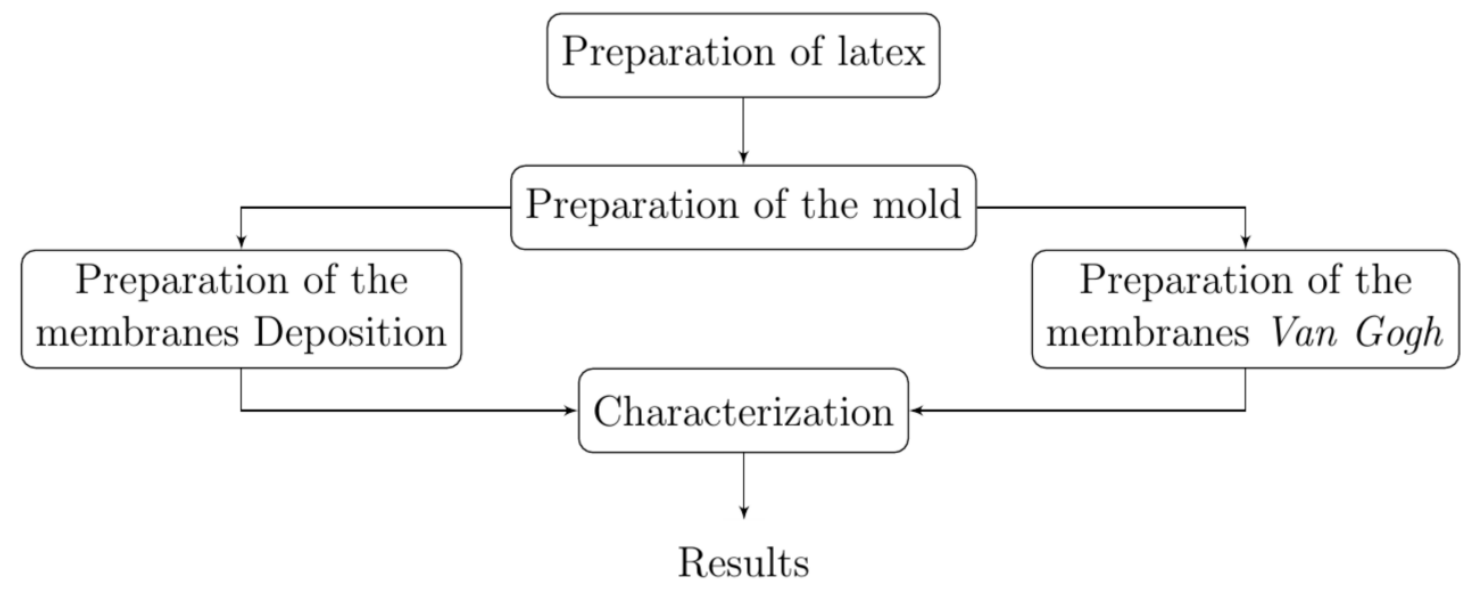

Figure 4.1 - Flowchart with steps to be performed.

The production of the latex membrane was carried out through these main steps, including different manufacturing techniques (deposition and Van Gogh). Then, the essays for the characterization of the prototype showed the results of its viability, after several tests.

For the confection of the occluder, it was necessary to evaluate its size, shape, and distribution, since a sudden change in the eye may cause discomfort. In direct contact with the eye, the latex membrane consequently makes a supporting structure that interacts physically-mechanically and physically-chemically with the organ, providing a response of a biomaterial-tissue interface. It is important, then, to study this behavior of eye reactivity with the occlusive membrane. 


\section{2 - MANUFACTURING PROCESS}

\subsection{1 - Preparation of latex}

Latex membrane an experimental model of the using the natural latex extracted from the Hevea brasiliensis rubber tree as raw material, which was purchased in the domestic market. We bought a few liters from separate vendors of the Southeast region of Brazil, based on some standard characteristics that were necessary, such as low sulfur content and high viscosity. A high concentration of sulfur would give the latex, after vulcanization, a sticky characteristic. Low viscosity would increase the duration of the manufacturing process.

An important factor in any application of the latex biomaterial is the uniformity of its properties, because it is an essential characteristic for obtaining reproducibility and reliability of the final products. To obtain this characteristic, the latex source must be the same, i.e. the latex should be derived from trees of the same clone, purchased in the national market, confirming the use of the same batch and a commercial origin from trustworthy manufacturer, such as "DU LATEX". The purchased latex is already centrifuged, with the suspensions of sulfur and resin, with the objective of giving the final compound the elasticity and resistance necessary and the same time decreasing the amount of protein naturally present in it, many of them responsible for allergic reactions. From this preparation process, latex becomes a compound that is vulcanized in contact with the skin, becoming adhesive. For its removal, however, only pure water is used.

From the natural latex, we have prepared a final compound with the addition of chemical substances following the protocol performed in (Mrué 1996), with the objective of giving the prototype the required characteristics for the membrane: elasticity, smoothness, resistance, impermeability and hipoalergenicity. After preparing the compound for use in the production of the membrane, the steps of filtering and dilution in bi-distilled water must be followed.

For this dilution, we have used $50 \%$ latex and $50 \%$ distilled water. The whole 
procedure must be performed at temperatures below $25^{\circ} \mathrm{C}$, to prevent a pre-vulcanization of the liquid due to heat. In the handling of latex, we have used glass sticks and a beater to stir it, glass container to store it, plastic wrap to protect it from contact with air, aluminum foil to protect it from light, and cotton flannel to clean it. For homogenization and storage, we used a baton and a glass container, sealed with plastic wrap to protect it from contact with air. Latex is a compound that, when in contact with the skin (due to body heat $\approx 36$ $\left.{ }^{\circ} \mathrm{C}\right)$, is vulcanized, becoming adhesive.

Several concentrations of latex were tested during the production of prototypes until we found a percentage that met the pre-established characteristics of softness, flexibility, transparency and resistance of the mixture.

The use of a mask is important for the inhalation of ammonia to be controlled, so as not to cause allergies, irritation and headaches, which were observed during the development of the study.

\subsection{2 - Preparation of the mold}

The first step was to know the eyeball and its particularities. To this end, we used a simplified human eye model.

During the development, firstly we produced the mold consisting of plastic material and coated with an acrylic layer of $3 \mathrm{~cm}$ width, $3 \mathrm{~cm}$ length and $1.5 \mathrm{~cm}$ of diameter the molds of the latex membrane with the Van Gogh technique. The mold was designed based on the anatomy and characteristics of the eye, taking as a model the spherical shape of a marble for prototype purposes, based on its size, shape and proportion. The confection of the membrane was completely individualized. Its shape and proportions closely follow the characteristics of the patient's eyes, providing greater comfort.

The membrane was made from the molds previously washed with soap and water, dried with hot air and sterilized in a stove at $70{ }^{\circ} \mathrm{C}$ for ten minutes. 


\subsection{3 - Preparation of the prototype}

The confection of the prototype began with the preparation of the environment, raw material and molds, and followed a series of steps, namely: applying the mold technique with latex in liquid form; drying the molds in the oven; removing the solidified latex from molds and final inspection.

In the process of manufacturing the membrane used firstly the techniques found in the literature (Mrué, 1996, Pinho et al., 2004, Herculano, 2009 and Rodrigues, 2009). Among them: successive baths of immersion, drip and deposition in order to prepare any occluding membrane.

In the Van Gogh technique, the membranes were prepared with thick brushstrokes using a flexible rod with tips covered by cotton $1 \mathrm{~cm}$ away from the mold with alternate movements until the mold was completely covered. This procedure was repeated for three or four times in succession, followed by drying in an oven at a temperature of $40{ }^{\circ} \mathrm{C}$, with time intervals of $2 \mathrm{~h}$, in order to obtain membranes with a thickness of approximate 0.2 $\mathrm{mm}$. After this drying period of $24 \mathrm{~h}$, the Van Gogh membranes rested for $24 \mathrm{~h}$ at room temperature to finish the vulcanization process. This membrane-obtaining process was named Van Gogh, a tribute to the Impressionist painter Van Gogh, who used a peculiar method of beating the canvas with brushes in his works. It was based on the immersion technique (Mrué, 1996), which consists in the introduction of the molds inside the final latex compound, perpendicularly to the plan, gradually and evenly, followed by heating in a stove with temperature control.

The materials used in the manufacture and packaging of the membrane were thoroughly cleaned with alcohol. The cooking process of the membranes was carried out in a series of steps summarized in the confection chart of the Van Gogh technique in Figure 4.2 . 


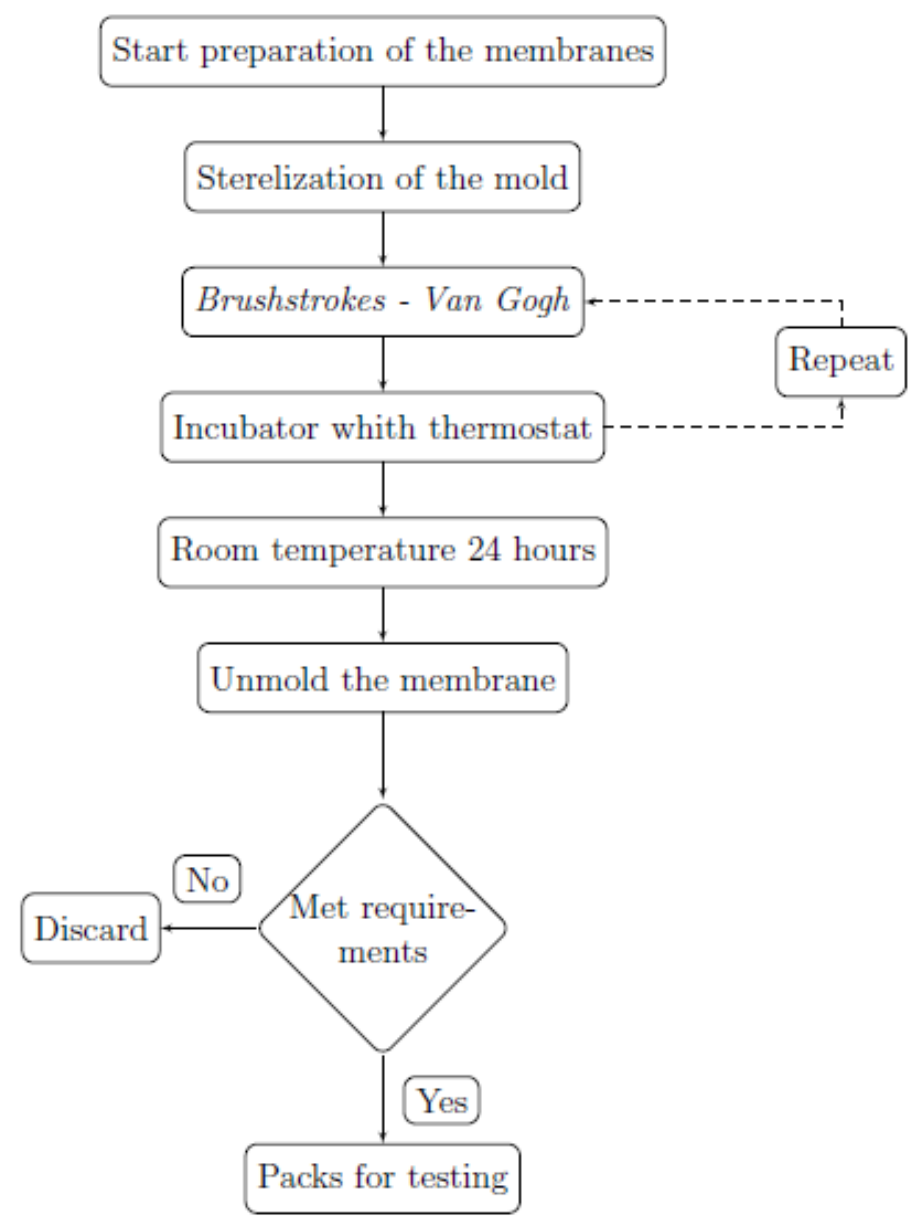

Figure 4.2 - Flowchart of membrane confection by the Van Gogh technique.

The Van Gogh membranes were registered under the brand LENCOC $^{\circledR 6}$.

To obtain the membranes with the technique of deposition on a Petri dish, everything was performed as described in the literature (Herculano, 2009, Mrué, 2000 e Pinho et al., 2004). The transparency of the membrane was favored by the room temperature. The vulcanization procedure at $70{ }^{\circ} \mathrm{C}$ can give the membrane have a yellower aspect. However, for the preparation of these membranes, three to four days were necessary on average for its total drying and polymerization, since the structure and format of the membrane must be evenly preserved, which requires a more thorough cooking

\footnotetext{
${ }^{6}$ Brand was registered under the number 906573572.
} 
process. The membranes obtained by deposition were produced by placing $5 \mathrm{ml}$ of latex in glass Petri dishes with $8 \mathrm{~cm}$ diameter and followed by drying in an oven at a temperature of $40{ }^{\circ} \mathrm{C}$ or $70{ }^{\circ} \mathrm{C}$ for $24 \mathrm{~h}$. After this drying period, the deposition membranes rested for $72 \mathrm{~h}$ at room temperature to finish the vulcanization process.

In the deposition technique, we performed the following steps according to the confection chart of that technique in Figure 4.3.

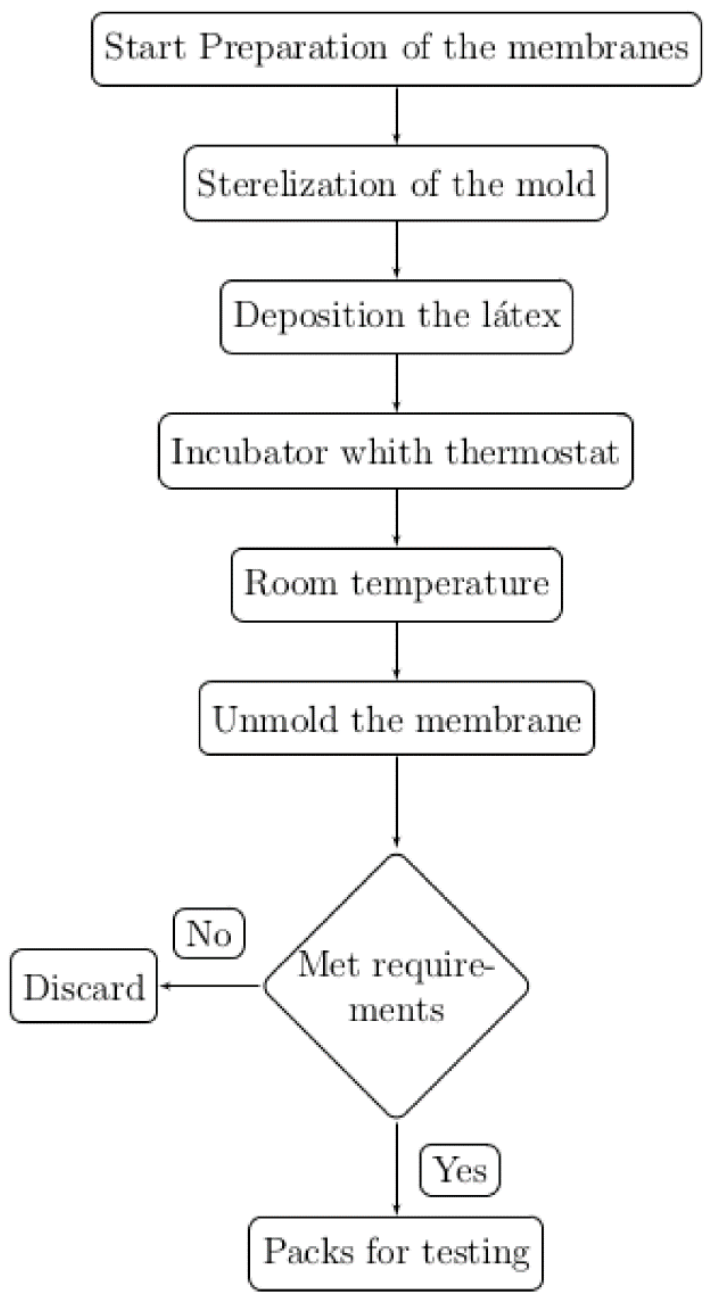

Figure 4.3 - Flowchart of membrane confection by the deposition technique.

There a method was based on the steps mentioned above, from preparation of latex to packaging for testing. It may undergo changes depending on the person and can be easily tested whenever necessary. 
The latex membranes obtained with both techniques were developed based on their history of evolution, with several different protocols until we obtained a model that met the main characteristics: light occlusion (partial or total), thickness and applicability.

Regarding the allergenicity and toxicity of latex products, it must be emphasized that the occlusive Van Gogh membrane presented is a membrane produced with a new technique that differs from the literature. This membrane has no toxic products, such as carbamates, or other additives and preservatives, which are conventionally used in the rubber industry (Mrué et al, 2004).

\section{3 - Characterization of the product}

The membranes developed were characterized according to the methods used to analyze the characteristics of latex in natura and of the natural rubber membranes, thermally treated at $40{ }^{\circ} \mathrm{C}$ and $70{ }^{\circ} \mathrm{C}$. The methods used to characterize the materials were: scanning electron microscopy (SEM), fluorescence measurements, X-ray diffraction (XRD), thermogravimetry (TG), differential scanning calorimetry (DSC), saline absorption analysis, Infrared spectroscopy (FT-IR) attenuated total reflection (ATR) mode, principal component analyses (PCA) and light crossing analysis.

\subsection{1 - Scanning Electron Microscopy}

The scanning electron microscope (SEM) is usually used for the study of surface structures or subsurface structures the membranes of relatively large samples; it has a large depth of focus, and is able to obtain different reliefs of the sample surface simultaneously and in focus. The SEM also produces high-resolution images, which guarantees close zooming without loss of sharpness (Agostini, 2009).

Sample preparation is performed on metallic surfaces, using conductive adhesives, such as carbon tapes or carbon colloidal suspensions. The coating of the sample 
with a conducting film has the objective of avoiding the accumulation of negative charge, if the sample is formed by a non-conducting film, as is the case of polymers.

SEM measurements were performed at the Magnetic and Optical Analysis Laboratory (LAMOp) at the University of the State of Rio Grande do Norte, Brazil. We used a TESCAN scanning electron microscope, model MIRA 3 FFG-SEM High Resolution Scanning Electron Microscope (filament, tungsten; voltage, $25.0 \mathrm{kV}$ ), with the MiraTC software, from the Electron Microscopy Laboratory. The samples were placed over an aluminum surface and fixed with a conducting carbon tape. A thin layer of carbon was sprayed over these films and the samples were metalized with gold in a QUARUM device, model Q150A ES.

\subsection{2 - Fluorescence Measurements}

This technique was used to quantify the components of the membranes and to check the variation of the components vulcanized at $40{ }^{\circ} \mathrm{C}$ and $70{ }^{\circ} \mathrm{C}$.

The fluorescence measurement was used to identify the chemical components in the membrane after every process. As the amount of energy released is specific to each element, it is possible to identify the chemical elements that are present at the point of incidence of the beam.

The most commonly elements found in natural rubber, besides carbon and hydrogen, are Phosphorus (P), Sulfur (S) and Potassium (K), since S and P are constituent elements of proteins and phospholipids that are present in latex, and $\mathrm{K}$ is a constituent element of plants. Other elements such as Zinc ( $\mathrm{Zn})$ and Rubidium (Rb) are the second most abundant group, and Copper $(\mathrm{Cu})$, Iron $(\mathrm{Fe})$, Manganese $(\mathrm{Mn})$ and Nickel $(\mathrm{Ni})$ are present in very low quantities (Rippel, 2005).

The fluorescence measurements were carried out at the Magnetic and Optical Analysis Laboratory (LAMOp) of the University of the State of Rio Grande do Norte, in a SHIMADZU EDX-7000 Energy Dispersive X-Ray Fluorescence Spectrometer equipment. 


\subsection{3 - X-ray Diffraction (XRD)}

The interaction between matter and X-rays is based on processes of emission, absorption, scattering, fluorescence and diffraction. The scattering of the X-rays in the ordered medium of a crystal results in the constructive or destructive interference between the scattered rays, because the distances between the scattering centers are of the same order of magnitude as the wavelength of radiation.

The X-ray diffraction measurements were performed at the Magnetic and Optical Analysis Laboratory (LAMOp) of the University of the State of Rio Grande do Norte, in RIGAKU - MiniFlex II diffractometer model RV-200B with a wavelength characteristic of $\mathrm{Cu}-\mathrm{K} \alpha(1,5405 \AA)$, target at $30 \mathrm{kV}$ and $30 \mathrm{~mA}$. The diffraction angle varied within the range of $5^{\circ}<2 \theta<50^{\circ}$ at a scan rate of $2^{\circ} \mathrm{min}^{-1}$.

\subsection{4 - Thermogravimetry (TG) / Differential Scanning Calorimetry (DSC)}

This is a dynamic technique in which the loss of mass of a sample is measured continuously while the temperature is increased at a constant rate. These analyses were performed at the Catalysis, Environment and Materials Laboratory at the University of the State of Rio Grande do Norte. We used a NETZSCH Leading Thermal Analysis equipment, model STA 449 F3 Jupiter, in room temperature $\left(\sim 25^{\circ} \mathrm{C}\right)$ and up to $800{ }^{\circ} \mathrm{C}$, using a mass of approximately $5 \mathrm{mg}$ for samples, with a heating ratio of $10^{\circ} \mathrm{C} /$ minute in an alumina crucible in an inert nitrogen atmosphere, with a flow of $25 \mathrm{~mL} / \mathrm{min}$.

Differential Scanning Calorimetry (DSC) is a thermal analysis technique used to detect physical or chemical changes that are accompanied by gain or loss of heat. When the substances are heated, several physical or chemical transformations involving heat absorption (endothermic process) or heat release (exothermic process) may occur. The DSC technique may be used to investigate the thermal properties of several materials, and is employed to characterize organic, inorganic, biologic and polymeric materials. Among its applications, we may highlight: qualitative and quantitative determination of phase 
transition, such as vitreous transition, fusion, crystallization, study of polymerization kinetics, decomposition kinetics and cure kinetics.

\subsection{5 - Saline absorption measurements}

Saline absorption was measured by immersing latex membranes in saline solution. The membranes capacity of absorbing water and saline solutions (aqueous solution of 0.9 $\% \mathrm{NaCl}$ and $0.1 \%$ purified water, physiological solution, Arboreto brand) was determined by using the starting dry mass, measured with an analytical SHIMADZU balance model AX200 Max 200g d=0.1 mg. These analyses were performed at the Catalysis, Environment and Materials Laboratory at the University of the State of Rio Grande do Norte, Brazil.

To this end, the membranes were prepared as described above and cut into $1 \mathrm{~cm}$ pieces, which were weighted and then immersed in saline serum. Samples were hydrated in $25 \mathrm{~mL}$ of the solutions previously mentioned, and were kept in them for a period of 24 hours in room temperature. The sample immersion was performed in a Becker glass with the aqueous solution in room temperature, with the samples at a horizontal position at the bottom of the Becker glass with the use of a metal ring, in order to avoid suspension due to the low mass of the membrane approximately $(\sim 0.2 \mathrm{~g})$. Afterwards, the membranes were taken out of the solution with a tweezer, dried in a sheet of absorbent paper, and quickly weighted. This operation was carried out as quickly as possible, and, after weighing, the membranes were again placed into the bath. During this period, the samples were weighted again to determine the final wet masses in time intervals of 15 minutes to 12 hours, in order to verify the absorption capacity of each sample.

The variation of mass gain was calculated according to equation (4.1):

$$
\frac{\mathrm{m}_{\mathrm{i}}-\mathrm{m}_{\mathrm{f}}}{\mathrm{m}_{i}} \times 100, \quad \text { equation }(4.1)
$$

Where:

$\mathrm{m}_{\mathrm{i}}$ is the starting mass and

$\mathrm{m}_{\mathrm{f}}$ is the final mass of the wet membrane. 
The handling of the membranes during the experiment must be very careful, because it may cause the samples to break or be damaged, especially the thinner samples; in this case, small pieces may get lost and alter the result of the weighing.

\subsection{6 - Infrared spectroscopy (FT-IR) ATR mode}

In a Fourier transformed infrared spectroscopy, the sample is placed between the output of the interferometer and the detector. As the sample absorbs certain wavelengths of light, the interferogram displays the difference source spectrum and the sample spectrum, or the source spectrum with reduced intensity at the wavelengths absorbed by the sample (Harris, 1999).

The technique known as attenuated total reflection (ATR), or internal reflection spectroscopy, allows the acquisition of qualitative spectra of solids, as is the case of natural rubber. This technique is based on the fact that a beam of light internally reflected by the surface of a transmitter medium penetrates a small distance beyond the reflecting surface and returns to the transmitter medium during the reflection process (Canevarolo, 2003). The natural latex membrane is put in contact with the reflective surface. The light passes through some micrometers and thus produces an absorption spectrum.

The spectroscopy measurements of latex membranes with infrared light in ATR mode were obtained at the Vibrational and Molecular Spectroscopy Laboratory (LEVM) from the Federal University of Ceará, Brazil (UFC - Pici Campus). The spectra were obtained within the spectral range of $4000-400 \mathrm{~cm}^{-1}$. Measurements were made in the transmittance mode with resolution of $2 \mathrm{~cm}^{-1}$ and 128 scans. We used a Bruker equipment model Vertex 70. For data analysis, we used the Qtiplot ${ }^{\circledR}$ software.

\subsection{7 - Principal component analyses of latex membrane (PCA)}

The principal component analysis (PCA) is a multivariate statistical technique that transforms a set of original variables into another set of the same size called principal 
component variables. The principal components have important properties: each principal component is a linear combination of all the original variables, they are mutually independent and estimated in order to retain, in an estimated order, the maximum amount of information in terms of total variation contained in the data.

The principal component analysis is associated with the idea of mass data reduction, with the least possible loss of information. The intention is to redistribute the variation observed in the original axis so as to obtain a set of uncorrelated orthogonal axes. This technique can be used for generating indices and grouping individuals. The analysis groups the individuals according to their variation, that is, individuals are grouped according to their variances, i.e., according to their behavior within the population, and is represented by the variation of the set of characteristics that define the individual, that is, the technique groups individuals of a population according to the variation of their characteristics (Regazzi, 2000).

The PCA analysis was performed using the Statistica 7 software in the Instrumental Chemistry Laboratory of the Federal Institute of Goiano - Ceres Campus.

\subsection{8 - Light crossing analysis}

The optical device called focimeter focuses the optical system to which light is sent to evaluate the degree of the lens; the scale interval that appears on the display is a dioptric numerical value. For this characterization we used a Nidek CLE-60 digital focimeter an optometry clinic in Goiânia, GO, Brazil.

To read the dioptric numbers, the sharpness of the reticles in the focimeter needs to be adjusted. The reticles are images overlapping the display that represent the light refracted in a lens of a certain diopter. When we make this reticle clear, it means diopter X of the lens being read is ideal for the formation of that particular image, and the dioptric readings are performed (Rosa \& Alves, 2012).

The light crossing analysis was performed with the objective of evaluating the passage of light trough the membranes and verifying the behavior of the surface light on the rugosity of the membranes produced using the Van Gogh technique. 


\section{5 - RESULTS AND DISCUSSION}

There are several approaches for characterizing the samples. In this study, we used optical engineering, using its principles in the treatment of amblyopia. The latex membrane was tested with several methodologies that will be cited below, and that were defined by comparing the anatomy of the normal eye with the properties of the biomaterial according to literature reports (Pinho et al., 2004, Pinho, 2011).

This membrane demonstrated to be compatible with the organ, and there was affinity of composition of the materials used. The technique in question was a complex system that included temperature and thickness techniques (Van Gogh), to obtain an occlusive membrane to cause occlusion (partial or total) of light.

\section{1 - LATEX MEMBRANE}

The membranes were developed based on their history of evolution, with several different protocols until we obtained a model that met the main characteristics: occlusion of light (partial or total), minimum thickness and applicability.

In the technical test, we used natural latex as a biomaterial for its qualitative properties, such as: impermeability, elasticity, smoothness, flexibility, and mechanical resistance.

To get to the final product, several vulcanization techniques were tested aiming a transparent membrane, with low thickness, low roughness and minimal water absorption. This process allowed an occlusion more biologically compatible with the eye. These results were significant, since the characteristics of the latex membrane enable an interaction with the eye without changing its properties.

In Figure 5.1, we can observe the membranes developed with their morphological aspect using the Van Gogh and deposition techniques. 

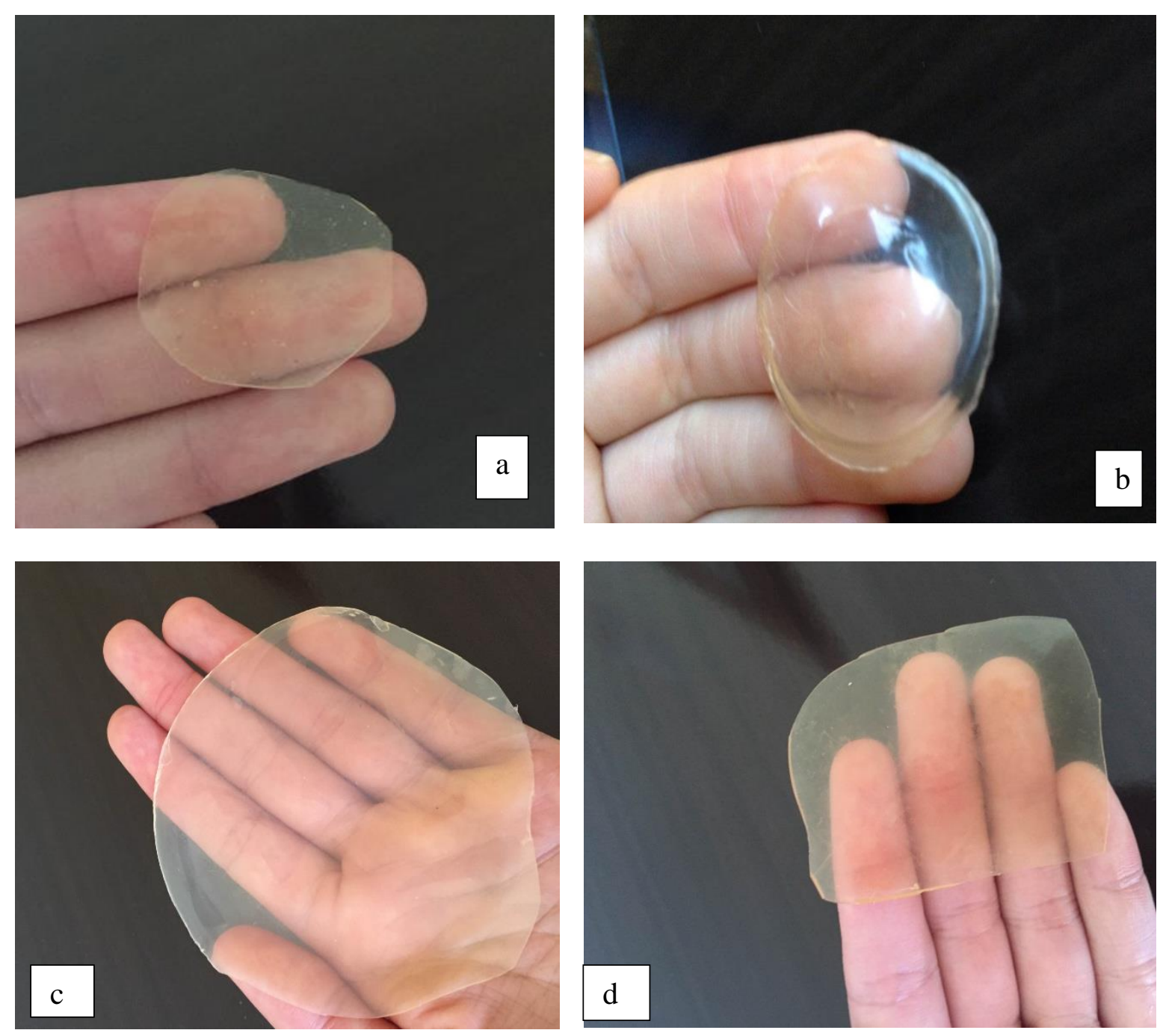

Figure 5.1 - Membranes prepared using the Van Gogh and deposition techniques, in (a) Van Gogh (three baths), (b) Van Gogh (four baths), (c) deposition (40 $\left.{ }^{\circ} \mathrm{C}\right)$, (d) deposition $\left(70{ }^{\circ} \mathrm{C}\right)$.

The Van Gogh latex membrane (M1 and M2) presented irregularities on the surface, lower thickness and transparency, which are desirable characteristics to obtain occlusion of light. M1 showed three layers of latex during confection, and M2 with four layers of latex. The latex membrane produced by deposition (M3 and M4) showed no irregularities on the surface. As they were vulcanized in different temperatures, they showed different coloration and large thickness than M1 and M2. 
The latex membranes will, from now on, be identified as Van Gogh membranes, obtained from three baths (M1) and four baths (M2), both vulcanized at $40{ }^{\circ} \mathrm{C}$, and membranes obtained with the deposition technique, vulcanized at $40{ }^{\circ} \mathrm{C}(\mathrm{M} 3)$ and $70{ }^{\circ} \mathrm{C}$ (M4) according to Table 5.1.

Table 5.1 - Identification of membranes

\begin{tabular}{lllll} 
Name & Technique & $\mathrm{N}^{\circ}$. of baths & $\begin{array}{c}\text { Temperature } \\
\left({ }^{\circ} \mathrm{C}\right)\end{array}$ & $\begin{array}{c}\text { Thickness } \\
(\mathrm{mm})\end{array}$ \\
\hline M1 Membrane & Van Gogh & 3 & 40 & 0.23 \\
M2 Membrane & Van Gogh & 4 & 40 & 0.27 \\
M3 Membrane & Deposition & - & 40 & 0.38 \\
M4 Membrane & Deposition & - & 70 & 0.38 \\
\hline
\end{tabular}

\section{2 - THICKNESS OF THE MEMBRANES}

The thickness of the membranes was measured using a King Tools digital that measures 0-150 $\mathrm{mm}$ in the Laboratory of General Physics of the Goiano - Ceres Campus IF (Federal Institute). For assessing the thickness of the membranes, 10 samples of each deposition method were selected and five measurements of the center of the film in different positions were performed, totaling 50 measurements for each membrane. After the measurements, the average for each sample was calculated and the standard deviation was $0.01 \mathrm{~mm}$. It is important to remember that the membrane is flexible and elastic; these variations occur because they are not rigid.

The membranes produced using the Van Gogh technique showed thickness of $0.23 \mathrm{~mm}$ after three baths and $0.27 \mathrm{~mm}$ after four baths. For the membranes obtained by the deposition technique, thickness was $0.38 \mathrm{~mm}$. In the literature, the thicknesses vary according to their application $0.5 \mathrm{~mm}$ (Pinho, 2011) to $1.5 \mathrm{~mm}$ (Herculano, 2009). 


\section{3 - CHARACTERIZATION OF THE LATEX MEMBRANE}

This section will present the results of characterization of latex using the techniques of scanning electron microscopy (SEM), fluorescence measurements, X-ray diffraction (XRD), thermogravimetry (TG), differential scanning calorimetry (DSC), saline absorption analysis, Infrared spectroscopy (FT-IR) attenuated total reflection (ATR) mode, principal component analyses (PCA) and light crossing analysis.

It is worth mentioning that the all equipment that was used for analysis was perfectly calibrated so the measurements present a high degree of reliability.

\subsection{1 - Scanning Electron Microscopy (SEM)}

Figure 5.2 shows the micrograph of the M1 and M2 membranes produced with the Van Gogh technique, thermally treated at $40{ }^{\circ} \mathrm{C}$ and M3, M4 membranes produced with the deposition technique. The M1 membrane that was prepared using 3 baths was rough and porous throughout the area of the micrograph, with the pores distributed throughout the membrane, allowing water absorption. The M2 membrane, which was prepared using 4 baths, was denser, as evidenced by the presence of rubber particles. This increased density decreased the size (less than $1 \mu \mathrm{m}$ ) and distribution of the pores throughout the membrane. The M3, which was thermally treated at $40{ }^{\circ} \mathrm{C}$, showed the presence of rubber particles more organized distribution and pores because used the technique of deposition on a Petri dish, allowing water absorption. In M4, which was thermally treated at $70{ }^{\circ} \mathrm{C}$, larger pores were observed because of the fast vulcanization process, allowing lower water absorption. 


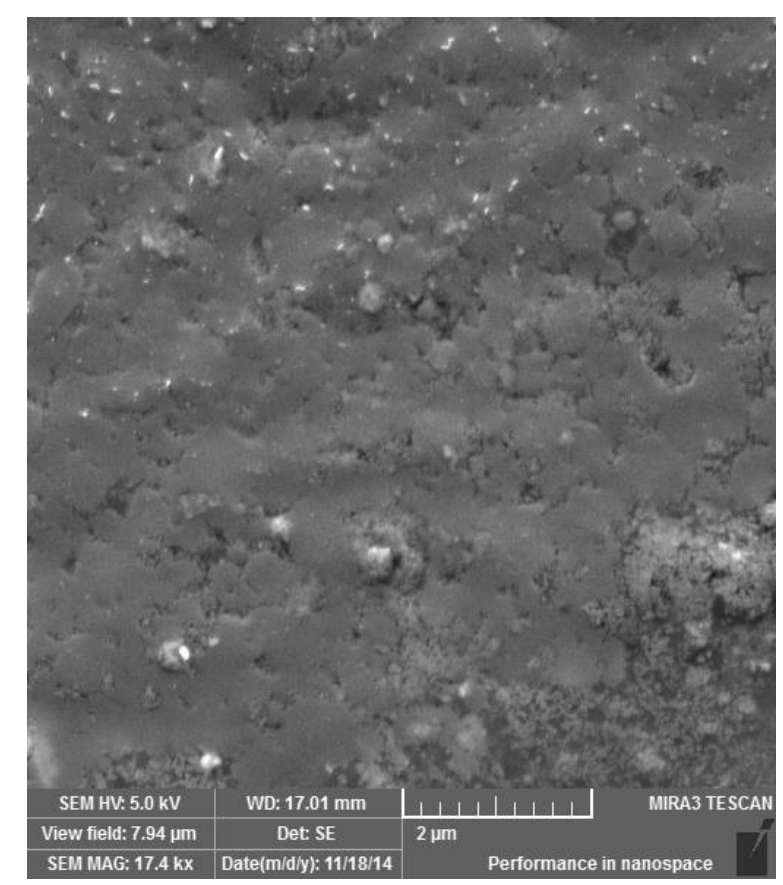

(a)

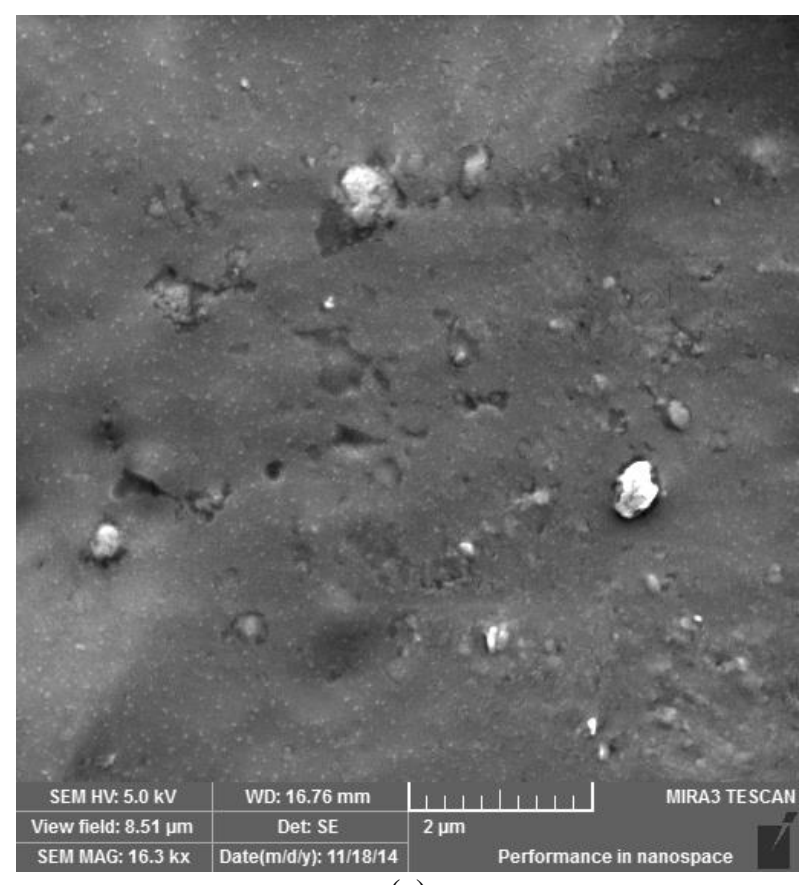

(c)

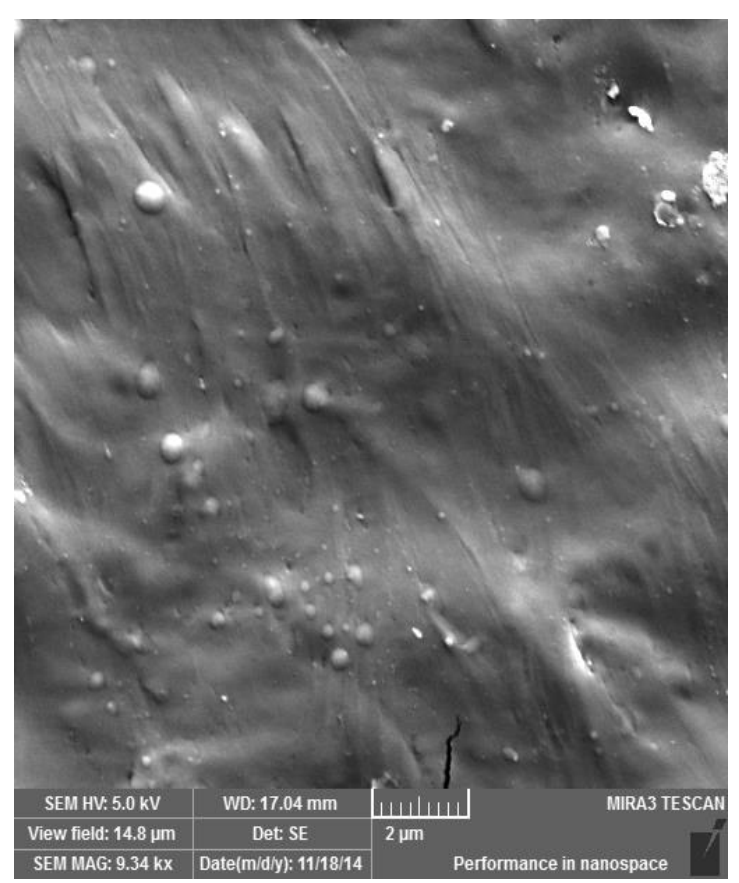

(b)

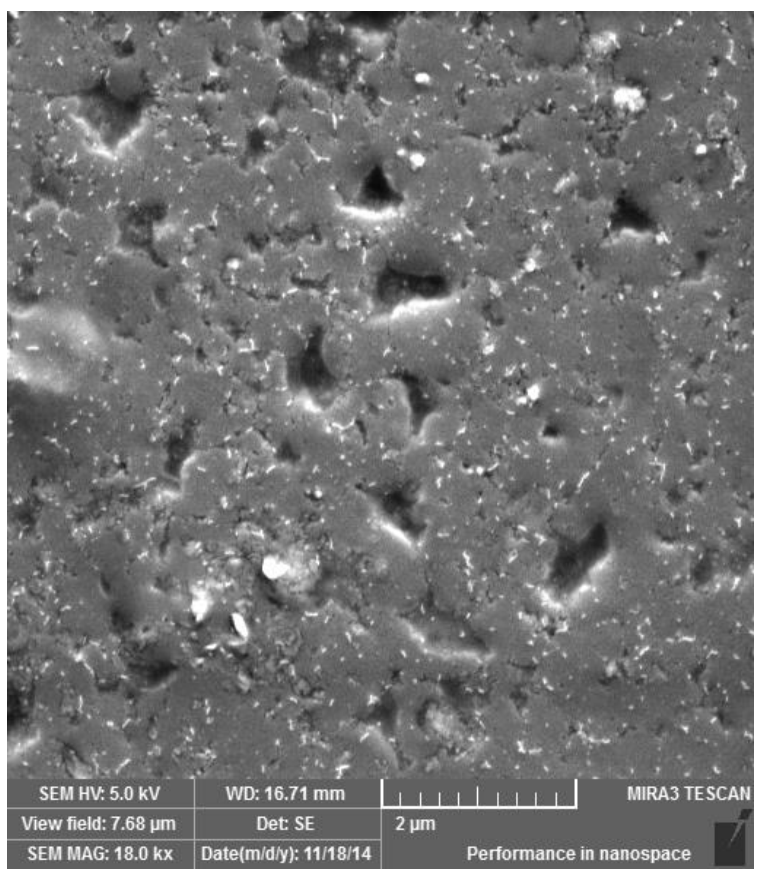

(d)

Figure 5.2 - Micrograph of the Van Gogh membrane M1 (a) and M2 (b), membranes produced with the deposition technique M3 (c) and M4 (d).

The SEM analysis visualized differences surface of the latex membrane, since 
each had a cooking process. Van Gogh's technique showed a shift in their roughness, the scratches generated no change in the surface.

\subsection{2 - Fluorescence measurements}

Table 5.2 presents the chemical composition obtained from Energy Dispersive XRay Fluorescence (EDX) data of the membranes. Using EDX, we identified the components in the latex, in the preparation and centrifugation techniques according to the samples of natural rubber membranes, both belonging to isoprene, the main constituent of latex, as well as to the functional groups.

High amounts of sulfur (S) and Potassium (K) were detected in all membranes, and the lower quantities of phosphorus $(\mathrm{P})$, zinc $(\mathrm{Zi})$, copper $(\mathrm{Cu})$ and iron $(\mathrm{Fe})$. Other elements with values insignificant were cobalt (Co) and gadolinium (Gd) and manganese (Mn). The membranes M1, M2 e M3 had slightly higher quantities of sulfur than the membrane M4, because the cooking preparation M4 of vulcanization at $70{ }^{\circ} \mathrm{C}$, which increased the amount of potassium in relation to that in other membranes.

Table 5.2 - Chemical composition of the M1, M2, M3, and M4 membranes $(\%)$

\begin{tabular}{llllllll}
\hline & S & K & P & Zn & Cu & Fe & Others \\
M1 & 79.70 & 16.80 & 2.20 & 1.00 & 0.17 & 0.08 & 0.05 \\
M2 & 70.50 & 25.60 & 2.40 & 1.12 & 0.15 & 0.10 & 0.13 \\
M3 & 69.70 & 21.18 & 1.45 & 6.36 & 0.49 & 0.22 & 0.60 \\
M4 & 57.77 & 32.86 & 3.78 & 3.82 & 0.76 & 0.23 & 0.78 \\
\hline
\end{tabular}

We can see a better solubility of sulfur than potassium. Therefore, when the membrane is vulcanized at high temperatures, there is higher molecular mobility; therefore, the amount of sulfur decreases and the amount of potassium increases for the M4 
membrane. The sum of $\mathrm{S}$ and $\mathrm{K}$ remains roughly the same at all samples, accounting for more than $90 \%$ the total constituent content, aside from carbon. Zinc had an increase in M3 due to the slow vulcanization of the latex compound in the Petri dish.

Other metals, such as copper and iron, did not have significant representation. These minerals will not cause allergy in contact with the eye, since they are already part of the human body and can also be found in food which are mandatory for the function of biological systems (Gondim et al., 2005, Nascimento et al., 2012).

In this technique it was observed that its main components were preserved without altering the chemical composition of natural rubber latex during the preparation of the latex membrane, maintaining its properties so it can be classified as a biomaterial.

\subsection{3 - X-ray Diffraction (XRD)}

Figure 5.3 shows the X-ray diffraction profiles of all samples. The X-ray diffraction profile of the membranes is predominantly amorphous, as expected with a broad peak, at $2 \theta=19^{\circ}$, which is in agreement with data previously reported in the literature (Agostini, 2009, Barros et al, 2015, Aielo et al., 2014).

Although the membranes present an amorphous character, a notable difference between the diffractograms of the membranes can be observed depending on the preparation technique. The X-ray diffraction profiles of membranes M3 and M4, developed at different vulcanization temperatures, showed some crystallinity, which was different from that of the membranes M1 and M2. Notably, increase in the time involved in preparing the membranes increased the chemical crosslinking between isoprene segments, which explains the higher crystallinity shown by the latex membrane prepared using the deposition technique.

The peaks membranes were more intense in membranes prepared by the deposition technique, membranes M4 e M3. 


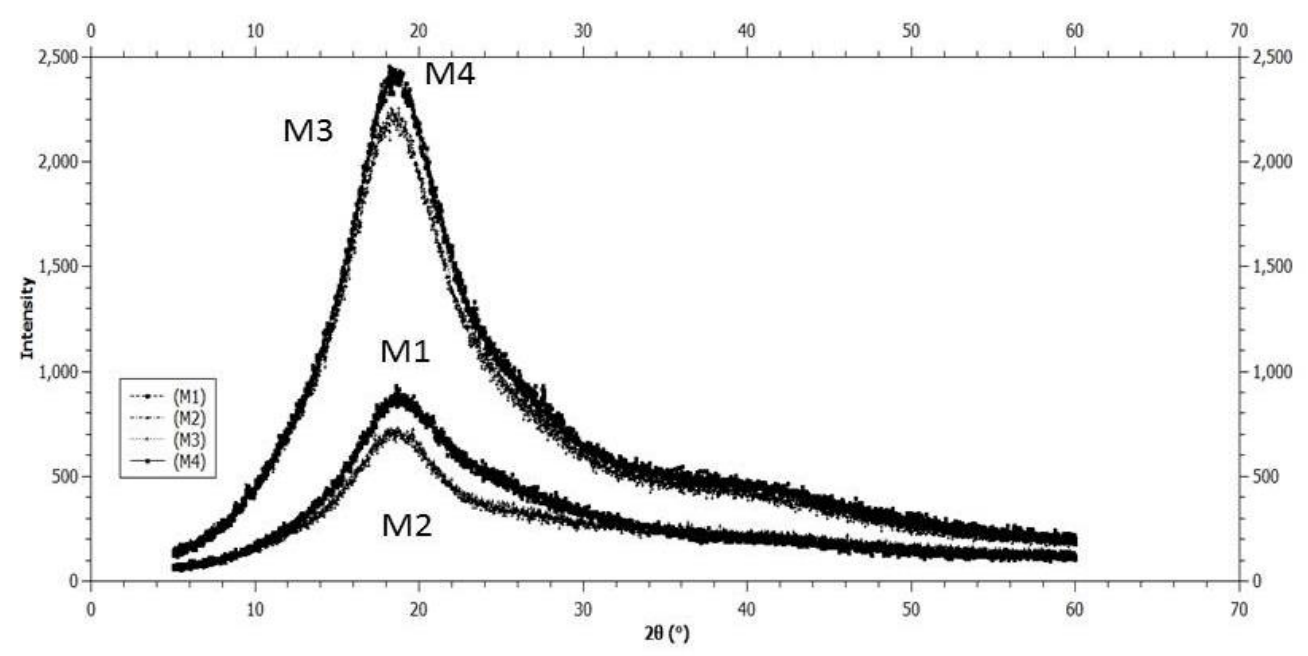

Figure 5.3 - X-ray diffractograms of latex membranes Van Gogh membrane M1 and M2 and membranes produced with the deposition technique M3 and M4.

Even when referring to amorphous materials one can obtain relevant information from X-ray diffraction measurements, regarding the distance between neighboring atoms when there is periodicity in the distribution of scattering centers. The scattering vector $q$ can be described as:

$$
q=\frac{4 \pi}{\lambda} \sin \left(\frac{2 \theta}{2}\right), \quad \text { equation }(5.1)
$$

Where $\lambda$ is the $\mathrm{X}$-ray wavelength and $2 \theta$ is the diffracted beam direction. The distance of the item that repeats in periodicity will be proportional to the inverse of $\mathrm{q}$, particularly $d=2 \pi / q$.

The scattering patterns in Figure 5.3 show a peak at $2 \theta=18.9^{\circ}$, which corresponds to $q=1,34 \AA^{-1}$. This value is equal to a repetition distance of approximately 4.69 $\AA$, which is compatible with the size of the isoprene monomer (Malachias et al., 2004, Schmacke, 2010).

The larger intensity of different samples indicates larger chains at the membranes. Possibly, the higher the temperature and the drier the membrane, the larger the intensity of the peak and, therefore, the larger the uniformity of the scattering agent. 


\subsection{4 - Thermogravimetric (TG) and differential scanning calorimetry (DSC)}

Figure 5.4 shows the TG curves for the M1 and M2 Van Gogh membranes and for the M3 and M4 membranes developed using the deposition method, and for the natural rubber latex (NRL). The complete degradation of NRL and the membranes occurs at a temperature of approximately $300{ }^{\circ} \mathrm{C}$. For all samples, no significant degradation was observed before $320{ }^{\circ} \mathrm{C}$. For all membranes, the maximum degradation temperature of the polymer was at approximately $375-377{ }^{\circ} \mathrm{C}$, which demonstrates that the preparation techniques did not significantly affect the thermal behavior of the membranes.

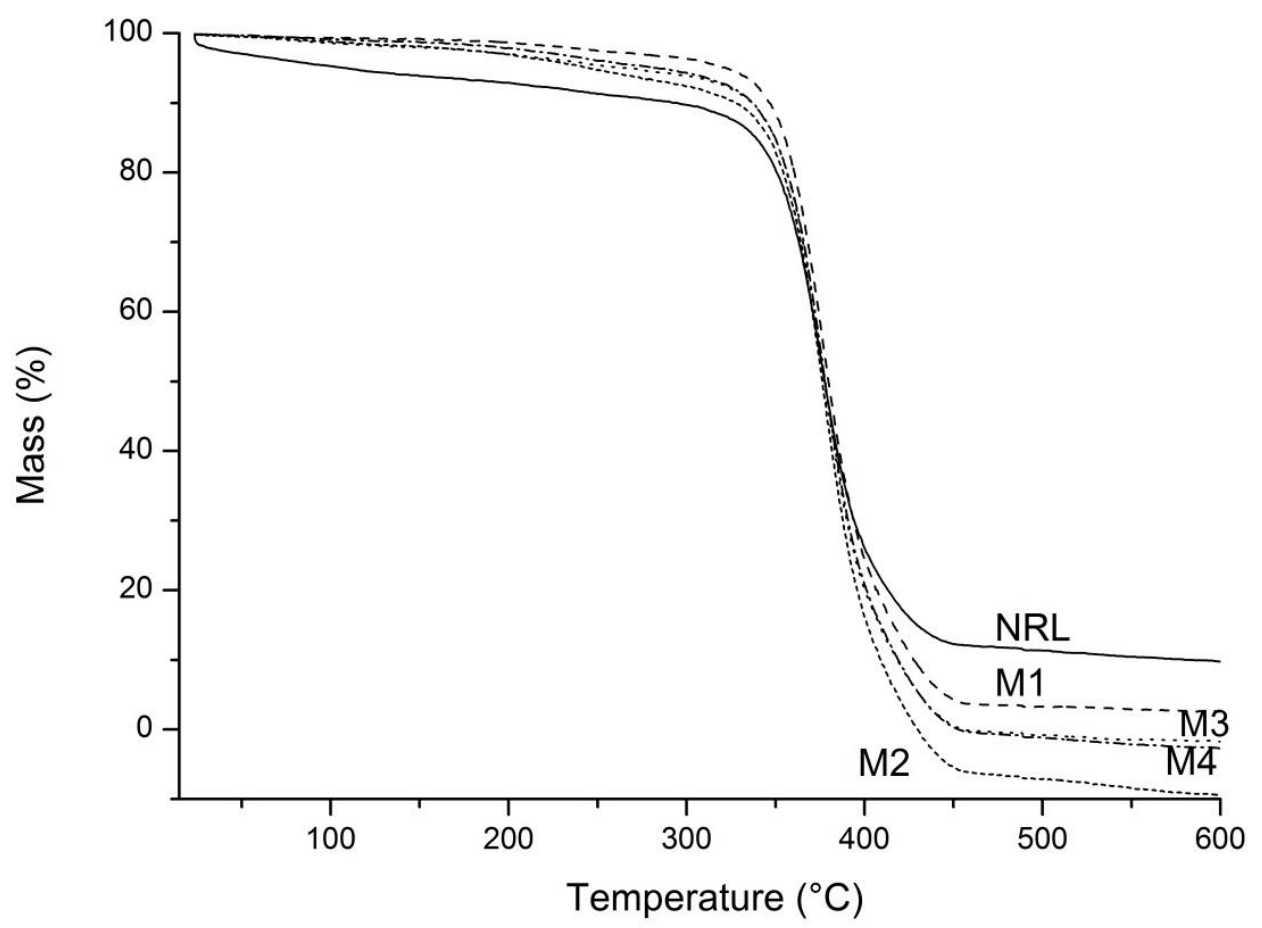

Figure 5.4 - TG curves for natural rubber latex (NRL) and membranes M1, M2, M3, and M4.

Thermogravimetric data obtained from TG and DTG curves are shown in Table 5.3, where we can observe the temperature ranges and the stages of degradation, mass losses established for each event, and final residue, where $\mathrm{T}_{0}$ is the initial temperature of 
thermal degradation, $T_{p}$ is the maximum temperature degradation, $T_{f}$ is the final temperature of that degradation stage, and $\mathrm{C}_{0}, \mathrm{C}_{\mathrm{p}}$, and $\mathrm{C}_{\mathrm{f}}$ are the mass percentage in $\mathrm{T}_{0}, \mathrm{~T}_{\mathrm{p}}$, and $\mathrm{T}_{\mathrm{f}}$, respectively.

Table 5.3 Thermogravimetric data obtained from the treated membranes

\begin{tabular}{lllllll}
\hline & $\mathbf{T}_{\mathbf{0}}\left({ }^{\circ} \mathbf{C}\right)$ & $\mathbf{T}_{\mathbf{p}}\left({ }^{\circ} \mathbf{C}\right)$ & $\mathbf{T}_{\mathbf{f}}\left({ }^{\circ} \mathbf{C}\right)$ & $\mathbf{C}_{\mathbf{0}}(\boldsymbol{\%})$ & $\mathbf{C}_{\mathbf{p}}(\%)$ & $\mathbf{C}_{\mathbf{f}}(\%)$ \\
\hline NRL & 296.7 & 375.1 & 460.9 & 89.9 & 53.7 & 12.0 \\
M1 & 297.6 & 376.1 & 469.0 & 95.2 & 53.2 & 3.1 \\
M2 & 298.9 & 375.7 & 468.6 & 96.2 & 52.5 & 4.6 \\
M3 & 303.2 & 376.3 & 464.1 & 95.1 & 53.7 & 4.2 \\
M4 & 303.2 & 376.6 & 463.9 & 95.1 & 51.9 & 5.0 \\
\hline
\end{tabular}

Further inspection regarding the thermal degradation of the membranes in Figure 5.5 shows that the derived thermogravimetric (DTG) curves present a slight asymmetry evidenced by a slant around $400-460{ }^{\circ} \mathrm{C}$. This asymmetry is due to the slow decomposition of polymer chains or highly cross-linked polymeric residues. Complete degradation of the membranes as well as that of the NRL occurred in a single stage, which was completed at a range of temperature of $464-469{ }^{\circ} \mathrm{C}$. These results are similar to those found in the literature (Liu et al., 2008). The mass loss observed in this temperature range can be linked to the oxidative pyrolysis of rubber, vaporization, and removal of volatile products. In thermodegradation of polyisoprene, fragmentation leads to depolymerization of the macromolecules generating the main products, isoprene and dipentene (Paoli, 2008). Above $470{ }^{\circ} \mathrm{C}$ no other significant decomposition event was observed, suggesting the presence of only decomposed gas, ash, and inorganic species (oxides, carbonates, phosphates and metal silicates) at this stage, which could be due to the presence of impurities or substances that would be naturally present in latex. 


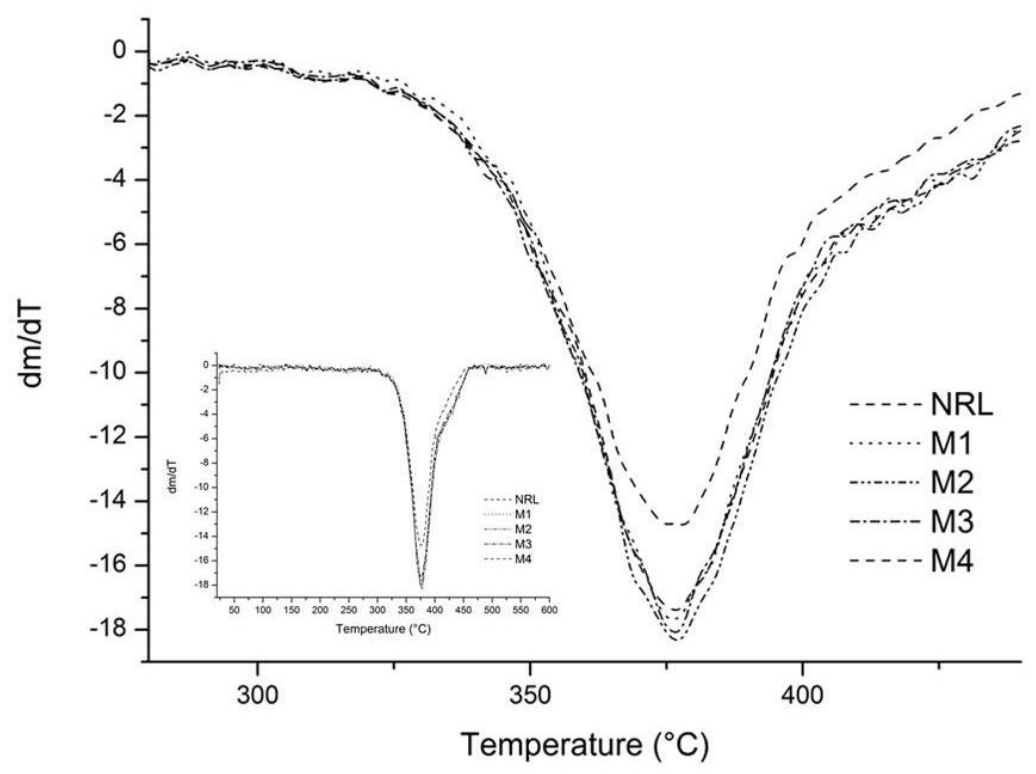

Figure 5.5 - DTG curves for natural rubber latex (NRL) and membranes M1, M2, M3, and M4.

Figure 5.6 shows the DSC curves for NRL, for the Van Gogh M1 and M2 membranes and for the M3 and M4 membranes prepared with the deposition method. Notably, all the membranes and NRL presented exothermic events. 


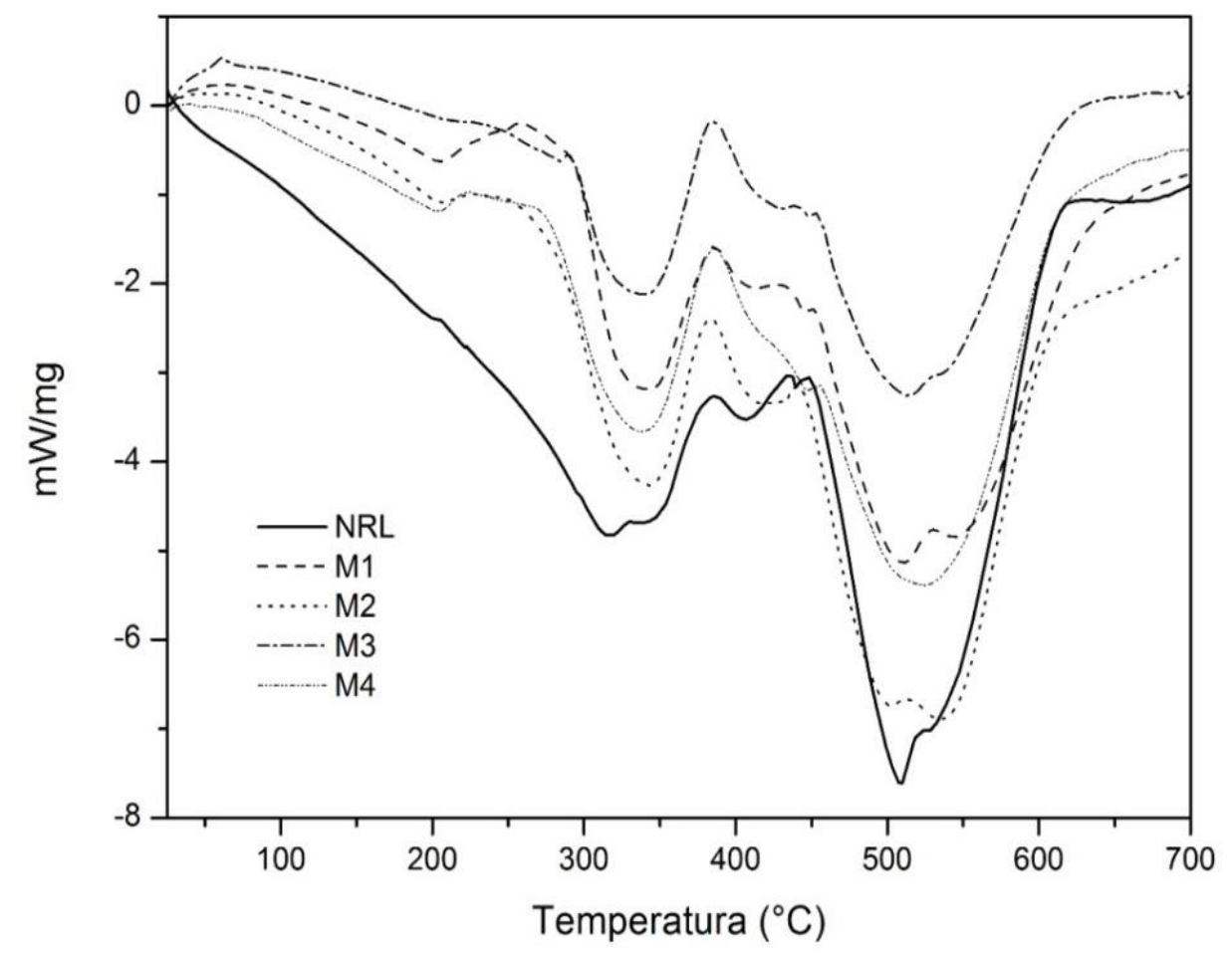

Figure 5.6 - DSC curves for natural rubber latex (NRL) and membranes M1, M2, M3 and M4.

The thermal behavior of the latex membranes is similar to that of the NRL (Figure 5.6), where the exothermic processes that occurred can be clearly observed. The exothermic event observed at $350-460{ }^{\circ} \mathrm{C}$ is consistent with the macromolecular thermodegradation of the membranes. First, the crosslinking between the polymer chains breaks in the vulcanization process. This is followed by depolymerization of the compound, an event that coincides with the thermogravimetric results already reported in the literature (Ooi et al., 2014). In addition, a significant difference between the DSC curves of the membranes was observed in this temperature range in which we perceive a wider range of energy related to the M3 and M4 membranes obtained by deposition, compared to the M1 and M2 Van Gogh membranes. This is consistent with the X-ray diffraction profile of the M3 and M4 membranes, which showed increased crosslinking between the isoprene chains. This increased crosslinking would consequently release a greater amount of energy following thermal degradation. 


\subsection{5 - Saline absorption measurements}

The saline absorption technique was performed to evaluate the weight gained by the membranes after their exposure to the saline solution in order to assess which membrane absorbed less water. For executing the technique, the following immersion times were adopted: 15, 30, 60, 105, 165, 255 and 375 minutes; at the end each time period, a systematic drying process of the excess water from surface of the sample was performed by using a paper towel; then, the weighing of samples was performed.

In the analysis of saline absorption, it was possible to observe how the membrane absorbs water when in contact with the eye, since the eye already has water in the aqueous humor.

During the calculations of the mass variation, an instrumental error was added, considering the equipment error, of $0.0001 \mathrm{~g}$, found by the following equation:

$$
\Delta \text { mass }=\frac{\Delta M_{f}}{M_{f}}+\frac{M_{f}}{M_{i}^{2}} \times \Delta M_{i} . \quad \text { equation (5.2) }
$$

The Qtiplot ${ }^{\circledR}$ software was used for fixing the data e determining time when the membrane stabilized and stopped gaining weight. Firstly, the normalization of the mass of the membranes and a non-linear function were determined considering the instrumental error (Figure 5.7).

The function of time in relation to the variation of weight was fixed by the equation:

$$
M(x)=M_{0}-M_{f} e^{\frac{-x}{t}}, \quad \text { equation (5.3) }
$$

where $\mathrm{M}_{0}$ corresponds to the initial weight and $\mathrm{M}_{\mathrm{f}}$ to the final weight. 

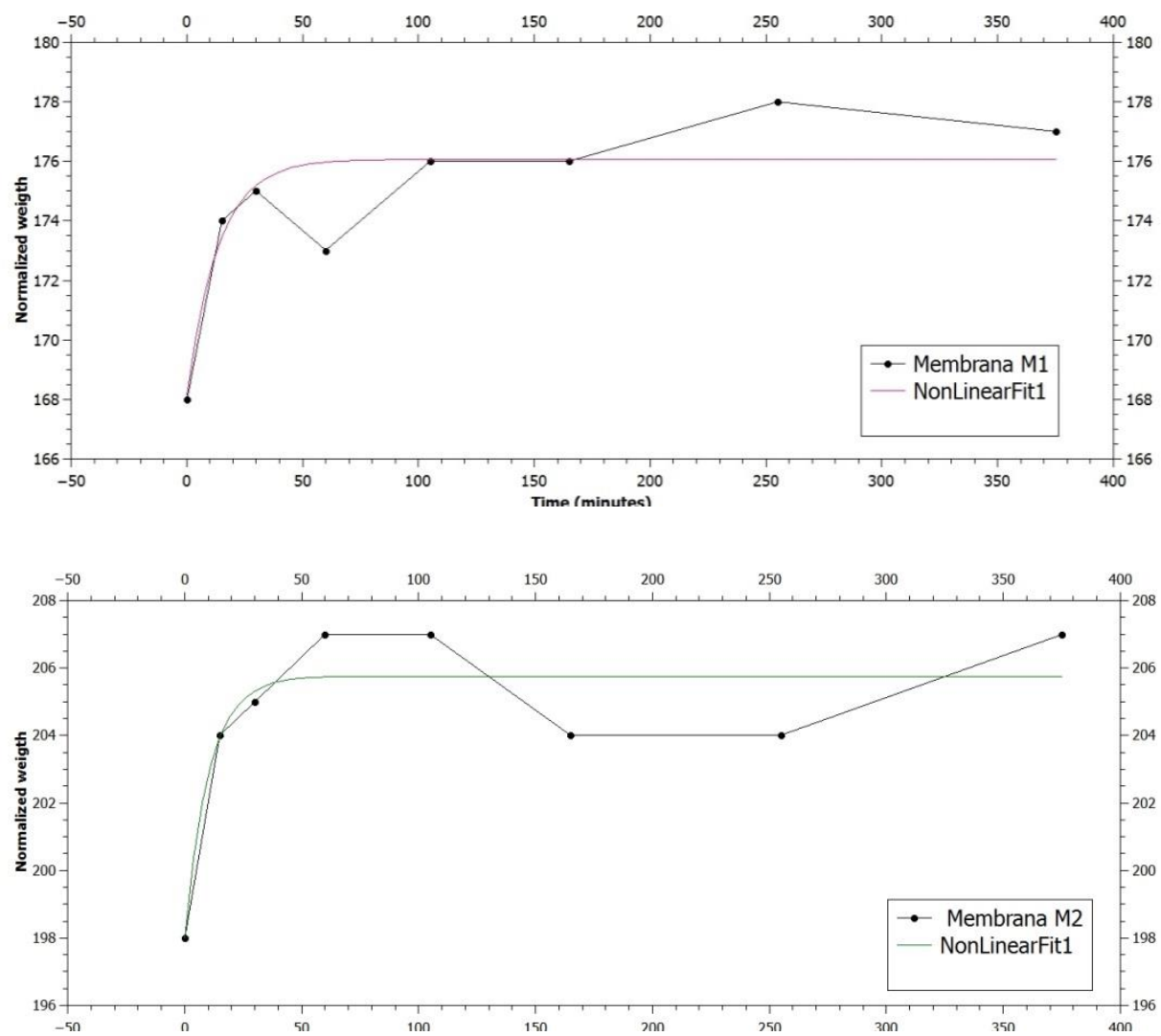

(b)

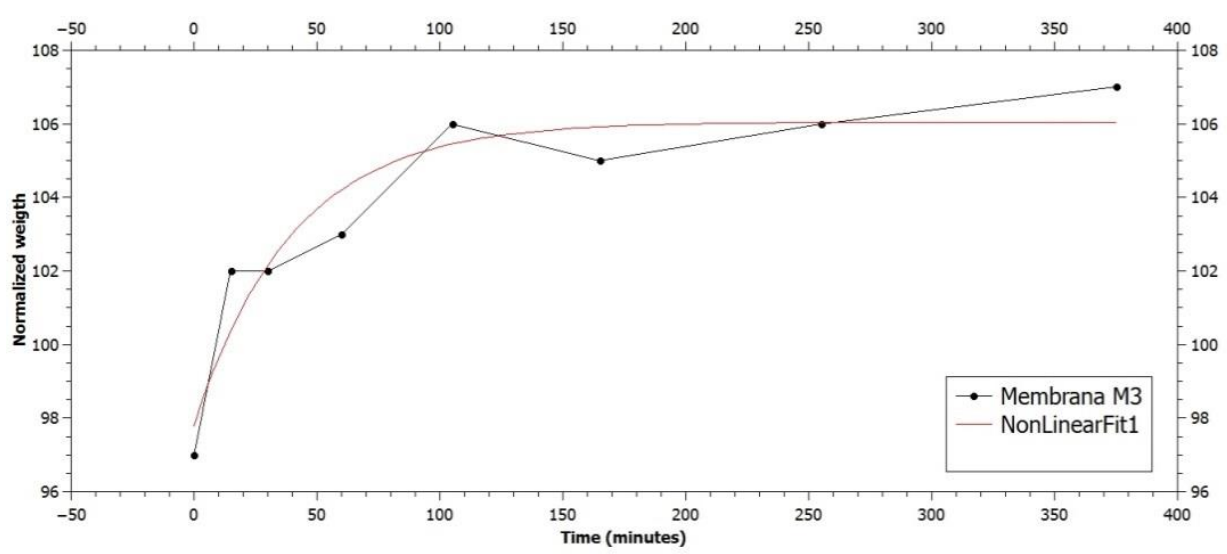

(c) 


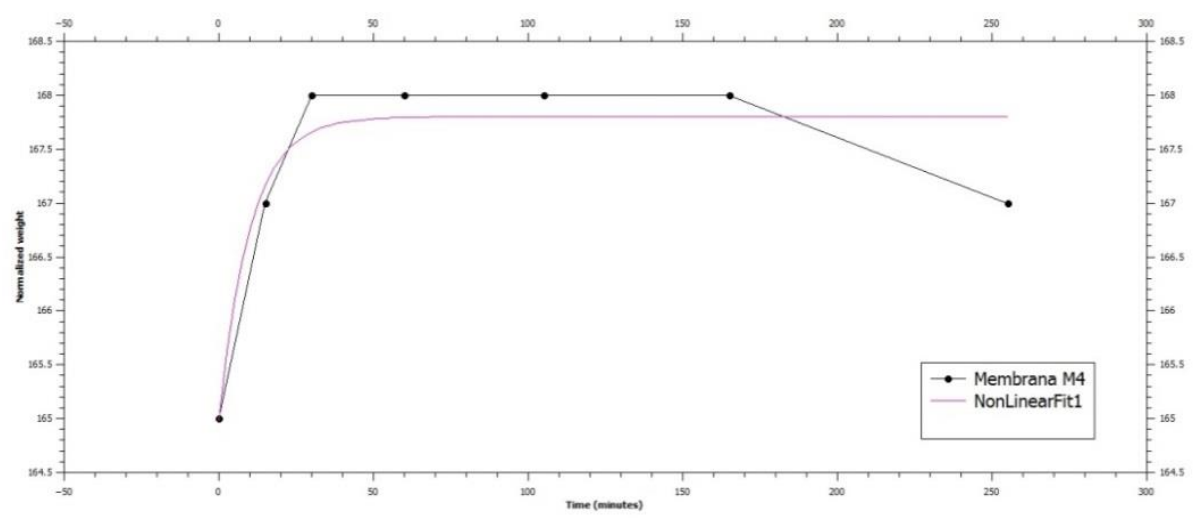

(d)

Figure 5.7 - Normalization of the mass of the membranes and a non-linear function, in Van Gogh membrane M1 (a) and M2 (b), membranes produced with the deposition technique

$$
\text { M3 (c) and M4 (d). }
$$

For a better analysis, the results are shown on Table 5.4, which shows the values obtained from the variation of weight of the membranes M1, M2, M3 and M4, and the stabilization time.

Table 5.4 - Time of absorption of the latex membranes

\begin{tabular}{lll}
\hline Sample & Time (minutes) & Weight $(\%)$ \\
\hline M1 & $14 \pm 8$ & $5.4 \pm 0.1$ \\
M2 & $10 \pm 6$ & $4.4 \pm 0.1$ \\
M3 & $40 \pm 1$ & $10.2 \pm 0.2$ \\
M4 & $10 \pm 5$ & $4.2 \pm 0.1$ \\
\hline
\end{tabular}

In this analysis, we observed that M3 absorbed more water in a longer period of time and, consequently, gained more weight. M2 and M4 gained less weight in less time, absorbing little water. Among the techniques, the Van Gogh M2 after 4 baths, it was observed, presented less absorption of water; with the deposition technique, M4 absorbed less water.

The Van Gogh technique show low water absorption; the difference of absorption between M1 and M2 was 5.4 and 4.4, respectively. This difference of only 1\% may not 
interfere in the total or partial occlusion since, when in contact with the eye, the membrane must absorb the least possible water to be as comfortable and flexible as possible on the patient's eye. The contact lenses available on the market are manufactured with $80 \%$ of water.

\subsection{6 - Infrared spectroscopy (FT-IR) ATR mode}

Figure 5.8 shows the FT-IR spectra obtained with the M1, M2, M3 e M4 latex membrane thermally treated at $40^{\circ} \mathrm{C}$, in the region of 4000 to $500 \mathrm{~cm}^{-1}$. The main chemical groups present in vulcanized natural rubber are characteristic of polyisoprene.

The spectra of the latex membrane M1 thermally treated at $40^{\circ} \mathrm{C}$, in the region of 4000 to $500 \mathrm{~cm}^{-1}$. Note the distinct regions containing several peaks. The first between 3250 and $3000 \mathrm{~cm}^{-1}$, which is related to the symmetrical stretching of the $\mathrm{O}-\mathrm{H}$ bonds. The second region, 3050 of the $2800 \mathrm{~cm}^{-1}$, shows $\mathrm{C}-\mathrm{H}$ bonds in the $\mathrm{CH} 3$. The next region of the spectrum is from 1735 to $800 \mathrm{~cm}^{-1}$ and contains several characteristic peaks that enable to evaluate the presence of functional groups such as in $1451 \mathrm{~cm}-1 \delta-\mathrm{C}-\mathrm{H} 2-$ and $1130 \mathrm{~cm}^{-1}$ in the $\mathrm{CH}$ bending plane, or (C-C) cis, or $\mathrm{CH} 2$ wag (Agostini, 2009).

The spectra of the latex membrane M2 thermally treated at $40^{\circ} \mathrm{C}$, in the region of 4000 to $500 \mathrm{~cm}^{-1}$, where two peaks were observed. The first peak was observed in 3046 to $2850 \mathrm{~cm}^{-1}$, representing $\mathrm{v}_{\mathrm{s}}(=\mathrm{C}=\mathrm{H})$, and between 3046 and 2920, $\mathrm{v}_{\mathrm{s}} \mathrm{C}-\mathrm{H}$ in $\mathrm{CH} 3$. The next region of the spectrum was between 1460 and $875 \mathrm{~cm}^{-1}$ and enables to evaluate $1400 \delta$-C$\mathrm{H} 2-$ and $840 \mathrm{~cm}^{-1}, \delta-\mathrm{C}=\mathrm{C}-\mathrm{H}$ (Agostini, 2009).

The spectra obtained from latex membrane $\mathrm{M} 3$, thermally treated at $40^{\circ} \mathrm{C}$, in the region of 4000 to $500 \mathrm{~cm}^{-1}$. Two higher intensity peaks were observed. The first on $3700 \mathrm{~cm}^{-1}$, represented by the free $\mathrm{O}-\mathrm{H}$, a presence that is evidenced in a diluted solution and $1000 \mathrm{~cm}^{-1} \mathrm{vC}-\mathrm{O}$ of ether. Intermediate peaks were between 3046 and 2960, which is attributed to $\mathrm{v}_{\mathrm{s}} \mathrm{C}-\mathrm{H}$ in $\mathrm{CH}_{3}$ and $1000 \mathrm{~cm}-1$. In $1450 \mathrm{~cm}^{-1}$, it is attributed to $\delta-\mathrm{C}-\mathrm{H} 2-$, at 650 $\mathrm{cm}^{-1}$ C-S (Agostini, 2009; Salmazo, 2011). 
The spectra of the M4 latex membrane thermally treated at $70^{\circ} \mathrm{C}$, in the region of 4000 to $500 \mathrm{~cm}^{-1}$. Three peak regions were observed. The first peak was observed at 3022 to $2960 \mathrm{~cm}^{-1}$, representing $\mathrm{v}_{\mathrm{s}}(=\mathrm{C}=\mathrm{H})$ and $\mathrm{v}_{\mathrm{s}}$. C-H in $\mathrm{CH}$. The next region of the spectrum comprises 1470 to $1415 \mathrm{~cm}^{-1}$ and enables to evaluate $1400 \delta$-C-H2-. And the third, 680 $\mathrm{cm}^{-1}$ (C-S) (Agostini, 2009; Salmazo, 2011).

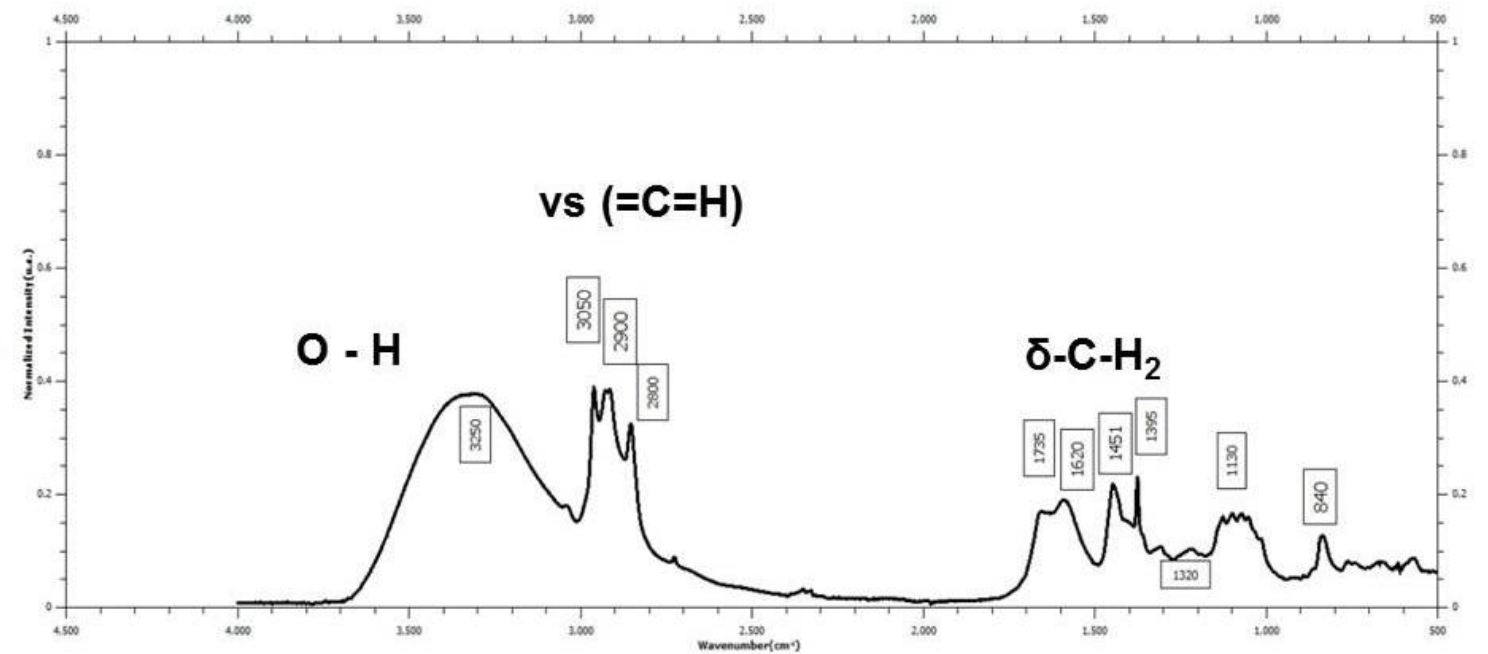

(a)

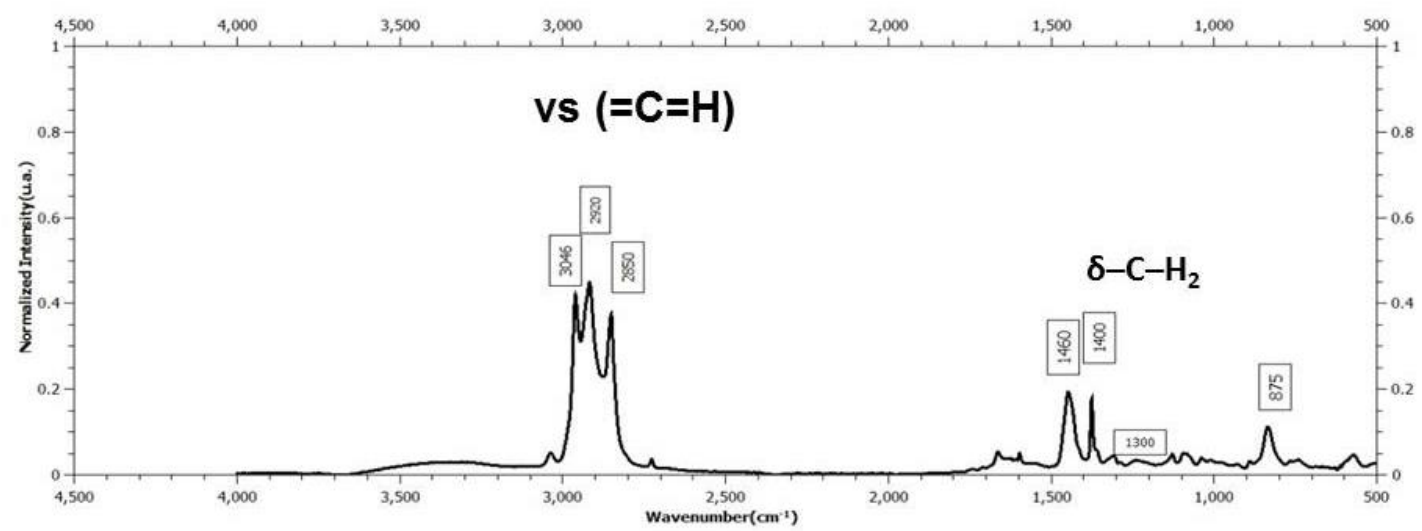

(b) 


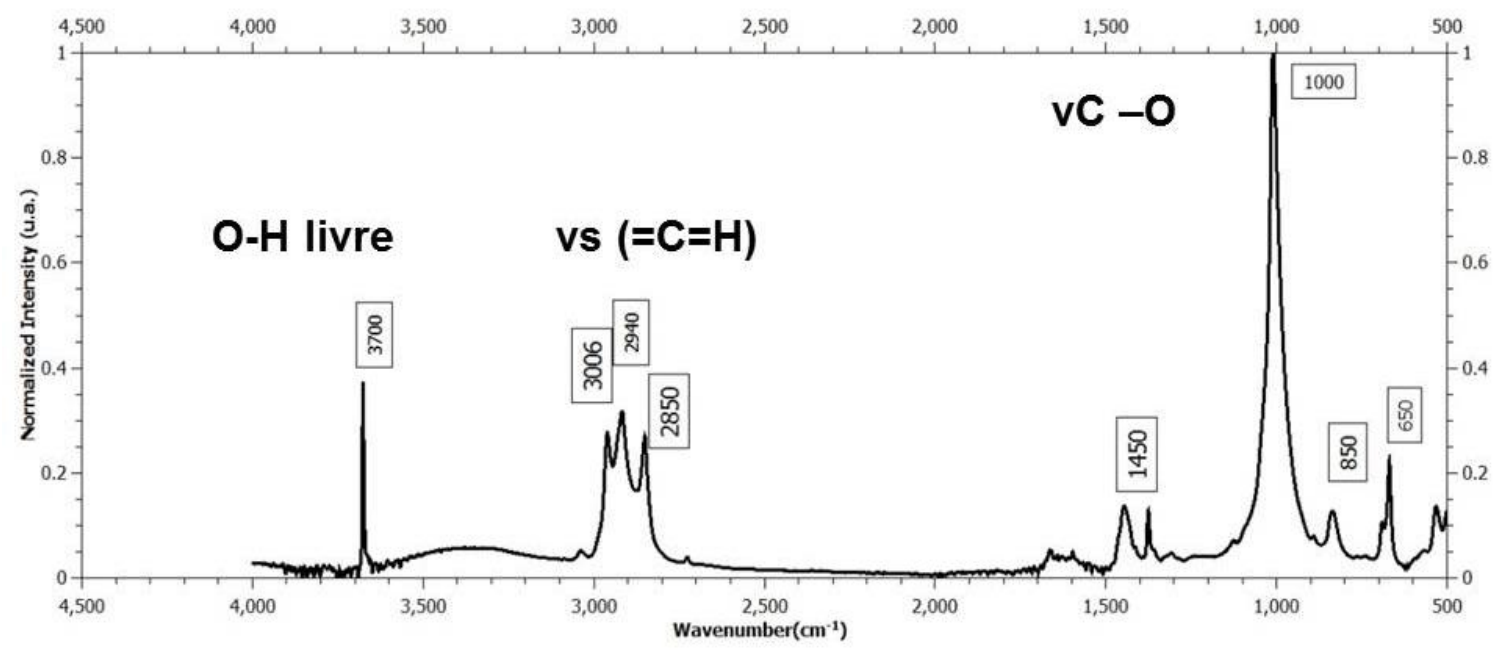

(c)

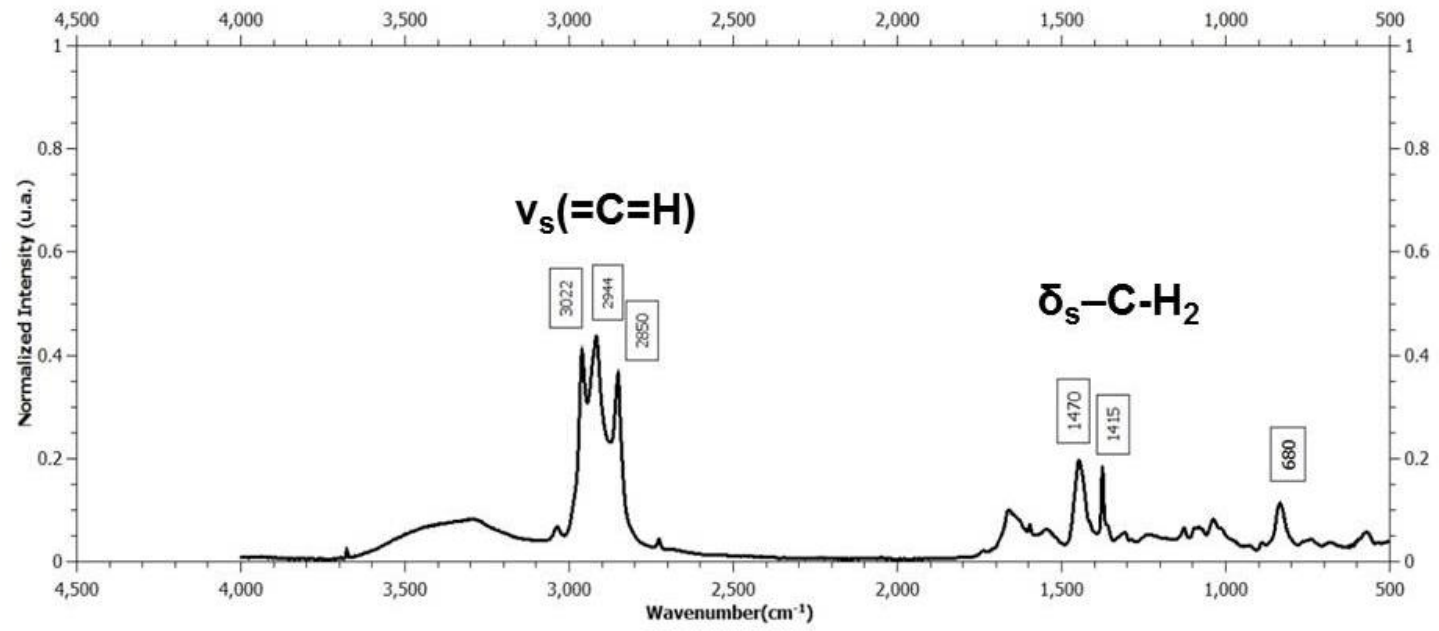

(d)

Figure 5.8 - Spectra of the infrared region in the ATR method of the Van Gogh membrane M1 (a) and M2 (b), membranes produced with the deposition technique M3 (c) and M4 (d) in the region of 4000 a $500 \mathrm{~cm}^{-1}$. 
Table 5.5 lists the attempted attributions of the ranges observed in the spectra of absorption in the infrared region of membranes M1, M2, M3 and M4, based on the references (Agostini, 2009, Salmazo, 2011).

Table 5.5 - Attributions of the ranges spectra of the infrared region in the ATR method

\begin{tabular}{|c|c|c|}
\hline Attribution & Literature & Experimental \\
\hline $\mathrm{O}-\mathrm{H}$ free & 3500 & 3700 \\
\hline $\mathrm{v}_{\mathrm{s}} \mathrm{O}-\mathrm{H}$ & 3200 & 3250 \\
\hline $\mathrm{v}_{\mathrm{s}}(=\mathrm{C}-\mathrm{H})$ & 3036 & 3050 \\
\hline $\mathrm{v}_{\mathrm{s}} \mathrm{C}-\mathrm{H}$ no $\mathrm{CH}_{3}$ & 2960 & $2900-2944$ \\
\hline $\mathrm{v}_{\mathrm{s}} \mathrm{C}-\mathrm{H}$ no $\mathrm{CH}_{2}-$ & 2855 & $1460-1450$ \\
\hline$\delta-\mathrm{CH}_{2}-$ & 1450 & 1395 \\
\hline$\delta_{\mathrm{s}}-\mathrm{CH}_{3}$ & 1371 & \\
\hline $\begin{array}{c}\mathrm{C}-\mathrm{H} \text { bending on } \\
\text { plane or }(\mathrm{C}-\mathrm{C}) \text { cis } \\
\text { or } \mathrm{CH} \mathrm{H}_{2} \text { wag. }\end{array}$ & 1128 & \\
\hline$\delta \mathrm{C}=\mathrm{C}-\mathrm{H}$ & & \\
\hline $\mathrm{C}-\mathrm{S}$ & 537 & 680 \\
\hline
\end{tabular}

When comparing membranes M1, M2, M3 and M4 on Figure 5.9, three common peak regions are observed in the absorption range of cis-1,4-polyisoprene. The first at 3000 to $2860 \mathrm{~cm}^{-1}$ and 1520 to $1400 \mathrm{~cm}^{-1}$, and the third at $860 \mathrm{~cm}^{-1}$. Natural rubber has $\mathrm{O}-\mathrm{H}$ bonds at $3400, \mathrm{C}-\mathrm{H}$ bonds at $3000, \mathrm{C}=\mathrm{O}$ bonds at 1715 , and $\mathrm{C}=\mathrm{H}$ bonds at 873 . These FT-IR correlations of the membranes are similar to what was found in the literature that compares natural rubber (Aielo, 2014; Agostini, 2009; Salmazo, 2011). The differences occurred in the membrane possibly refer to the preparation of the diluted latex and manner of preparing the membranes. 


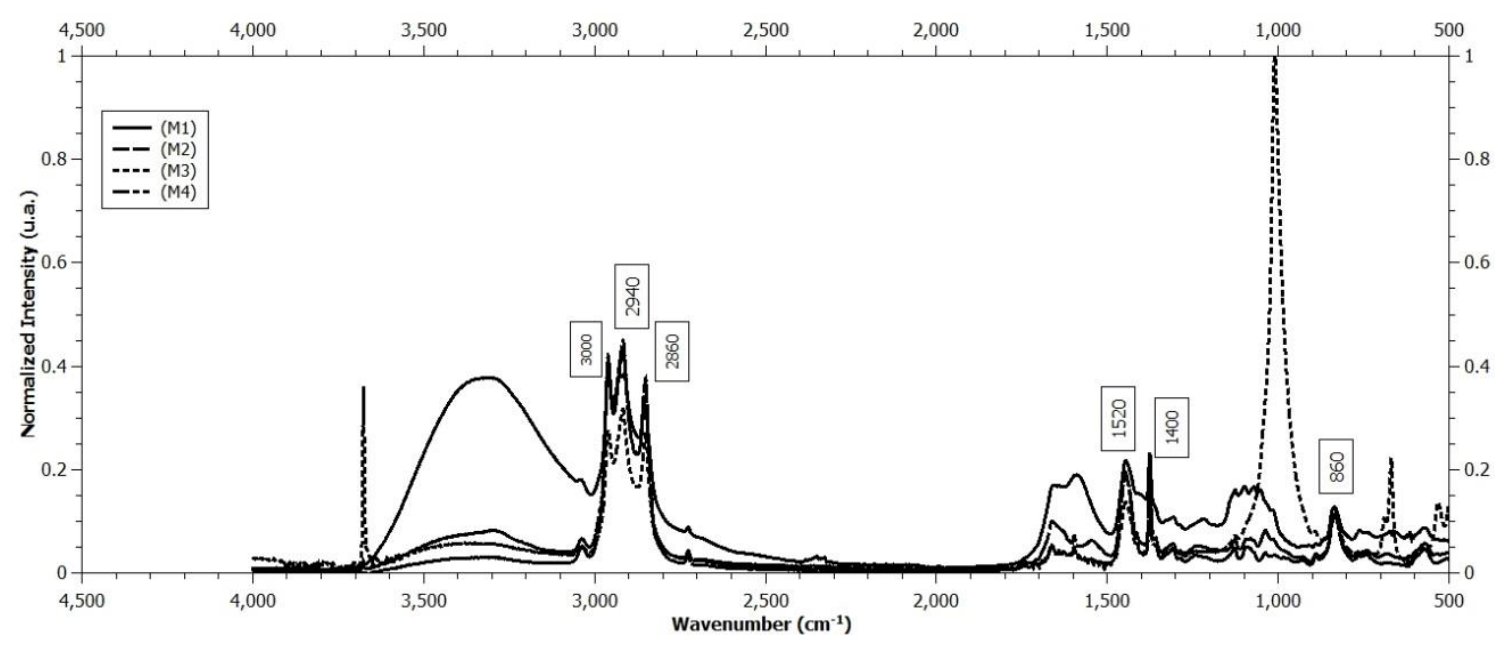

Figure 5.9 - Spectra of the infrared region in the ATR method of the M1, M2, M3 and M4 latex membranes, in the region of 4000 a $500 \mathrm{~cm}^{-1}$.

\subsection{7 - Principal component analyses of latex membrane (PCA)}

The PCA analysis was performed in order to verify the behavior of the membranes from the quantitative data of the characterization. For this analysis, the variables were defined as show non Table 5.6, which are the values obtained before and shown in the tables 5.2 and 5.4.

Table 5.6 - Analyzed components

\begin{tabular}{lllllll}
\hline Samples & S \% & K \% & P \% & Zn \% & $\begin{array}{l}\text { Time of } \\
\text { absorption } \\
\text { min (Tabs) }\end{array}$ & $\begin{array}{l}\text { Absorption } \\
\text { weight } \\
\text { (Mabs) \% }\end{array}$ \\
\hline M1 & 79.70 & 16.80 & 2.20 & 1.00 & 14 & 5.4 \\
M2 & 70.50 & 25.60 & 2.40 & 1.12 & 10 & 4.4 \\
M3 & 69.70 & 21.80 & 1.45 & 6.36 & 40 & 10.2 \\
M4 & 57.77 & 32.86 & 3.78 & 3.82 & 10 & 4.2 \\
\hline
\end{tabular}


Figure 5.10 shows the projection of the variables of the membranes and their chemical components and by the water absorption technique, according to Table 5.6. The variance of the data explains $98.4 \%$ in the plane, and the plane 1 (PC1) $-60.8 \%$ and in the plan 2 (PC2) - $37.6 \%$. The minerals $\mathrm{K}$ and $\mathrm{P}$ are correlated to $\mathrm{M} 4$, and $\mathrm{Zn}$, absorbed weight and Time are correlated with to M3. S is correlated to M1. This correlation confirms the data obtained previously, since the M3 has a higher amount of $\mathrm{Zn}$ and absorbed more water in more time; M4 had a greater amount of $\mathrm{K}$ and $\mathrm{P}$ due to its higher temperature during preparation, and M1 had greater amounts of sulfur. M2 showed no correlation with these variables. In fact, M2, in the results already presented, showed lower water absorption in less time and minerals in expected quantities.

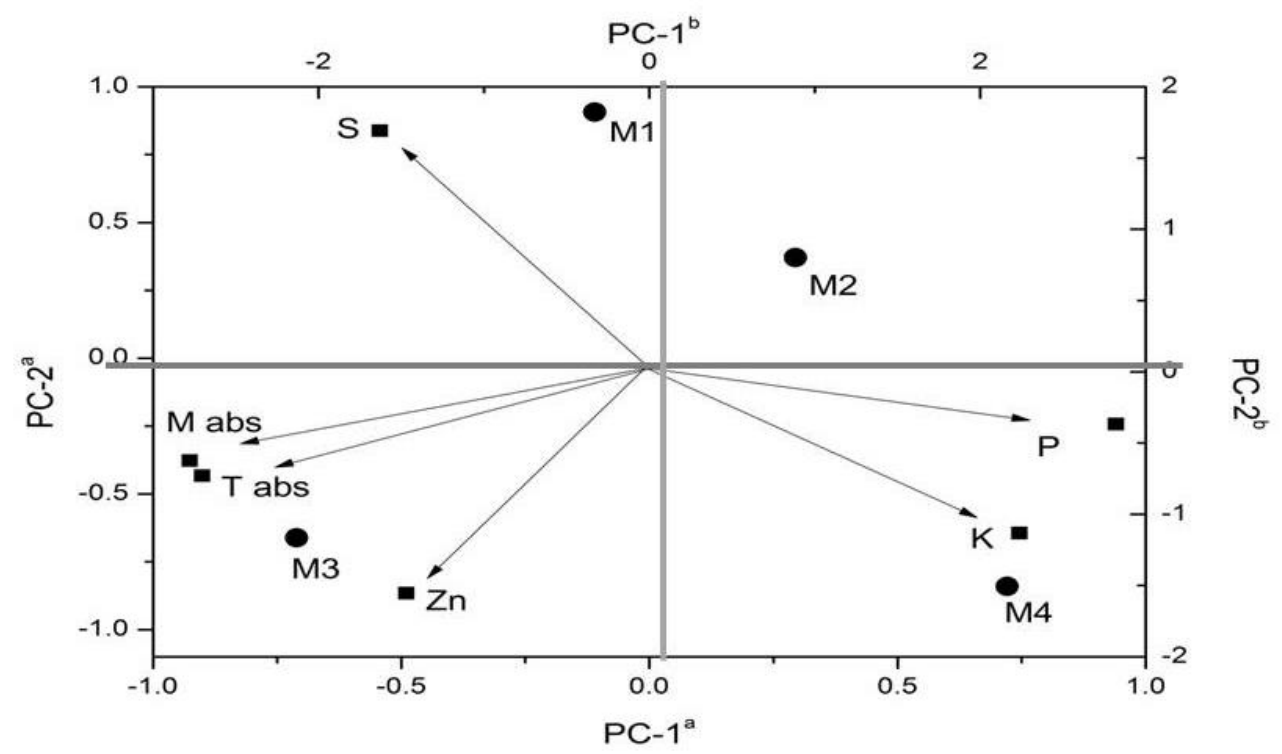

Figure 5.10 - On the biplot, $\mathrm{PC}^{\mathrm{a}}$ with vectors coming from the origin shows the relation of the variables $(\bullet)$. PC $^{\mathrm{b}}$ shows the relations of the samples $(\bullet)$.

Observing the axes, the first axis (PC1) separates the membranes by techniques: M1 and M2 membranes were prepared with the Van Gogh technique $\left(40{ }^{\circ} \mathrm{C}\right)$; the second axis (PC2) shows M3 and M4, prepared with the deposition technique. M2 and M4 are not correlated to time and weight absorption, which can be explained by lower values found in relation to M1 and M3. 
The static analyses showed a similarity between the results of fluorescence measurement and water absorption techniques, and the method of preparation of Van Gogh and deposition membranes, since the material used, natural latex, was the same, and the difference is given during the manufacturing, with the brushes turning the Van Gogh membranes rugose, which is a desirable characteristic to obtain partial or total occlusion.

\subsection{8 - Light crossing analysis}

The focimeter is used on specific materials for glasses and contact lenses. In an eyeglass lens, for example, the values presented in $\mathrm{S}$ and $\mathrm{C}$ represent the degree, with positive for astigmatism and negative for myopia; A represents the axis and the prism $(\Delta)$ the variance of the light beam.

In a normal contact lens, the values presented are: $\mathrm{S}=0.25, \mathrm{C}=0.25, \mathrm{~A}=24$ and $\Delta=0$. These values represent two values for diopters and two values for the axis. When measuring the membranes, the numerical value of the instrument was disregarded, as such values cannot be assessed in latex.

In the focimeter device, we observed the measurement of the light beam on the latex membrane. In this essay, five samples of each membrane were tested in order to verify their reproducibility. Figure 5.11 presents the assessment of the passage of light from membranes M1, M2, M3 and M4. 

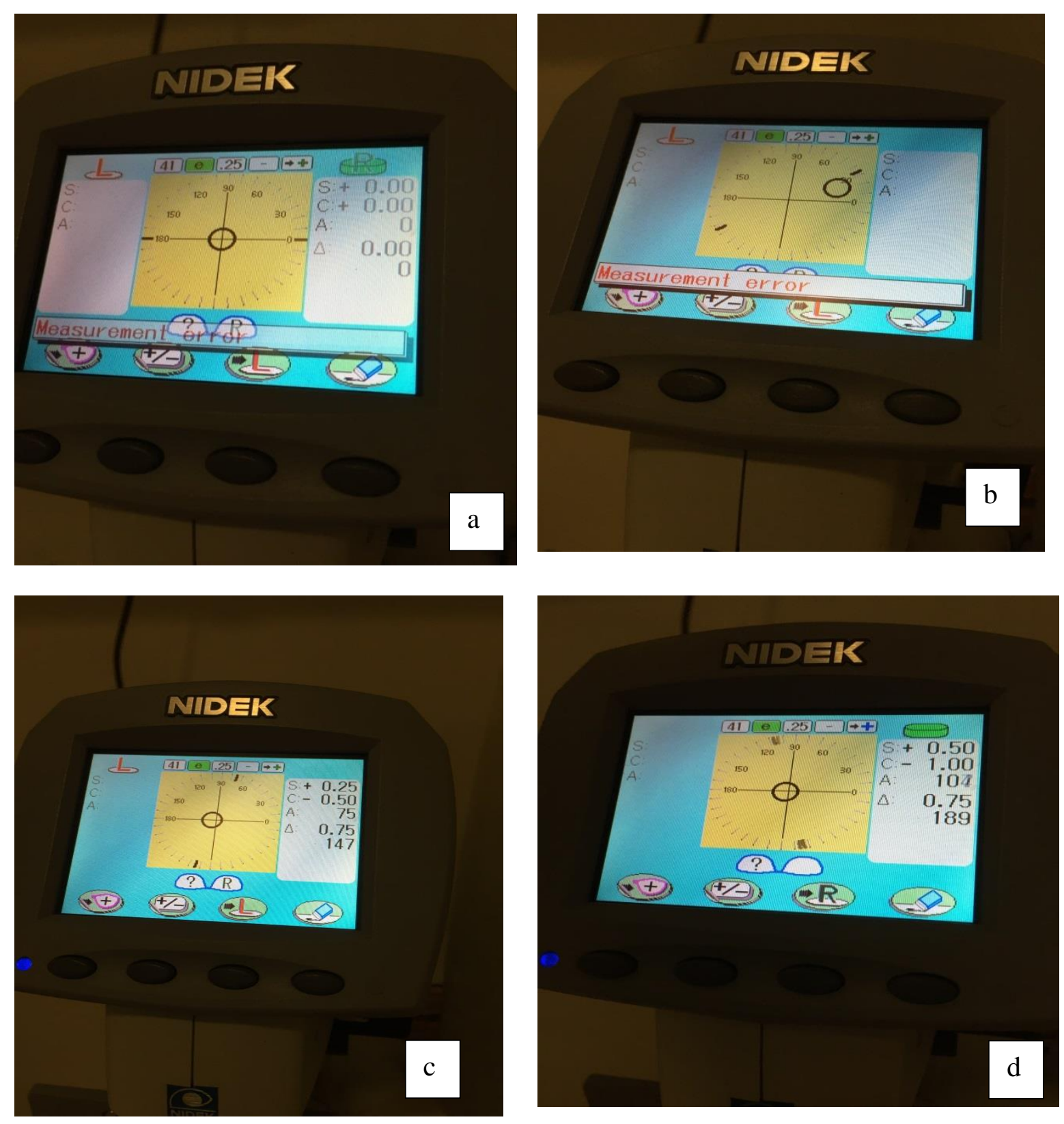

Figure 5.11 - Measuring the membranes with the focimeter, M1 (a), M2 (b), M3 (c) e M4 (d). In the images, the angle of the focimeter display and the dark environment of the optometry clinic.

On membrane M1, it can be observed that the beam locates the optical center, indicating a small passage of light. Due to the irregular surface caused by the brushes, the 
equipment shows an error in measurement. Consequently, the Van Gogh technique, with its brushes, made the surface rugose and gave a diffuse passage of light.

On membrane M2, all membranes did not present passage of light. The focimeter did not locate the optical center, which caused a measurement error. Membrane M2 has the most irregular surface due to a difference in manufacturing from M1, because the number of brushes was higher. This data prove the membrane is opaque, which is a characteristic of occlusion.

The membranes M1 and M2 were moistened in saline for an hour and after that time the measurements were the same as previous. Thus it was shown that the absorption of physiological saline did not affect the property of passing light.

On membranes M3 and M4, produced with the deposition technique, the surface did not have irregularities. The focimeter performed the reading through the optical center, measuring the values, with no errors and total passage of light.

Thus, the Van Gogh technique can be considered as viable for the manufacturing of latex membranes for treating amblyopia. The passage of light was diffuse due to the rugosity and opacity, which will provide partial or total light occlusion in the eye of the patient. M1 presented a diffuse passage of light, which can stimulate the eye beyond the occlusion. M2 presented opacity with total occlusion of the light, which can benefit the treatment when compared with the eyepatch.

\section{4 - CONCLUSION}

The characterization techniques showed the applicability and feasibility of Van Gogh technique for the manufacture of membranes for the treatment of amblyopia. For a better analysis, the results are shown on Table 5.7, which shows the values obtained the characterization of the membranes M1, M2, M3 and M4.

The technique scanning electron microscope (SEM) was used for the study of surface structures or subsurface structures the membranes of relatively large samples; it has a large depth of focus and rough the membranes prepared Van Gogh. The M1 membrane 
was rough and porous throughout the area of the micrograph, the M2 membrane was denser, as evidenced by the presence of rubber particles, the M3 showed the presence of rubber particles more organized distribution and pores and M4 were observed larger pores. The Van Gogh technique was rough, to obtain an occlusive membrane, this is an advantage in relation to the technique deposition.

This technique fluorescence measurements was used to quantify the components of the membranes and to check the variation of the components vulcanized at $40{ }^{\circ} \mathrm{C}$ and 70 ${ }^{\circ} \mathrm{C}$. Using EDX, we identified the components in the latex, as high amounts of sulfur (S) and Potassium $(\mathrm{K})$ were detected in all membranes, and the lower quantities of phosphorus $(\mathrm{P})$, zinc $(\mathrm{Zi})$, copper $(\mathrm{Cu})$ and iron $(\mathrm{Fe})$. Other elements with values insignificant were cobalt (Co) and gadolinium (Gd) and manganese (Mn). The amount of sulfur decreases and the amount of potassium increases for the M4 membrane and Zinc had an increase in M3.

The X-ray diffraction profile of the membranes is predominantly amorphous, as expected with a broad peak, at $2 \theta=19^{\circ}$. Notably, increase in the time involved in preparing the membranes increased the chemical crosslinking between isoprene segments, which explains the higher crystallinity shown by the latex membrane prepared using the deposition technique.

The technique TG/DSC was a dynamic technique in which the loss of mass of a sample is measured continuously while the temperature is increased at a constant rate to evaluate the technique altered property latex. For all samples, no significant degradation was observed before $320{ }^{\circ} \mathrm{C}$. For all membranes, the maximum degradation temperature of the polymer was at approximately $375-377^{\circ} \mathrm{C}$, which demonstrates that the preparation techniques did not significantly affect the thermal behavior of the membranes. In DSC all the membranes presented exothermic events. The Van Gogh technique did not make in relation to the technique deposition.

The technique saline absorption was measured by immersing latex membranes in saline solution. The membranes capacity of absorbing saline solutions during period, the samples were weighted again to determine the final wet masses in time intervals of 15 minutes to 12 hours. We observed that M3 absorbed more water in a longer period of time and, consequently, gained more weight. M2 and M4 gained less weight in less time, 
absorbing little water. The Van Gogh technique show low water absorption; the difference of absorption between M1 and M2 was 5.4 and 4.4, respectively.

The technique Infrared spectroscopy (FT-IR) ATR mode known allows the acquisition of qualitative spectra of solids of natural rubber in the region of 4000 to 500 $\mathrm{cm}^{-1}$. The main chemical groups present in vulcanized natural rubber are characteristic of polyisoprene. The first at 3000 to $2860 \mathrm{~cm}^{-1}$ and 1520 to $1400 \mathrm{~cm}^{-1}$, and the third at 860 $\mathrm{cm}^{-1}$. Natural rubber has $\mathrm{O}-\mathrm{H}$ bonds at $3400, \mathrm{C}-\mathrm{H}$ bonds at $3000, \mathrm{C}=\mathrm{O}$ bonds at 1715 , and $\mathrm{C}=\mathrm{H}$ bonds at 873 . All membranes present $\mathrm{v}_{\mathrm{s}}(=\mathrm{C}=\mathrm{H})$ bonds at 3000 to $2860 \mathrm{~cm}^{-1}$.

The principal components analysis (PCA) have important properties, each principal component is a linear combination of all the original variables, was performed in order to verify the behavior of the membranes from the quantitative data of the characterization. The results techniques: M1 and M2 membranes were prepared with the Van Gogh technique $\left(40{ }^{\circ} \mathrm{C}\right)$; the second axis (PC2) shows M3 and M4, prepared with the deposition technique. M2 and M4 are not correlated to time and weight absorption, which can be explained by lower values found in relation to M1 and M3.

The light crossing analysis was performed with the objective of evaluating the passage of light trough the membranes and verifying the behavior of the surface light on the rugosity of the membranes produced using the Van Gogh technique. On membrane M1, it can be observed the Van Gogh technique, with its brushes, made the surface rugose and gave a diffuse passage of light. On membrane M2, all membranes did not present passage of light. This data prove the membrane is opaque, which is a characteristic of occlusion. On membranes M3 and M4, produced with the deposition technique, the surface did not have irregularities, total passage of light. 
Table 5.7 - Abstract characterizations of membranes

\begin{tabular}{|c|c|c|c|c|}
\hline $\begin{array}{c}\text { Techniques } \\
\text { /Sample }\end{array}$ & M1 & M2 & M3 & M4 \\
\hline SEM & $\begin{array}{l}\text { rough and } \\
\text { porous }\end{array}$ & $\begin{array}{c}\text { rough and } \\
\text { porous }\end{array}$ & $\begin{array}{l}\text { organized } \\
\text { distribution } \\
\text { and pores }\end{array}$ & $\begin{array}{c}\text { organized } \\
\text { distribution } \\
\text { and larger } \\
\text { pores }\end{array}$ \\
\hline EDX & Sulfur (S) & Sulfur (S) & Zinc $(\mathrm{Zi})$ & $\begin{array}{l}\text { Potassium } \\
(\mathrm{K})\end{array}$ \\
\hline XDR & $\begin{array}{c}\text { lower } \\
\text { crystallinity }\end{array}$ & $\begin{array}{c}\text { lower } \\
\text { crystallinity }\end{array}$ & $\begin{array}{c}\text { higher } \\
\text { crystallinity }\end{array}$ & $\begin{array}{c}\text { higher } \\
\text { crystallinity }\end{array}$ \\
\hline TG/DSC & $\begin{array}{c}\text { even thermal } \\
\text { behavior }\end{array}$ & $\begin{array}{c}\text { even thermal } \\
\text { behavior }\end{array}$ & $\begin{array}{c}\text { even thermal } \\
\text { behavior }\end{array}$ & $\begin{array}{c}\text { even thermal } \\
\text { behavior }\end{array}$ \\
\hline $\begin{array}{c}\text { Saline } \\
\text { Absorption }\end{array}$ & $\begin{array}{c}\text { low } \\
\text { absorption }\end{array}$ & $\begin{array}{c}\text { low } \\
\text { absorption }\end{array}$ & $\begin{array}{c}\text { higher } \\
\text { absorption }\end{array}$ & $\begin{array}{c}\text { low } \\
\text { absorption }\end{array}$ \\
\hline $\begin{array}{c}\text { FT-IR mode } \\
\text { ATR }\end{array}$ & $\mathrm{v}_{\mathrm{s}}(=\mathrm{C}=\mathrm{H})$ & $\mathrm{v}_{\mathrm{s}}(=\mathrm{C}=\mathrm{H})$ & $\mathrm{v}_{\mathrm{s}}(=\mathrm{C}=\mathrm{H})$ & $\mathrm{v}_{\mathrm{S}}(=\mathrm{C}=\mathrm{H})$ \\
\hline PCA & correlated & correlated & correlated & correlated \\
\hline $\begin{array}{c}\text { Light } \\
\text { crossing } \\
\text { analysis }\end{array}$ & $\begin{array}{c}\text { diffuse } \\
\text { passage of } \\
\text { light }\end{array}$ & $\begin{array}{l}\text { not present } \\
\text { passage of } \\
\text { light }\end{array}$ & $\begin{array}{c}\text { present } \\
\text { passage of } \\
\text { light }\end{array}$ & $\begin{array}{c}\text { present } \\
\text { passage of } \\
\text { light }\end{array}$ \\
\hline
\end{tabular}

This technique Van Gogh showed that the latex membrane is an occluder with physics, chemical and thermal properties for the performance of the material with the characterization of the biomaterial in light refraction without eliminating it completely and maintaining the characteristics of the eye in movement. This is an advantage in relation to the traditional treatment with the use of eyepatch, since there is a loss of eye movement. 
When in direct contact with the eye, this latex membrane with total occlusion may replace the occlude with its same function, with the added benefit of it being more difficult for the patient to remove, providing a faster response to treatment due to its use for longer periods of time. Also, it helps avoiding bullying at school, for example, which helps prevent psychological disorders in the future, thus, providing a better quality of life to the patient.

As it is a new technique, errors are possible; however, all interfering factors were minimized. The Van Gogh technique was effective for partial or total light occlusion, because presented a roughness that interfered in the passing of light.

It is important to mention that the optometrist must investigate each case and identify the best treatment. With this, we aimed at using biotechnology and engineering to improve the therapy for a disease that is related to visual disability, improving the quality of life of patients and thus reducing the possibility of future problems.

Regardless of the biomaterial developed, the first level of testing in the evaluation of biocompatibility (ISO 10993-5, 2009) is the determination of cytotoxicity, by in vitro tests. In comparison with the investigations in vivo, in vitro studies are more easily controlled, have better reproducibility, and are proposals extremely reasonable. In addition, cytotoxicity assays are consistent with the principles of the 3Rs: reduction, refinement and replacement, preconized by Russell and Burch in the book "The Principles of Humane Experimental Technique" is that one can envisage the possibility of combining the maintenance of scientific quality of research and the ethical conduct of experiments (Hendriksen, 1996, Balls \& Straughan, 1996).

The tests to be developed in the development stage may vary according to the characteristics of the new product. Reports and reports of tests and validations should be included in the technical report, submitted to ANVISA, as well as other document required for the product registration.

In this study, the latex biomaterial has passed through several stages of characterization and compatibility and still in vitro tests need to be performed as the record LENCOC $^{\circledR}$ product. 


\section{CONCLUSIONS AND PERSPECTIVES}

This optical engineering study highlights the potential use and great advantages of the LENCOC $^{\circledR}$ latex membrane presented perspectives a safe and comfortable option for treating amblyopia.

The ATs bring new tools for the patient, enabling new abilities in the treatment of conditions, with a consequent improvement in the quality of life of the patient. LENCOC ${ }^{\circledR}$ can be considered an orthesis, via AT, as it is a device applied to the human eye with the function of inhibiting the entrance of light (total or partial) and stimulating the eye in the treatment of ocular diseases.

In this study, a complex system was elaborated to achieve the final product: a latex occlusive membrane for the treatment of amblyopia. Several techniques were used to reinforce its applicability and viability. Also, interfering factors were eliminated. After performing the tests, we conclude that:

i. The natural latex of the rubber tree can be used as biomaterial, due to its structural properties, to develop an occlusive membrane for the treatment of amblyopia;

ii. A protocol was established after several trials for the completion and consolidation of the Van Gogh technique. The properties examined were obviously satisfactory regarding visibility, flexibility and thickness. The transparent color of the membrane is due to the reduction in temperature when it is manufactured. The results show strong indications that the membranes produced with the Van Gogh technique are membranes promising in the treatment of amblyopia.

iii. During the characterization process, we defined four distinct types of membrane samples according to different temperatures, and the use of Van Gogh or deposition techniques. All of them have been tested using different equipment for the physical and chemical analysis of the biomaterials. The M1 membrane allowed the passage of diffuse light, causing partial occlusion, which preserves the movements and stimuli in the eye; Membrane M2 is opaque, without passage of light, and it is thin, 
transparent and has low water absorption; so, it can be used to treat amblyopia, replacing the cap with more comfort and providing a shorter treatment.

This study presented use of a LENCOC $^{\circledR}$ latex membrane for the treatment of amblyopia. The Van Gogh technique demonstrated that the physical and chemical characteristics of the latex membrane present results compatible with the eye when applied as an occluder, reinforcing its biomaterial characteristic. The confection method is reproducible and the latex membrane is very stable.

The latex membrane may offer a more effective adherence to the treatment of amblyopia, with better acceptance by the child and shorter treatment time, as well as lower possibility of rejection, since it is a biomaterial. It can be used at period times by the patient. In the case of children, especially, it would be more difficult to remove it, which would avoid embarrassing situations. It is also more effective, since its use would be prolonged and because it allows stimulation of the eye through partial occlusion.

Owing to the importance of biosafety in medical bioengineering research, extensive studies to confirm the efficacy of new treatment methods are critical. Thus, the development of natural latex membranes can lead to improvements in the treatment of amblyopia patients.

Further studies are naturally required to better understand this new latex membrane LENCOC $^{\circledR}$. Among them, other characterizations in vitro and cell culture analysis. Thus, we conclude that the natural latex membrane presented here is a promising material for use in the field of medicine in the treatment of amblyopia. In vivo studies are needed to determine the feasibility of this technique, because only with such studies we can be closer to a new technique and a new material to treat amblyopia. 


\section{REFERENCES}

Agostini, D.L.D.S. (2009). Caracterização dos constituintes do látex e da borracha natural que estimulam a angiongênese. Dissertação de Mestrado, Universidade Estadual Paulista Júlio de Mesquita Filho (UNESP), Bauru - Presidente Prudente.

Aielo, P. B., Borges, F. A., Romeira, K. M., Miranda, M. C. R., Arruda, L. B., Filho, P. N. L., Drago, B.C., Herculano, R.D. (2014). "Evaluation of Sodium Diclofenac Release Using Natural Rubber Latex as Carrier”. Materials Research, 17(Suppl. 1): 146-152.

Almeida, L. O. C (2005). “Análise do custo do tratamento da ambliopia para o paciente em hospital universitário”. Arquivo Brasileiro de Oftalmologia, 68(4): 475-480.

Alves, M.R.C. (2004). Estudo da borracha natural para utilização em períodos de entressafra num mesmo composto, Tese de Doutorado, Faculdade de Engenharia Química, Universidade Estadual de Campinas, 84p.

Andrade, T. A. M., Leite, S. N., Frade, M. A. C. (2008). "Neoformação tecidual em camundongos induzida pela biomembrana de látex da seringueira Hevea Brasiliensis". $21^{\circ}$ Congresso Brasileiro de Engenharia Biomédica, Salvador, BA, 152-155.

Anvisa. (2015). Agência Nacional de Vigilância Sanitária. Disponível em: http://portal.anvisa.gov.br/wps/portal/anvisa/home. Acesso em: 30 outubro 2015.

Arakaki, M.R., Schellini, S.A., Heimbeck, F.J., Furuya, M.T., Padovani, C.R. (2004). “Adesão ao tratamento da ambliopia". Arquivo Brasileiro de Oftalmologia; 67:201205.

Balabanian, C.A., Coutinho Netto, J., Lamano-Carvalho, T.L., Lacerda, S.A. e Brentegani, L.G. (2006). "Biocompatibility of natural latex implanted into dental alveolus of rats". In: Journal of Oral Science; 48(4):201-205.

Balls, M., Straughan, D.W. (1996). "The 3Rs of Russel \& Burch and the testing of biological products". In: BROWN F., CUSSLER K., HENDRIKSEN C. (Eds). Replacement, reduction and refinement of animal experiments in the 
development and control of biological products. Dev. Biol. Stand.,v.86, p. 11-18.

Bolognesi, L.F, Borges, F.A; Cinman, J.L.F, Silva, R.G., Santos, A.G; Herculano, R.D. (2015). "Natural Latex Films as Carrier for Casearia sylvestris Swartz Extract Associated with Ciprofloxacin". A Chem Sci J. 2015.5(1): 17-25.

Brandner, M., Lindner, S., Langmann, A. (2012).“Amblyopietherapie - Empfehlungen des Consilium Strabologicum Austriacum in Zusammenarbeit mit Orthoptik Austria”. Spektrum Augenheilkd, 26:236-240. DOI 10.1007/s00717-012-0122-9

Brandão, M.L., Coutinho-Netto J., Thomazini J.A., Lachat J.J., Muglia V.F e Piccinato C.E. (2007). "Prótese vascular derivada do látex". In: Jornal Vascular Brasileiro, 6(2), 130-141.

Brasil. (2016). Revista da Propriedade Industrial - INPI, seção II, n. 2364 de 26 de abril de 2016, 4317 p.

Brasil. (2015). Revista da Propriedade Industrial - INPI, seção I, n. 2306 de 17 de março de $2015,230 \mathrm{p}$.

Brasil. (2014). Portal Brasil - Dia Mundial da Visão alerta para a prevenção da cegueira no País. Julho 2014. Disponível em: http://www.brasil.gov.br/saude/2012/10/diamundial-da-visao-alerta-para-a-prevencao-da-cegueira-no-pais. Acesso em: 27 julho 2015.

Brasil. (2009). Brasil. Subsecretaria Nacional de Promoção dos Direitos da Pessoa com Deficiência. Comitê de Ajudas Técnicas. Tecnologia Assistiva. Brasília: CORDE, $138 \mathrm{p}$.

Barros, N. R., Chagas, P.A.M, Borges, F.A., Gemeinder, J.L.P., Miranda, M.C.R, Garms, B.C, Herculano, R.D. (2015). "Diclofenac potassium transdermal patches using natural rubber latex biomembranes as carrier". Journal of Materials, Volume 2015, Article ID 807948, 7 pages, http://dx.doi.org/10.1155/2015/807948.

Carvalho, B.R., Reis, R.M., Coutinho-Netto, J., Moura, M.D., Nogueira, A.A. e Ferriani, R.A. (2008). "Molde de látex natural (Hevea brasiliensis) para neovaginoplastia". In: Revista Brasileira de Ginecologia e Obstetrícia, Rio de Janeiro, v. 30, n. 1, 31-35. 
Canevarolo Jr., S.V. (2003). Técnicas de Caracterização de Polímeros. ArtLiber, p. 31, São Paulo, Brasil.

Cavalcante, R.A.L. (2013). Efeito da adição do líquido da castanhado caju nas propriedades térmicas, ópticas, mecânicas emorfológicas da borracha natural. Dissertação de Mestrado. Universidade de Brasília - UnB, 105 p.

Cólon, D., Rodrigues, S.S.F.R., Oliveira, D. S., Balthazar, J. M. ; Reis, C. A. (2015). "Skin Model and Some Processing Properties of a Drilling Simulation in the Abdominal". International Journal of Advanced Engineering Research and Science (IJAERS). v. 2, p. 50-55.

Coral-Ghanem, C. and Kara-José, N. (1998). Lentes de contato na clínica oftalmológica. 2.ed. - Rio de Janeiro: Cultura Médica.

Drewnowska O, Turek B, Carstanjen B, Gajewski Z. (2013). "Chitosan - a promising biomaterial in veterinary medicine". Polish J Vet Sci. 16(4). 843-848.

Frade, M.A.C., Cursi, I.B., Andrade, F.F., Coutinho-Netto, J., Barbetta, F. M. e Foss , N. T. (2004). "Management of Diabetic Skin Wounds with a Natural Latex Biomembrane”. In: Medicina Cutánea IberoLatino-Americana, vol. 32, n.6, 157-162.

Fielder AR, Irwin M, Auld R, Cocker KD, Jones HS, Moseley MJ. (1995). “Compliance in amblyopia therapy: objective monitoring of occlusion”. Br J Ophtalmol.;79(6):585-9.

Friolani, M. (2008). "Utilização da biomembrana de látex de seringueira Hevea Brasiliensis em lesões diafragmáticas de coelhos - estudo experimental”. Dissertação de Mestrado, Faculdade de Ciências Agrárias e Veterinária, Universidade Estadual Paulista, Jaboticabal, SP.

Fujimoto, F., Jervásio, A.C., Misawa, A.K., Garcia, R., Matayoshi, S. (2007). "Uso da biomembrana de látex em cavidade exenterada: relato de caso". Arq Bras Oftalmol.;70(5):854-7

Gondim, J.A.M., Moura, M.F.V., Dantas, A.S., Medeiros, R.L.S., Santos, K.M. (2005). "Composição centesimal e de minerais em cascas de frutas". Ciênc. Tecnol. Aliment., Campinas, 25(4): 825-827. 
Grant, N. (2015). The Amazing Eye. Disponível em:

https://www.tes.com/lessons/Tg01GFwLhe02bA/the-amazing-eye?redirect-bs=1. Acesso em: 20 outubro 2015.

Guastaldi, AC. (2004). Biomaterial - ponderações sobre as publicações científicas. Rev. Assoc. Paul. Cir. Dent., São Paulo, vol. 58, n. 3,205-206.

Guyton, A.C., Hall J.E. (2011). Guyton \& Hall: Tratado de Fisiologia Médica. 12a edição, Ed. Elsevier.

Harris, D. C. (1999). Quantitative Chemical Analysis, Quinta Edição, W. H. Freedman and Company, New York, USA.

Helene, O. and Helene, A. F. (2011). "Alguns aspectos da óptica do olho humano". Revista Brasileira de Ensino de Física, v. 33, n. 3, 3312.

Hendriksen, C.F.M. (1996). "A short history of the use of animals in vaccine development and quality control”. In: BROWN F, CUSSLER K, HENDRIKSEN C (Eds). Replacement, reduction and refinement of animal experiments in the development and control of biological products. Dev. Biol. Stand.v. 86, p. 3-10.

Herculano, R.D. (2009). Desenvolvimento de membranas de látex natural para aplicações médicas. Tese de doutorado. Faculdade de Filosofia Ciências e Letras de Ribeirão Preto. Universidade de São Paulo, 151 p.

Herculano, R.D., Guimarães, S.A.C., Belmonte, G.C., Duarte, M.A.H., Oliveira Júnior, O.N., Kinoshita, A. e Graeff, C.F.O. (2010). "Metronidazole release using natural rubber latex as matrix”. In: Materials Research, São Carlos, v. 13, n. 1, 57-61.

International Standard ISO 10993-5. (2009). Biological evaluation of medical devices-Part 5: Tests for in vitro cytotoxicity. Geneva: International Organization for Standardization.

ITeB (2015). "Você Sabia? Highlights Sobre a Borracha Natural”. Disponível em: http://www.iteb.org.br. Acesso em: julho, 2015.

Juve, A.E. (1998). "On Testing of Rubber" (Goodyer medal Awards Lecture). In: Rubber Chemical Technologic. 37, XXIV (abr./jun.). 
Li, J, Thompson B, Ding ZF, Chan LY, Chen X, Yu MB, et al. (2012). "Does partial occlusion promote normal binocular function?" Invest Ophthalmol Vis Sci. 53(11):6818-6827.

Liu, Chi, Shao Yan, Jia Demin. (2008). "Chemically modified starch reinforced natural rubber composites". Polymer;49:2176-2181.

Macdonald, E. M. (1990). Terapia ocupacional em reabilitação. São Paulo: Santos. 119 p.

Malachias, A., Neves, B. R. A., Rodrigues, W. N., Moreira, M. V. B., Kyciay, S., Metzger, T. H., and Magalhães-Paniago, R. (2004). "X-ray Scattering from Self-Assembled InAs Islands". In: Brazilian Journal of Physics, vol. 34, no. 2B, June.

Marques, P.C., Gonçalves, P.S., Galveas, P.A.O. (2007). "Clones de seringueira recomendadas para o Estado do Espírito Santo”. In: Incaper, 143, 2ª Edição.

Mente, E.D., Ceneviva, R., Netto, J.C. (2001). "Transplante de ilhotas pancreáticas em dispositivo de imunoisolamento celular - resultados iniciais”. In: Acta Cirúrgica Brasileira, v.16, supl.1, São Paulo.

Moreira, S.M.B, Moreira, H, Moreira, L.B. (2004). Adaptação de lentes de contato em crianças. Lentes de contato. $3^{\mathrm{a}}$ ed. Rio de Janeiro: Cultura Médica.

Mrué, F. (1996). Substituição do Esôfago Cervical por Prótese Biossintética de látex: estudo experimental em cães, Dissertação de Mestrado Faculdade de Medicina da Universidade de São Paulo - Ribeirão Preto, 114p.

Mrué, F. (2000). Neoformação tecidual induzida por biomembrana de látex natural com polilisina. Aplicabilidade em neoformação esofágica e da parede abdominal. Estudo experimental em cães, Tese (Doutorado em Medicina) - Universidade de São Paulo, Faculdade de Medicina de Ribeirão Preto, 112p.

Mrué, F., Coutinho-Netto, J., Ceneviva, R., Lachat, J.J, Thomazini, J.A., Tambelini, H. (2004). "Evaluation of The Biocompatibility of a New Biomembrane". Materials Research, V.7, n 02, p. 277-283.

Nascimento, B. L., Silva, L.D, Oliveira, J. D. (2012). "Quantificação de Ferro e Cobre em Olerícolas oriundas de sistema orgânico e convencional". ACSA - Agropecuária 
Científica no Semi-Árido, 8(4): 49-54.

Nunes, G.A.M.A., Reis, M.C., Rosa, M.F.F., Peixoto, L.R.T., Rocha, A.F., Rosa, S.S.R.F. (2016). "A system for treatment of diabetic foot ulcers using led irradiation and natural latex". Research on Biomedical Engineering, 32(1):3-13. https://dx.doi.org/10.1590/2446-4740.0744.

Ooi, Zhong Xian, Ismail, Hanafi, Bakar, Azhar Abu. (2014). 'Study on the ageing characteristics of oil palm ash reinforced natural rubber composites by introducing a liquid epoxidized natural rubber coating technique”. Polymer Testing, 37; 156-162.

Oliveira, J.A.A, Hyppolito, M.A., Coutinho-Netto, J., Mrué, F. (2003). "Miringoplastia com a utilização de um novo material biossintético". In: Revista Brasileira de Otorrinolarigologia, v. 69, 649-55.

Orefice, R.L., Pereira, M.M., Mansur, H.S. (2005). Biomateriais: Fundamentos $e$ Aplicações, Ed. Cultura Médica, Rio de Janeiro.

Palmer, S. E. (1999). Vision Science - Photons to Phenomenology. Massachusetts: MIT Press.

Paoli, Marco-Aurelio de. (2008). Degradação e Estabilização de Polímeros. $2^{\mathrm{a}}$ versão online (revisada). Chemkeys, São Paulo.

Park, J.B. and Lakes, R.S. (2007). Biomaterials: an introduction. $3^{\mathrm{a}}$ edição, Ed. Springer Science corp., New York.

Paula, P.M.C. (2010). Análise da aplicabilidade do módulo CFE ${ }^{\circledR}$ (controlador de fluxo esofagiano) e sua instrumentação para monitoração de aspectos fisiológicos do esôfago. Dissertação de mestrado, Departamento de Engenharia Elétrica, Universidade de Brasília, Brasília, DF, 122 p.

Paulo, N.M., Lima, F.G., Siqueira Júnior, J.T., Fleury, L.F.F., Sant'Ana, F.J.F., Borges, A.C. e Telles, T.C. (2005). "Membrana de látex da seringueira (Hevea brasiliensis), com e sem polilisina a $0,1 \%$ e tela de marlex na reconstrução de defeitos iatrogênicos da parede abdominal de ratos". In: Acta Cirurgia Brasileira, v. 20, n.4, 305-310. 
Peres, A.C.C., Lopes, L.M.A., Visconte, L.L.Y e Nunes, R.C.R.( 2006). "Uso de DSC na Determinação de Parâmetros de Vulcanização de Látex de Borracha Natural”. In: Polímeros, v.16, n.1, São Carlos, jan./mar.

Pinheiro, E. G. (2001). Modelos numéricos aplicados à vulcanização de pneus. Dissertação de Mestrado, Escola Politécnica da Universidade de São Paulo, 125p.

Pinho, E.C.C.M., Sousa, S.J.F., Schaud, F., Lachat, J.J., Coutinho-Netto, J. (2004). "Uso experimental da biomembrana de látex na reconstrução conjuntival”. In: Arquivo Brasileiro de Oftalmologia, v.67, n.1, 27-32.

Pinho, E.C.C.M. (2011). O uso da Biomembrana de látex natural comparado ao transplante conjuntival autólogo na superfície ocular, Tese de doutorado. Universidade de São Paulo. Faculdade de Medicina de Ribeirão Preto, 158p.

Procianoy, E., Procianoy, L., Procianoy, F. (2004). "Resultados do tratamento da ambliopia com levedopa combinada à oclusão". Arquivo Brasileiro de Oftalmologia, 67(5):717-20.

Rabelo, E.R., Sant'Ana, F.J.F e Paulo, N.M. (2005). "Emprego do compósito látex, poliamida e polilisina a $01 \%$ na correção cirúrgica de hérnias umbilicais recidivantes em bovinos leiteiros". In: Acta ScientiaeVeterinariae., v. 33, n. 2, 169-175.

Recum, A.V. and Jacobi, J.E. (1998). Handbook of biomaterials evaluation: scientific, technical, and clinical testing of implant materials, $2^{\mathrm{a}}$ edição, Ed. Edwards Brothers.

Regazzi, A.J. (2000). Análise multivariada. Departamento de Informática da Universidade Federal de Viçosa, v.2.

Reis, M.C. (2013). Sistema indutor de neoformação tecidual para pé diabético com circuito emissor de luz de LEDs e utilização do látex natural.Tese de Doutorado, Universidade de Brasília, Brasília, DF, Brasil.

Rhein, L. (2013). Manual Prático de Ambliopia, $1^{\circ}$ Edição, All Print Editora, São Paulo.

Ribeiro, J.A., Rodrigues, S.S., Brasil, L.M. (2013). Occlusion child derived from natural latex for amblyopia treatment. Health Care Exchanges (PAHCE), Pan American, vol., no., pp.1,1, April 29 2013-May 42013 doi: 10.1109/PAHCE.2013.6568293. 
Ribeiro, J.A, Rosa, S.R.F., Rosa, M. (2014). Experimental technique designated Van Gogh for making lens prototype. XXIV Brazilian Congress on Biomedical Engineering, Proceedings of the XXIV Brazilian Congress on Biomedical Engineering, Uberlândia, MG, Brazil, v. 1, p. 871-874.

Ribeiro, J. A., Rodrigues, S.S.F.R, Oliveira, D. S. (2015). "Biomaterial Latex Manufactured Occlusion Contact Lens: Proposal for Amblyopia Treatment". International Journal of Advanced Engineering Research and Science (IJAERS). v. 2, p. 65-69.

Ribeiro, J.A. and Rodrigues, S.S.F.R. (2014). Modelagem Matemática do Olho Amblíope para Tratamento com Oclusor Derivado de Látex. VIII Congresso Nacional de Engenharia Mecânica. Uberlândia, MG, Brazil.

Rippel, M. M. (2005). Caracterização microestrutural de filmes de látex de borracha natural. Tese de doutorado. Universidade Estadual de Campinas, Instituto de Química, 350p.

Rodrigues, S. S. F. R. (2009). Desenvolvimento de um sistema de controle de fluxo esofagiano para tratamento da obesidade, 1. ed. São Paulo: Edgard Blücher Ltda, v. 1. $121 \mathrm{p}$.

Rogero, S.O. Lugão, A.B., Ikeda, T.I. e Cruz. A.S. (2003). "Teste in vitro de citotoxicidade: estudo comparativo entre duas metodologias". In: Materials Research, São Carlos, v. 6, n. 3, 317-320.

Rosa, M.F.F., Souza, E.K.F., Rosa, S.S.R.F. (2015). "Sistema complexo bio inspirado Modelagem matemática da pele humana via Bond Graph". Estudos Tecnológicos (Online), v. 10, p. 49-56.

Rosa, L.L.F. and Alves, L.A.P. (2012). Manual de boas práticas dos estabelecimentos de comércio, adaptação e dispensação de armações, lentes oftálmicas, óculos de proteção solar, lentes de contato e acessórios ópticos. Rio de Janeiro: Confederação Nacional de Bens, Serviços e Turismo, $1^{\circ}$ Edição.

Sader, S.L., Coutinho-Netto, J., Mazzetto, S.A., Alves Jr., P., Vanni, J.C. e Sader A.A. (2000). "Substituição parcial do pericárdio de cães por membrana de látex natural". 
In: Revista Brasileira Cirurgia Cardiovascular, v.15, 338-344.

Salame, A.L.A., Simon, E.J.M., Leal, F., Lipener, C. e Brocchetto, D. (2008). "Lente de contato em crianças: aspectos epidemiológicos”. Arq Bras Oftalmol.; v.71, n.3, p.348-351.

Salata, A.C.F., Villaça, V.T.N., Roma, R.L., Norato, D.Y.J. e Carvalho, K.M.M. (2001). “Terapia oclusiva em ambliopia: fatores prognósticos". Arquivo Brasileiro de Oftalmologia, 64:123-6.

Salmazo, L.O. (2011). Influência da adição de nanopartículas paramagnéticas $\mathrm{Ni}_{0,5} \mathrm{Zn}_{0,5} \mathrm{Fe}_{2} \mathrm{O}_{4}$ nas propriedades estruturais e dielétricas de filmes de borracha natural: Preparação e caracterização. Dissertação de mestrado, Universidade Estadual Paulista Júlio de Mesquita Filho (UNESP), Presidente Prudente.

Schmacke, Saskia. (2010). Investigations of Polyethylene Materials by Means of X-ray Diffraction Artificial Ageing of Polyethylene Gas Pipes. Dissertation, zur Erlangung des Doktorgrades der Naturwissenschaften der Fakultät Physik der Technischen Universität Dortmund.

Silva, M.A., Guimarães, P.C.L., Pereira, T.D., Honório-França, A.C. (2012). “Biomateriais e sua biocompatibilidade numa abordagem multidisciplinar na área de saúde, alimentos funcionais e medicina regenerativa". Revista eletrônica da Univar. 2012: n. ${ }^{\circ} 8 \mathrm{Vol}-1$ p. $87-90$.

Souza, E.K.F., Tahmasebi, R., Rosa, S.S.R.F., Gomes, R.R. (2014). Modelagem matemática da perfuração por agulha da pele humana: região abdominal. VIII Congresso Nacional de Engenharia Mecânica. Uberlândia, MG, Brazil.

Teoh, S.H. (2004). "Introduction to biomaterials engineering and processing - an overview". In: Engineering materials for biomedical applications, Ed. World Scientific Pub Co Inc, v. 1, Singapore.

Thomazini, D., Gelfuso, M.V., Nascimento, T.A.C, Fonteles, E.F. (2004). “A utilização da Simulação Computacional na Confecção de Órteses Alternativas para membros superiores". Revista Tecnológica, Fortaleza, v. 25, n. 1, p. 74-79, jun. 
Trombetta F. et al. (2007). APOSTILA Curso Básico em Tecnologia de Elastrômeros. In: Tecnologia dos Látices. Ministério da Indústria e do Comércio Conselho Nacional da Borracha (SUDHEVEA - Superintendência da Borracha).

Vasconcelos, G. C. and Costa, M. F. (2013). "Current treatment of amblyopia: where are we?" Arquivos Brasileiros de Oftomologia, Editorial, p. V-VI.

Zanoni, L.Z., Biberg-Salum, T.G., Espíndola, Y.D. e Cônsolo, C.E. Z. (2010). Prevalência da baixa acuidade visual em alunos do primeiro ano do ensino fundamental de uma escola pública”. Revista da AMRIGS, Porto Alegre. Jan-mar; 54(1): 19-24.

Zimmermann, M. (2007). A membrana de látex como implante para correção de defeitos musculares em cães e coelhos, Dissertação de mestrado, Faculdade de Medicina Veterinária, Universidade Federal de Santa Maria, Santa Maria, 78p.

Zimmermann, M.; Raiser, A. G.; Barbosa, A. L. T.; Novosad, D.; Steffen, R. P. B.; Lukarsewsk, R.; Silva, M. S.; Lindinger, R.; Pastore, F. (2007). "Teste de Biocompatibilidade e reistência de membranas de látex em cães”. Ciência Rural. Santa Maria, v.37, n.6, 1719-1723.

Willians, D. F. (1987). "Definitions in biomaterials". Proceedings of a consensus conference of the european society for biomaterials, v. 4. Chester, England, March 3-51986. New York: Elsevier. 


\section{PUBLICATIONS}

Ribeiro J.A., Rosa M.F.F., Rosa L.L.F., Rocha A.F., Rodrigues S.S. (2010). Oclusão infantil derivada do látex natural para o tratamento de ambliopia. In: XXII Congresso Brasileiro em Engenharia Biomédica, Tiradentes-MG. Anais do XXII Congresso Brasileiro em Engenharia Biomédica.

Ribeiro, J.A., Rodrigues, S.S., Brasil, L.M. (2013). Occlusion child derived from natural latex for amblyopia treatment. Health Care Exchanges (PAHCE), Pan American, vol., no., pp.1,1, April 29 2013-May 42013 doi: 10.1109/PAHCE.2013.6568293.

Ribeiro, J.A, Rosa, S.R.F., Rosa, M. (2014). Experimental technique designated Van Gogh for making lens prototype. XXIV Brazilian Congress on Biomedical Engineering, Proceedings of the XXIV Brazilian Congress on Biomedical Engineering, Uberlândia, MG, Brazil, v. 1, p. 871-874.

Ribeiro, J.A. and Rodrigues, S.S.F.R. (2014). Modelagem Matemática do Olho Amblíope para Tratamento com Oclusor Derivado de Látex. VIII Congresso Nacional de Engenharia Mecânica. Uberlândia, MG, Brazil.

Ribeiro, J. A., Rodrigues, S. S. F. R, Oliveira, D. S. (2015). "Biomaterial Latex Manufactured Occlusion Contact Lens: Proposal for Amblyopia Treatment". International Journal of Advanced Engineering Research and Science (IJAERS). v. 2, p. 65-69.

Ribeiro J. A., Rodrigues, S.S.F.R, Leite, C. R. M., Vasconcelos, C. L., Soares, J. M. (2015)."Characterization analysis of Natural Latex membranes applied in the amblyopic eye". In: 23rd ABCM International Congress of Mechanical Engineering 
- COBEM2015, Rio de Janeiro. 23rd ABCM International Congress of Mechanical Engineering - COBEM2015. Rio de Janeiro: ABCM, 2015. v. 1. p. 100-110.

Ribeiro J. A., Cristal, O., Fundação Universidade de Brasília (BR/DF), Rodrigues, Suélia de Siqueira Fleury Rosa, Shzu M. A. M., Rosa, L. L. F. . Lente de Contato Oclusora. 2012, Brasil. Patente: Privilégio de Inovação. Número do registro: BR1020120074834, data de depósito: 02/04/2012, título: "Lente de Contato Oclusora", Instituição de registro: INPI - Instituto Nacional da Propriedade Industrial.

Ribeiro J. A. Concessão de registro de marca em vigor. Número de Registro: 906573572. Data de depósito: 01/08/2013. Apresentação: Mista, Natureza: Marca de Produto Elemento nominativo: LENCOC CFE: 16.3.19 NCL (10): 9, Especificação: LENTES DE CONTATO, Instituição de registro: INPI - Instituto Nacional da Propriedade Industrial. 